ORGANIC-INORGANIC COATINGS 


\title{
ELECTRODEPOSITION OF ORGANIC-INORGANIC FILMS FOR BIOMEDICAL APPLICATIONS
}

\section{BY IMRAN A. DEEN, B.ENG. \& SCTY.}

\author{
A Thesis \\ Submitted to the School of Graduate Studies \\ in Partial Fulfillment of the Requirements \\ for the Degree of \\ Master of Applied Science \\ McMaster University \\ (C) Copyright by Imran A. Deen, August 2012
}


MASTER OF APPLIED SCIENCE (2012)

(Department Materials Science \& Engineering)
McMaster University

Hamilton, Ontario

TITLE: Electrodeposition of Organic-Inorganic Films for Biomedical Applications

AUTHOR: Imran A. Deen, B.Eng. \& Scty. (McMaster University)

SUPERVISOR: $\quad$ Professor Igor Zhitomirsky

NUMBER OF PAGES: $\quad$ xvi, 120 


\section{Abstract}

Electrochemical methods show great promise in the deposition of biocompatible coatings for biomedical applications with advanced functionality. Consequently, methods of creating coatings of bioactive materials, such as halloysite nanotubes (HNT), hydroxyapatite (HA), chitosan, hyaluronic acid (HYH), poly-L-ornithine (PLO) and polyL-lysine (PLL) and polyacrylic acid (PAA) have been developed through the use of electrophoretic deposition (EPD). The co-deposition of these materials are achieved at voltages ranging from 5 to $20 \mathrm{~V}$ on a 304 stainless steel substrate using suspensions of 0.5 and $1.0 \mathrm{gL}^{-1}$ biopolymer (chitosan, PAA, PLO, PLL) containing $0.3,0.5$ 0.6, 1.0 and 2.0 $\mathrm{gL}^{-1}$ bioceramic (HNT, HA). The resulting films were then investigated to further understand the kinetics and mechanics of deposition, determine their properties, and evaluate their suitability for physiological applications. The films were studied using XRay Diffraction (XRD), Differential Thermal Analysis and Thermogravimetric Analysis (DTA/TGA), Scanning Electron Microscopy (SEM), Quartz Crystal Microbalance (QCM) and Linear Polarisation. The results indicate that film thickness, composition and morphology can be controlled and modified at will, and that the deposition of composite films, multilayer laminates and functionally graded films are possible. 


\section{Acknowledgment}

I would like to express my deepest gratitude to my supervisor, Dr. Igor Zhitomirsky for his help, advice, and guidance throughout my graduate studies. It is thanks to him that I was given this opportunity to further develop my skills and deepen my knowledge in engineering.

I would also like to thank the staff of the Materials Science and Engineering Department for all their help over the past few years, who ensured that my time at McMaster was as problemfree as possible.

My colleagues Yaohui Wang, Kangmin Wu, Yingying Li, Deepak Kumarappa, Mustafa Sami Ata, Yanchao Sun, Lijia Yang, Xiaofei Li, and Xin Pang deserve acknowledgement as well. They were all extremely supportive, and any problems that arose in the lab were swiftly resolved thanks to the teamwork everyone exhibited.

The staff of the BIMR deserve thanks as well for all the technical aid they provided-Steve Koprich, Andy Duft, Frank Gibbs, Fred Pearsons, Wen He Gong, Dr. Glynis de Silveira and Chris Butcher were always available and eager to give their time any students that came their way seeking aid, something I took full advantage of.

I would like to recognize the contributions of the Natural Sciences and Engineering Research Council of Canada (NSERC) for the funding they provided, without which this research would not have been possible.

Last, but not least, I would like to give thanks my family, especially my father, whose support and encouragement is in no small part responsible to my being where I am today, and my mother for her care, love and support throughout my life. I also thank my two brothers, Tariq and Arif for being supportive and for their love and understanding. 


\section{Table of Contents}

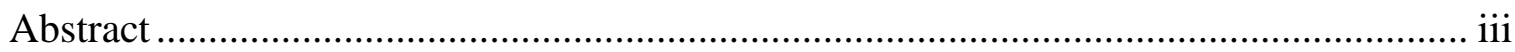

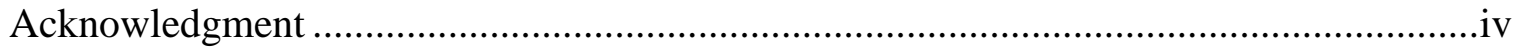

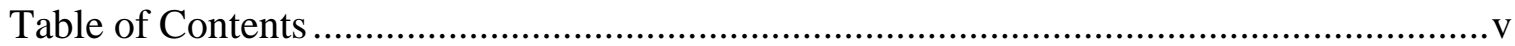

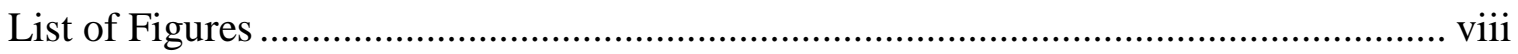

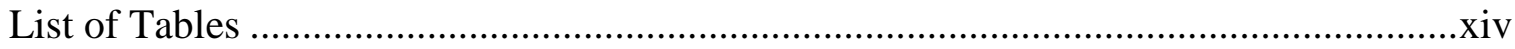

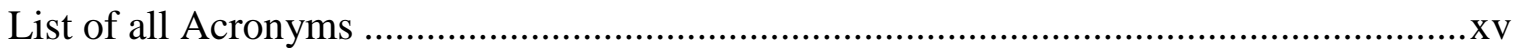

Declaration of Academic Achievement ...............................................................................

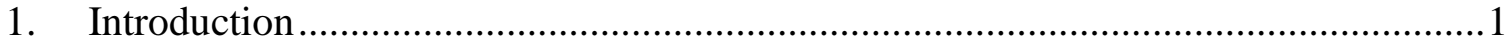

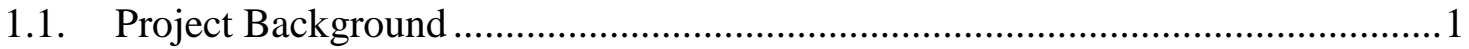

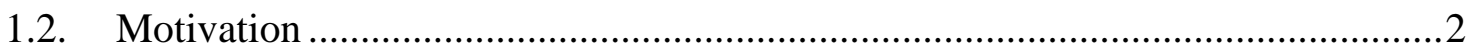

1.3. Materials science in biomaterials research .................................................. 3

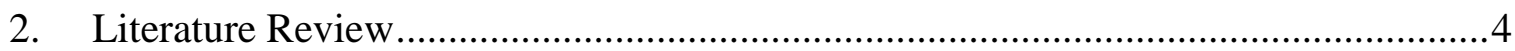

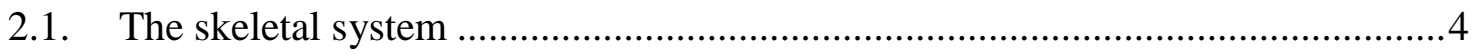

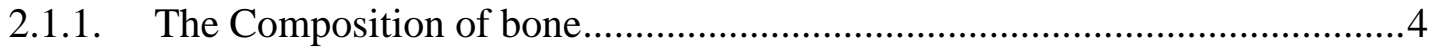

2.1.2. The Structure of bone..............................................................................

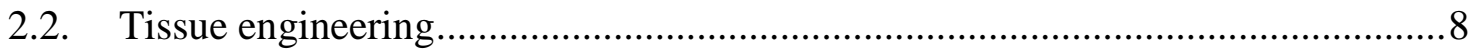

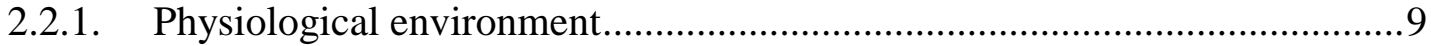

2.3. Scaffold design in tissue engineering ................................................. 11

2.4. Materials for applications in biomedical implants ..................................... 13

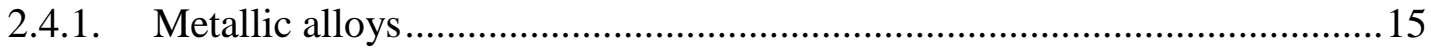

2.4.2. Biopolymers for biomedical implants ............................................... 18

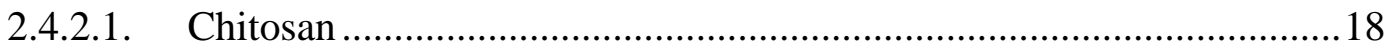

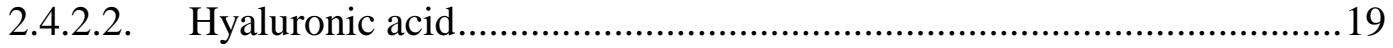

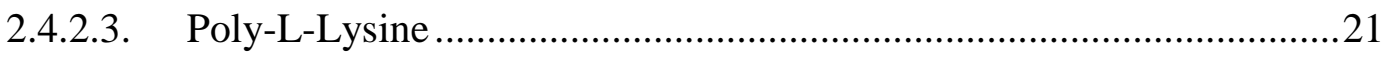

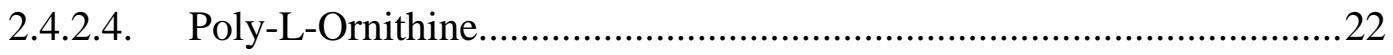

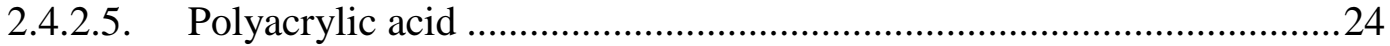

2.4.3. Bioactive ceramics and apatites for biomedical implants .........................26

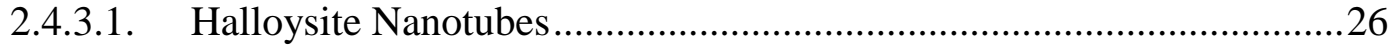




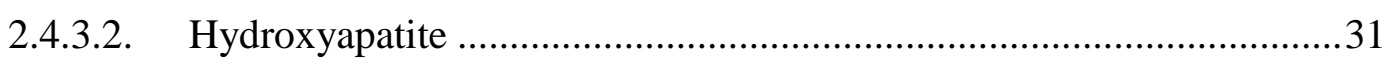

2.5. Composite biomedical implants ...................................................................33

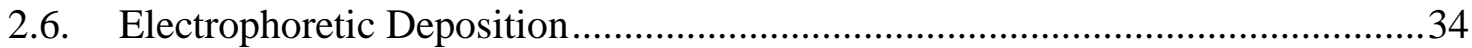

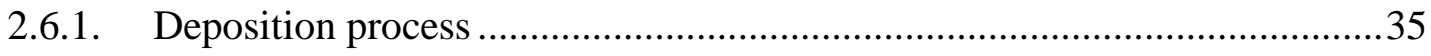

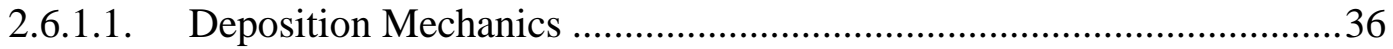

2.6.1.2. Deposition of polymers....................................................................

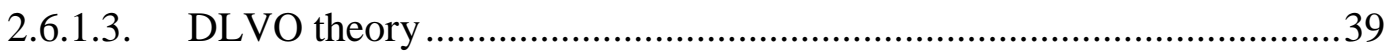

2.6.1.4. The Double layer ..........................................................................42

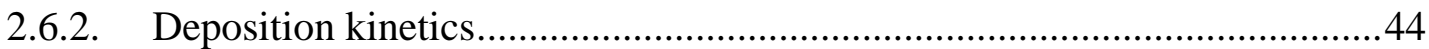

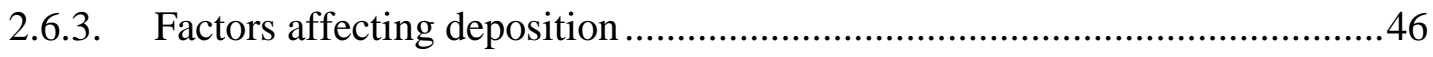

2.6.3.1. Choice of solvent .............................................................................

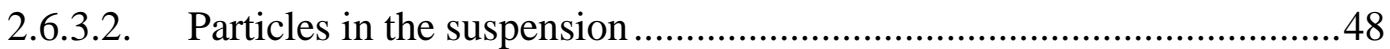

2.6.3.3. Deposition conditions ...................................................................50

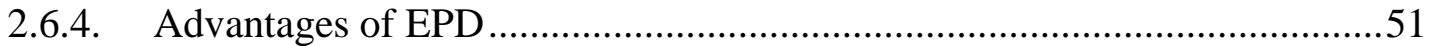

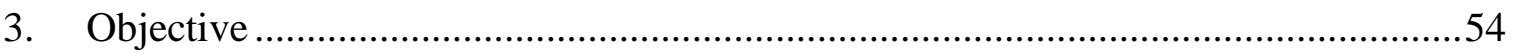

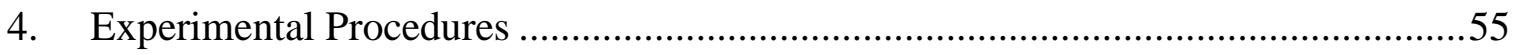

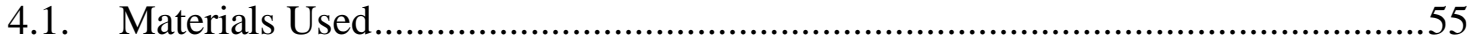

4.1.1. Commercially supplied materials ………………...................................55

4.1.2. Synthesis of hydroxyapatite nanoparticles..................................................56

4.2. Electrophoretic Deposition Process ...................................................................56

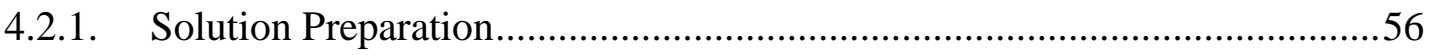

4.2.2. Experimental set-up for deposition ........................................................57

4.2.3. Electrophoretic deposition procedure ………............................................58

4.3. Materials and Film Characterization ...........................................................59

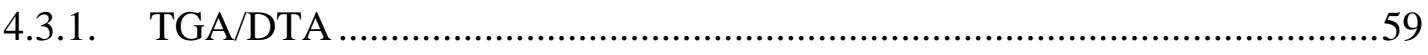

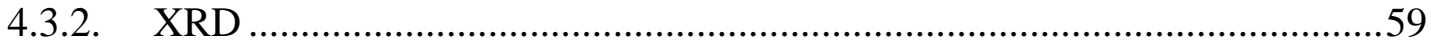

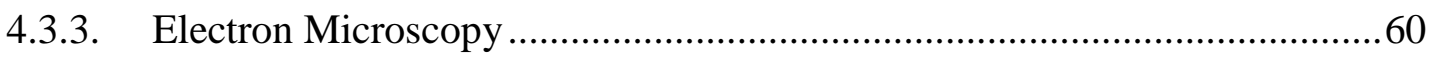

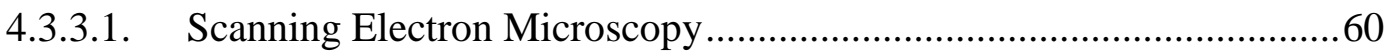

4.3.3.2. Transmission Electron Microscopy ……..............................................63 
4.3.4. Measuring deposition yield of EPD .......................................................63

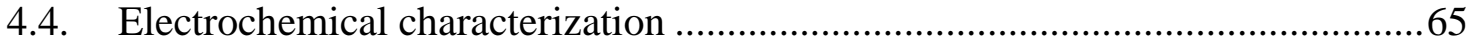

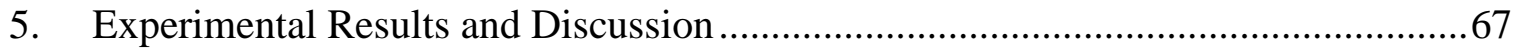

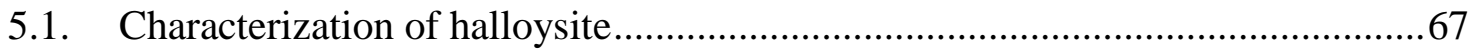

5.2. Electrodeposition of biopolymers and composite films .................................70

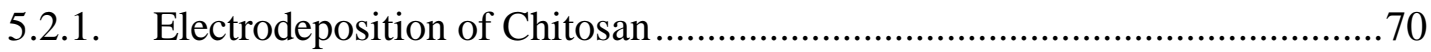

5.2.1.1. Chitosan and Halloysite Films ..................................................... 70

5.2.1.2. Multilayered Chitosan, Halloysite and Hydroxyapatite Films .............76

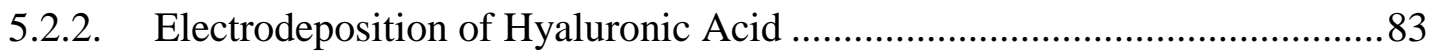

5.2.3. Electrodeposition of Poly-L-Lysine and Poly-L-Ornithine .......................91

5.2.4. Electrodeposition of Polyacrylic acid .................................................96

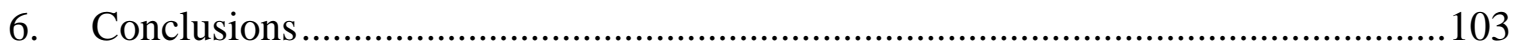

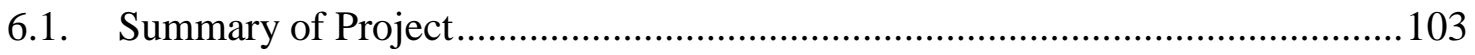

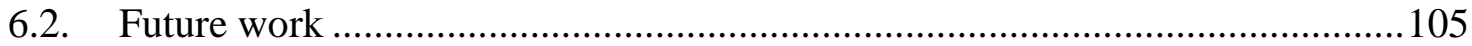

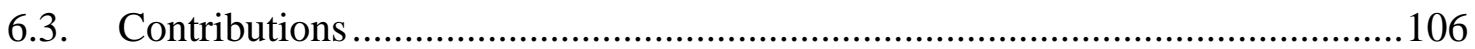

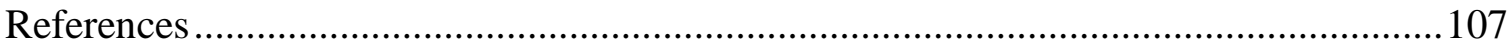




\section{List of Figures}

Figure 2.1: Hierarchical structure of bone [11] .......................................................

Figure 2.2: Collagen fibril composed of collagen molecules and bone crystals [11] .........7

Figure 2.3: Multi-layer structure of bone components .............................................

Figure 2.4: Distribution of mass of a body for an average young adult male for various

fluids [17] 10

Figure 2.5: Ionic compositions of body fluids [18] .............................................. 10

Figure 2.6: Important factors in the design of optimal scaffolds for bone tissue [14] .......12

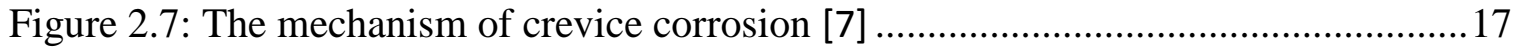

Figure 2.8: Comparison of chemical structure of a) chitin b) chitosan and c) cellulose ...18

Figure 2.9: Changes in the diameter of alginate microcapsules during 14-day saline incubation at $37^{\circ} \mathrm{C}$. Capsules were coated with either PLL or PLO [30]....23

Figure 2.10: Effect of PLL and PLO coatings on microcapsule mechanical strength. Ruptured capsules were quantified following subjection to induced osmotic stress. Following $36 \mathrm{~h}$ of bead agitation, broken capsules in both PLL- and PLO-coated capsules were quantified [30].

Figure 2.11: SEM photographs of the surface of the thick films prepared with and without

PAA [45] .25

Figure 2.12: FE-SEM photographs of silica particles prepared with different amounts of

PAA added [45] .25 
Figure 2.13: Weights of silica films deposited as a function of PAA added. Open marks indicate that there were no cracks on the surface of the films. Filled marks indicate that micro-cracks were observed by SEM [45] ..........................26

Figure 2.14: Halloysite from the CLA1 site in Maralinga Tjarutja in the Barton locality in South Australia [23]

Figure 2.15: Structure of A) layers of halloysite and B) halloysite nanotube [50] .28

Figure 2.16: Zeta-potential plot for halloysite [24] .29

Figure 2.17: XRD patterns for halloysite from a) NZ and b) Indiana [24] ......................30

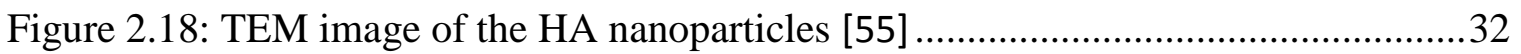

Figure 2.19: Schematic of the force between two particles in suspension as a function of separation [67]

Figure 2.20: Schematic of the deposition mechanism by lyosphere distortion and thinning [67] .38

Figure 2.21: Energy of interaction between two particles [67] .40

Figure 2.22: Structure of the double layer structure and distribution of potential (surface charge is assumed to be positive) [59] .43

Figure 2.23: Evolution of the potential in the deposition cell during EPD. [60] .45

Figure 2.24: Deposited weight (fraction of initial weight of solid in the suspension) for different conditions [67] .46

Figure 2.25: The electrical conductivity of suspensions vs. the dielectric [73] .48 
Figure 2.26: Particle distribution structures in the Nerst layer: a) stable state, b) flocculated state, c) coagulated state [74] 49

Figure 2.27: Relationship between thickness and deposition time for $\mathrm{ZnO}$ coatings deposited on copper electrode at (a) 20, (b) 60, and (c) $100 \mathrm{~V}$ [76]............51

Figure 2.28: Typical thickness of coatings obtained by different process methods [21]...53

Figure 4.1: Schematic diagram of an EPD cell for cathodic deposition ..........................58

Figure 4.2: Example of sample holder prepared for SEM .......................................61

Figure 4.3: Schematic diagram of an EPD cell for cathodic deposition on a Si wafer ......62

Figure 4.4: Schematic of a standard TEM sample holder........................................63

Figure 4.5: Schematic of the QCM set-up for cathodic deposition yield measurement ....64

Figure 5.1: As-received HNT viewed under TEM .................................................67

Figure 5.2: As-received HNT viewed under SEM ...................................................68

Figure 5.3: XRD pattern for as-received HNT ( $\nabla$ - JCPDS file 29-1487 of halloysite, JCPDS file 33-0018 of gibbsite, o - JCPDS file 46-1045 of quartz) ..........68

Figure 5.4: DTA/TGA results for as-received HNT ...................................................69

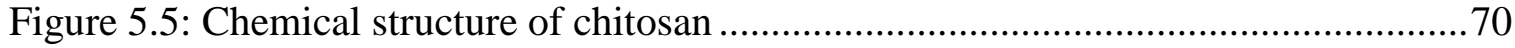

Figure 5.6: QCM results for the EPD of $0.1 \mathrm{gL}^{-1}$ chitosan and a) no $\left.\mathrm{HNT}, \mathrm{b}\right) 0.01 \mathrm{gL}^{-1}$ HNT and c) $0.05 \mathrm{gL}^{-1} \mathrm{HNT}$ .72

Figure 5.7: DTA/TGA results for chitosan-HNT film prepared from a $0.5 \mathrm{gL}^{-1}$ chitosan suspension with $0.3 \mathrm{gL}^{-1} \mathrm{HNT}$ .73 
Figure 5.8 XRD patters for a) as-received HNT and b) chitosan-HNT film prepared from a $0.5 \mathrm{gL}^{-1}$ chitosan suspension containing $0.3 \mathrm{gL}^{-1} \mathrm{HNT}$ ( $\nabla$ - JCPDS file 291487 of halloysite, • - JCPDS file 33-0018 of gibbsite, o - JCPDS file 461045 of quartz). The XRD pattern of HNT of Figure 5.3 is presented here for comparison. .74

Figure 5.9: SEM of chitosan-HNT films containing A,B) 0.3 and C,D) 0.6 gL-1 HNT at low and high magnification .75

Figure 5.10: SEM of chitosan-HNT films containing $0.6 \mathrm{gL}-1$ HNT (arrows show film thickness, F-film, S - substrate) .76

Figure 5.11: XRD patterns for a) as-received HNT, b) as-prepared HA, c) chitosan film without additives, d) chitosan-HNT film and e) chitosan-HNT-HA film prepared from a $0.5 \mathrm{gL}^{-1}$ chitosan suspension containing $0.3 \mathrm{gL}^{-1} \mathrm{HNT}$ and $1.0 \mathrm{gL}^{-1} \mathrm{HA}(\nabla$ - JCPDS file 29-1487 of halloysite, • - JCPDS file 33-0018 of gibbsite, ○ - JCPDS file 46-1045 of quartz, $\mathbf{\nabla}$ - JCPDS file 9-0432 of HA). Previous XRD patterns of HNT and chitosan-HNT from Figure 5.8 are presented for comparison. .77

Figure 5.12: SEM of chitosan-HNT films prepared from a $0.5 \mathrm{gL}^{-1}$ chitosan suspension containing $0.6 \mathrm{gL}^{-1} \mathrm{HNT}$ A) without $\mathrm{HA}$ and $\mathrm{B}$ ) with $1.0 \mathrm{gL}^{-1} \mathrm{HA}$ (arrows show HNT) .78

Figure 5.13: SEM of chitosan-HNT-HA films prepared from a $0.5 \mathrm{gL}^{-1}$ chitosan suspension containing $1.0 \mathrm{gL}^{-1} \mathrm{HA}$ and $(\mathrm{A}, \mathrm{B}) 0.3$ and $(\mathrm{C}, \mathrm{D}) 0.6 \mathrm{gL}^{-1} \mathrm{HNT}$ (arrows show HNT) at low and high magnification .79 
Figure 5.14: SEM of chitosan-HNT-HA multilayer films cross-section prepared from a $0.5 \mathrm{gL}^{-1}$ chitosan suspension containing a) no additives, b) $0.6 \mathrm{gL}^{-1} \mathrm{HNT}$, and c) $1.0 \mathrm{gL}^{-1} \mathrm{HA}$ (arrows indicate layer thickness) ..............................81

Figure 5.15: SEM of chitosan-HNT-HA films cross-sections prepared from a $0.5 \mathrm{gL}^{-1}$ chitosan suspension containing a) $1.0 \mathrm{gL}^{-1} \mathrm{HA}$, and b) $0.6 \mathrm{gL}^{-1} \mathrm{HNT}$ .82

Figure 5.16: Tafel plots for a) uncoated stainless steel and stainless steel coated with a film prepared from a $0.5 \mathrm{gL}^{-1}$ chitosan suspension containing $0.3 \mathrm{gL}^{-1} \mathrm{HNT}$ and b) no $\mathrm{HA}$ and c) $1.0 \mathrm{gL}^{-1} \mathrm{HA}$

Figure 5.17: Chemical structure of hyaluronic acid................................................. 84

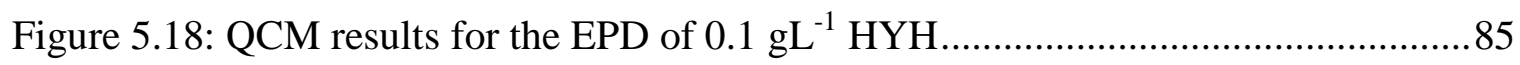

Figure 5.19: DTA/TGA results for HYH-HNT film prepared from a $1.0 \mathrm{gL}^{-1} \mathrm{HYNa}$ suspension containing $0.3 \mathrm{gL}^{-1} \mathrm{HNT}$ .86

Figure 5.20: SEM images of HYH-HNT films prepared from solution of $1.0 \mathrm{gL}^{-1} \mathrm{HYH}$ containing A,B) $0.3 \mathrm{gL}^{-1} \mathrm{HNT}$ and C,D) $0.6 \mathrm{gL}^{-1} \mathrm{HNT}$.

Figure 5.21: SEM images of HYH-HA-HNT films prepared from solutions of $1.0 \mathrm{gL}^{-1}$ HYH containing $1.0 \mathrm{gL}^{-1} \mathrm{HA}$ and A) $0.3 \mathrm{gL}^{-1} \mathrm{HNT}$ and B) $0.6 \mathrm{gL}^{-1} \mathrm{HNT} . .88$

Figure 5.22: SEM images of HYH-HA-HNT films prepared from solutions of $1.0 \mathrm{gL}^{-1}$ HYH containing $2.0 \mathrm{gL}^{-1} \mathrm{HA}$ and A,B) $0.3 \mathrm{gL}^{-1} \mathrm{HNT}$ and C,D) $0.6 \mathrm{gL}^{-1}$ HNT .89

Figure 5.23: SEM images of HYH-HNT-HA film cross-section prepared from a $1.0 \mathrm{gL}^{-1}$ HYNa suspension containing $0.3 \mathrm{gL}^{-1} \mathrm{HNT}$ and $2.0 \mathrm{gL}^{-1} \mathrm{HA}$ .90 
Figure 5.24: XRD patters for a) as-received HNT, b) as-prepared HA, c) HYH film without additives, d) HYH-HNT film and e) HYH-HNT-HA film ( $\nabla$-JCPDS file 29-1487 of halloysite, •-JCPDS file 33-0018 of gibbsite, ○-JCPDS file 46-1045 of quartz, $\boldsymbol{\nabla}$ - JCPDS file 9-0432 of HA)

Figure 5.25: Chemical structure of A) PLL and B) PLO..............................................92

Figure 5.26: Film prepared from a $2.0 \mathrm{gL}^{-1}$ PLO suspension containing $\left.\mathrm{A}, \mathrm{B}\right) 2.0 \mathrm{gL}^{-1} \mathrm{HA}$ (low and high magnification), C) $0.3 \mathrm{gL}^{-1} \mathrm{HNT}$ .94

Figure 5.27: Film prepared from a $2.0 \mathrm{gL}^{-1}$ PLL suspension containing A) $2.0 \mathrm{gL}^{-1} \mathrm{HA}$ and B) $0.3 \mathrm{gL}^{-1} \mathrm{HNT}$ .95

Figure 5.28: Film prepared from a $2.0 \mathrm{gL}^{-1} \mathrm{PLO}$ suspension containing $0.5 \mathrm{gL}^{-1} \mathrm{HA}$ deposited at A) $10 \mathrm{~V}$ and B) $20 \mathrm{~V}$, and containing $2.0 \mathrm{gL}^{-1} \mathrm{HA}$ deposited at C) $10 \mathrm{~V}$ and D) $20 \mathrm{~V}$ .96

Figure 5.29: Structure of PAA .97

Figure 5.30: DTA/TGA of a deposit prepared from $1.0 \mathrm{gL}^{-1}$ PAA suspension containing $0.6 \mathrm{gL}^{-1} \mathrm{HNT}$ .98

Figure 5.31: PAA films prepared from $1.0 \mathrm{gL}-1$ PAA containing A,B) $0.1 \mathrm{gL}-1 \mathrm{HNT}$, C,D) 0.3 gL-1 HNT, E,F) 0.6 gL-1 HNT (A,C,E at low magnification and $\mathrm{B}, \mathrm{D}, \mathrm{F}$ high magnification) 101

Figure 5.32: Cross-sections of PAA films prepared from $1 \mathrm{gL}^{-1}$ PAA containing A) 0.1 $\left.\left.\mathrm{gL}^{-1} \mathrm{HNT}, \mathrm{B}\right) 0.3 \mathrm{gL}^{-1} \mathrm{HNT}, \mathrm{C}\right) 0.6 \mathrm{gL}^{-1} \mathrm{HNT}$ (low magnification) and D) $0.6 \mathrm{gL}^{-1} \mathrm{HNT}$ (high magnification) (F-Film, S-Substrate) 102 


\section{List of Tables}

Table 2.1: Classification, Applications and Features of Different Biomaterials ...............15

Table 2.2: Properties and applications of metallic alloys in biomedical implants [7] .......17

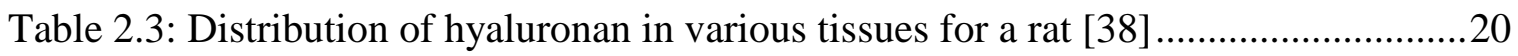

Table 2.4: Characteristics of different electrodeposition techniques ..............................35

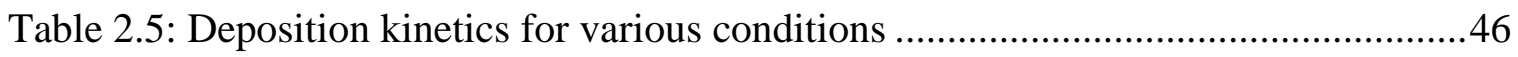

Table 2.6: List of solvents used in EPD and their properties.....................................47

Table 2.7: Comparison of Deposition Methods ......................................................52

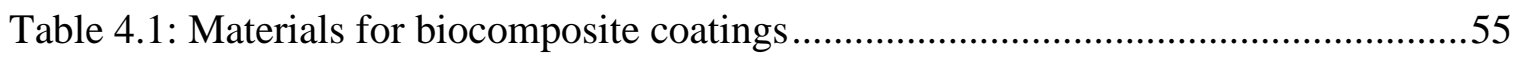




\section{List of all Acronyms}

CHIT - Chitosan

DLVO - Derjaguin and Landau, Verwey

and Overbeek

DTA - Differential Thermal Analysis

ECM - Extracellular Matrix

ELD - Electrolytic Deposition

EPD - Electrophoretic Deposition

FE-SEM - Field Emission Scanning

Electron Microscope

HA - Hydroxyapatite

HNT - Halloysite nanotube

HYH - Hyaluronic acid

IM - intramedullary
PAA - Poly Acrylic Acid

PLL - Poly-L-Lysine

PLO - Poly-L-Ornithine

QCM - Quartz-Crystal Microbalance

SBF - Simulated Body Fluid

SCE - Standard Calomel Electrode

SEM - Scanning Electron Microscope

SEM - Scanning Electron Microscopy

TEM - Transmission Electron

Microscope

TGA - Thermogravimetric Analysis

XRD - X-Ray Diffraction 


\section{Declaration of Academic Achievement}

This thesis was written by myself, Imran A. Deen. The experiments as outline in this thesis were designed and conducted by myself and my supervisor, Dr. Igor Zhitomirsky. I performed and analysed all the experiments dealing with the deposition of coatings. Xin Pang helped with the deposition of coatings shown in Section 5.2.1.2.

Technical assistance was provided for use of the SEM by Steve Koprich, Dr. Glynis de Silveira, Chris Butcher and Andy Duft. TEM images were taken by myself and Fred Pearson. Xin Pang was present to help with the SEM picture seen in Figures 5.12, 5.13. 5.14, 5.15. XRD analysis was conducted by Wen He Gong using samples prepared by myself. TGA/DTA data was obtained by Frank Gibbs using samples prepared by myself. 


\section{Introduction}

\subsection{Project Background}

Biomedical implants are devices that have long been used as a method of reinforcing damaged tissue to aid in their healing. Recently, biomaterials have begun to see implementation in biomedical implants to aid in regeneration. Biomaterials are materials used in devices that interact with a biological system, with the goal of coexisting in the body with a minimal risk of failure [1]. When choosing a material for biological applications, there are two characteristics that determine whether they are suitable or not: biofunctionality and biocompatibility. This first one is determined by the function of the material, and refers mainly to the mechanical properties of the material (e.g. yield strength, ductility, fatigue strength and fracture toughness).Biocompatibility, on the other hand, refers to the interaction between the material and the body, and whether or not the material will be accepted or rejected by the body. In short, it is what determines if a material is suitable for biological application [2].

Thus, the fundamental requirement of a biomaterial is that it must have no undesirable effects on the body [1]. Given that the material operates in an environment that it is both hostile and sensitive to foreign substances, if a material is not biocompatible it will result in the degradation of the material or rejection by the body [2].

One of the main uses of biomaterials is in the muscoskeletal system, where they are used to repair damaged bones, joints and teeth. These are referred to as orthopaedic 
implants and include devices such as bone plates, screws, total hip joints, knee joints, elbow joints, shoulder joints and reattachment for tendons and ligaments [1].

In the U.S. there are 1.3 million surgical procedures undertaken per year due to bone fracture and damage [3], while in Canada the aging population has led to an increase in the number of degenerative joint diseases, and thus an increase in the number of knee and hip replacements needed for the elderly [4].

\subsection{Motivation}

While there are many materials already used for biomedical implants for the repair or replacement of bone tissue or teeth, these show poor biocompatibility, which leads to poor integration between the body and the implant, and possible rejection of the latter. To remedy this, coated implants with different biocompatible materials are being investigated, which mimic the morphology of bone tissue and therefore promote better integration between the implant and the surrounding tissue $[5,6]$.

This project focuses on the coatings deposited through the co-deposition of biocompatible ceramics and polymers onto stainless steel substrates using electrophoretic deposition (EPD). The objective of this is to form a coating that would act as scaffolding for tissue and would be suitable for use in implants.

Currently, orthopaedic implants lack three of the most critical characteristics that would help them integrate with living tissue [7]:

- The ability to self-repair 
- The ability to maintain a blood supply

- The ability to modify their structure and properties

As such, it is necessary to shift the design of implants from the goal of supporting damaged tissue to tissue regeneration in order to satisfy the need for long-term orthopaedic repair [7].

\subsection{Materials science in biomaterials research}

Biomaterials research involves interdisciplinary collaboration from various fields, including medical science, biochemistry, biomedical engineering, clinical science and materials science. Knowledge in materials science is vital, as knowledge of materials synthesis, processing, and the structure and properties of biomaterials are essential for their research and application [8].

For biomedical implants that interact with the body this is especially true, as the interface between the substitute biomaterials and biological tissue is a key factor in the integration of the implant, and must be studied not only from a biological/physiological sciences standpoint, but a materials one as well [8]. 


\section{Literature Review}

\subsection{The skeletal system}

\subsubsection{The Composition of bone}

Skeletal systems act as the structural support for the body through a porous organic-inorganic composite that is composed of a tough organic matrix reinforced by calcium salts. On average, compact bone is roughly $30 \mathrm{wt} \%$ matrix and $70 \mathrm{wt} \%$ salts, while newly formed bone has a considerable lower ratio of salts [9]. More specifically, bone consists (on a volumetric basis) of $33-43 \%$ apatites, $32-44 \%$ organics and $15-25 \%$ water (this last one is important as it acts as a plasticiser, contributing to the composite's overall toughness) [10].

The organic matrix of bone is composed of 90-95\% collagen (which can be found as either fibrils, fibers or bundles [11]), while the remainder is a homogeneous gelatinous medium called "ground substance" (extracellular fluid plus proteoglycans, especially chondroitin sulfate and hyaluronic acid). The collagen fibrils extend primarily along the lines of tensional force in the bone and are what give it its strong tensile strength [9].

The crystalline salt found in the organic matrix is composed of calcium and phosphate and belongs to a family of minerals known as apatites. The apatite found in bone is called hydroxyapatite (HA), and has the following chemical formula: $\mathrm{Ca}_{10}\left(\mathrm{PO}_{4}\right)_{6}(\mathrm{OH})_{2}$ [9]. The flat, plate-shaped crystals are approximately $400 \AA$ 1ong, 10-30 $\AA$ thick and $100 \AA$ wide, while the collagen found in bone are only a few nanometers wide: [11] 
- Fibrils: $1.5-3.5 \mathrm{~nm}$

- Fibers: $50-70 \mathrm{~nm}$

- Bundles: $150-250 \mathrm{~nm}$

\subsubsection{The Structure of bone}

Bones are composed of a fairly complex structure that must be understood when designing an implant that will properly "mesh" with it. The component phases of bone have a structural relationship across various levels of a hierarchical structural organisation (see Figure 2.1). These levels and structures are [11]:

1) The macrostructure - cancellous and cortical (compact) bone, where the cortical bone forms a dense shell around cancellous bone.

2) The microstructure $(10-500 \mu \mathrm{m})$ - Sheets of mineralized collagen (lamellae) can wrap in concentric circles (3-8 lamellae thick) around a central point, creating an osteon. These are roughly $200-250 \mu \mathrm{m}$ in diameter and parallel to the long axis of the bone. In some cases, together with bone tissue, these can form a larger, plywood-type stacking of layers 150-300 $\mu \mathrm{m}$ thick around the bone (this is known as the "lamellar bone")

3) The sub-microstructure $(1-10 \mu \mathrm{m})$ - mineralized collagen fibers form into planar arrangements called lamellae that are 3-7 $\mu \mathrm{m}$ thick.

4) The nanostructure (a few hundred nanometers to $1 \mu \mathrm{m}$ ) - fibril collagen and embedded minerals form collagen fibers.

5) The sub-nanostructure (below a few hundred nanometers) - molecular structure of constituent elements, i.e. mineral, collagen and non-collagenous organic proteins 
pack into layers. The apatite crystals of bone grow with their c-axis roughly parallel to the long axes of the collagen fibrils.

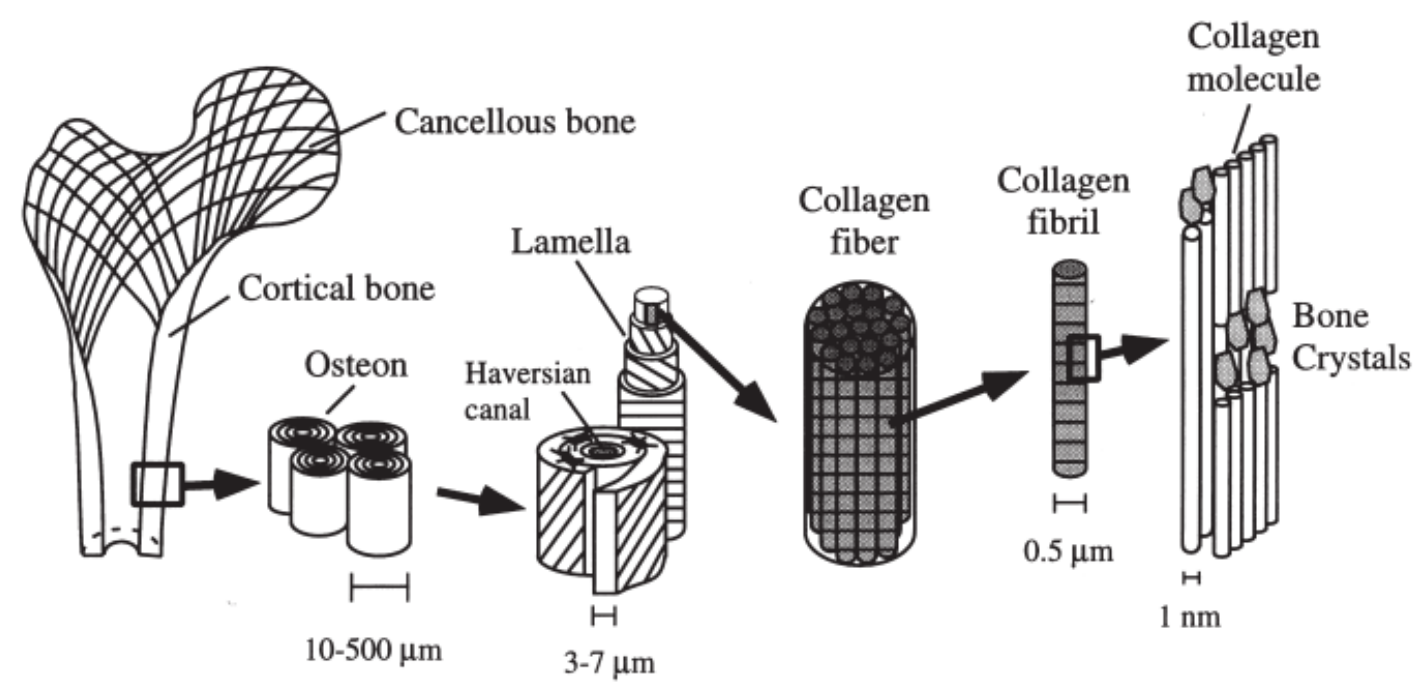

Microstructure

Nanostructure

Macrostructure

Sub-microstructure

Sub-nanostructure

Figure 2.1: Hierarchical structure of bone [11]

Collagen fibers of compact bone are composed of repeating periodic segments every $640 \AA$, where HA crystals lie adjacent to the fiber bound tightly together; this prevents shearing from occurring. Additionally, the collagen fibers overlap each other, which cause the HA crystals to overlap as well, creating a structure similar to bricks forming a wall (see Figure 2.2). Since the collagen fibers have great tensile strength, and the HA crystals compressive strength, these two elements provide the skeletal system with both an extreme tensile and compressive strength [9]. 


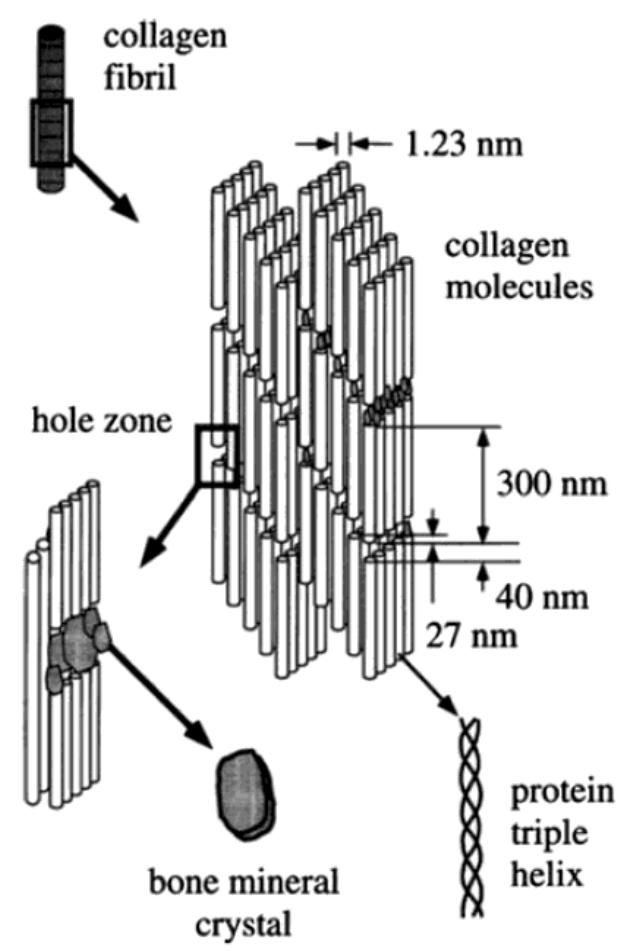

Figure 2.2: Collagen fibril composed of collagen molecules and bone crystals [11]

In addition to the organic (collagen) and inorganic (mineral) phase, recent work by Wise et al. has shown that there is a third component to bone - a polysaccharide layer that acts as the interface between the two, binding them together (see Figure 2.3). It was found that this polysaccharide phase plays a central role in biomineralization by modulating mineral phase and crystallinity. By directing the formation of amorphous inorganic phases and preventing uncontrolled crystallization, it prevents the growth of weak spots within the bone [12]. Further work by Reid et al., who examined the mineral interface in teeth (which is similar to bone in many respects) and found it to be similar to bone, has built on the work done by Wise $e t$ al and hypothesized that polysaccharides are "universal participants in nonpathological formation of biominerals based on calcium and phosphate [13]." 


\begin{tabular}{|l|}
\hline Organic phase (collagen) \\
\hline Interface (polysaccharide) \\
\hline Inorganic phase (mineral) \\
\hline
\end{tabular}

Figure 2.3: Multi-layer structure of bone components

\subsection{Tissue engineering}

Tissue engineering is the use of biomaterials to form biodegradable scaffolds that can incorporate functional cells, and has the potential to restore function to damaged tissue [14]. While the actual concept of cell-based therapies for tissue regeneration is not new, as research in the field of tissue engineering progresses, new techniques and materials are investigated and refined that allow for the innovation of improved biomedical tools. Nowadays, the main issue with tissue engineering is devising costeffective, scalable processes that can assure product viability as well as satisfy regulators $[7,15]$.

Ideally, scaffolds used for tissue regeneration should have the following properties which would allow the scaffold to enhance and direct tissue growth [15]:

- Direct and controlled degradation

- Promote cell viability, differentiation and extracellular matrix (ECM) production

- Allow for the diffusion of nutrients and waste products

- Adhere and integrate with the surrounding tissue

- Provide mechanical integrity suitable to its location 
Currently there are a variety of natural and synthetic materials that have been investigated for use in scaffolds for tissue repair, including natural polymers such as alginate, agarose, fibrin, hydroxyapatite (HA), collagen, gelatin, chitosan, chondroitin sulfate and cellulose. Natural materials have the advantage in that they can interact with cells and regulate or direct cell function without producing an anti-immune response from the surrounding tissue. As such, they have a better reception from the body as they promote adhesion and growth of tissue instead of facing rejection [16]. Additionally, degradation of these polymers produces non-toxic waste which can be absorbed into the body without producing an inflammatory response [15].

\subsubsection{Physiological environment}

In order to fabricate biomedical implants that function properly, it is important to consider what conditions they'll be working under, i.e. what the physiological environment is composed of. Factors such as $\mathrm{pH}$ changes, solvent conditions, and temperature must all be examined and taken into account. The fluids that a body is composed of are of particular interest. In an average $70 \mathrm{~kg}$ adult, body fluids account for approximately $60 \%$ of the body mass - approximately $42 \mathrm{~L}$. Of this, $28 \mathrm{~L}$ is made up of intracellular fluids (fluids inside the body's cells) and $14 \mathrm{~L}$ is made up of extracellular fluids (fluids outsides of cells). Extracellular fluids can be further broken down into interstitial fluids and plasma (the noncellular component of blood), which account for three quarters and one quarter of extracellular fluids, respectively $[9,17]$ (see Figure 2.4). 
Master Thesis

McMaster University
Imran A. Deen

Materials Science and Engineering

Intracellular water Extracellular water

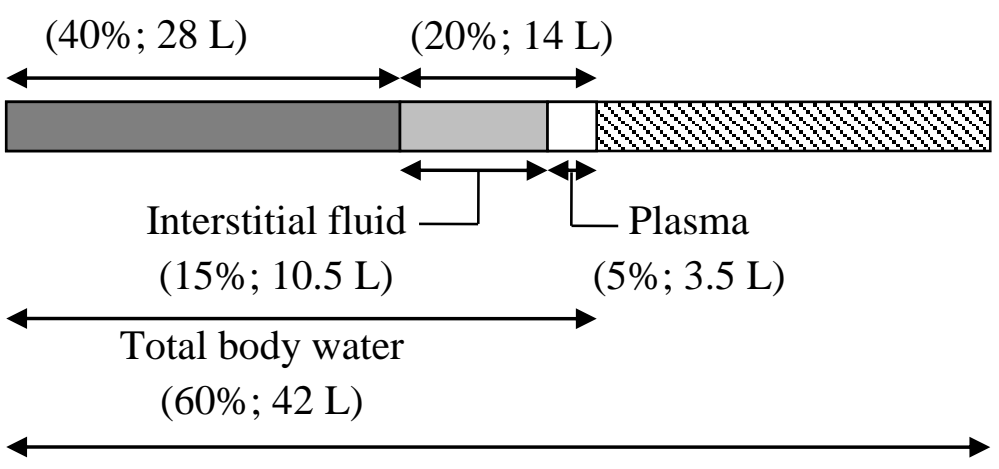

Total body mass

$(70 \mathrm{~kg})$

Figure 2.4: Distribution of mass of a body for an average young adult male for various fluids [17]

Both intracellular and extracellular fluids contain a significant amount of ionic components and differ in composition (blood plasma and interstitial fluids have a similar composition as they are only separated by capillary membranes that are permeable to almost all solutes in interstitial fluids, except proteins) $[9,17]$ (see Figure 2.5).

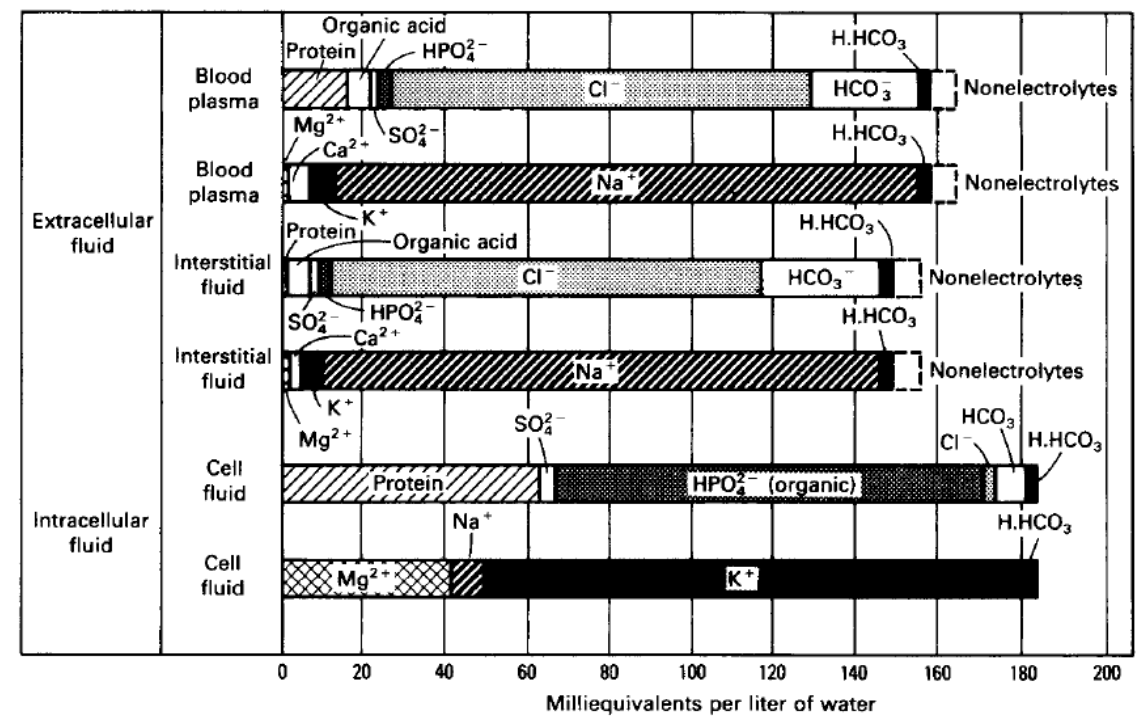

Figure 2.5: Ionic compositions of body fluids [18] 
These body fluids are an important factor to consider when designing a biomedical implant. Not only to they have a high concentration of ions, but there are other factors to consider when working in a physiological environment that would affect any device implanted in the body. In addition to the ionic concentration, body fluids also operate at a lower than neutral $\mathrm{pH}$ and a high temperature. Body fluids have been compared to warm, aerated seawater, as they can contain $100 \mathrm{~mL} \mathrm{Cl}^{-}$per liter water, have a $\mathrm{pH}$ of 5.2 (normally the $\mathrm{pH}$ is around 7.4, but at injured sites it shifts to 5.2 or even 4) and operate at $37^{\circ} \mathrm{C}[9,17,18]$.

\subsection{Scaffold design in tissue engineering}

Some of the most promising biomaterials for bone tissue engineering include hydroxyapatite (HA), calcium phosphates, bioactive silica glasses and related composite materials. These bioactive inorganic materials are combined with biodegrable polymers that react with physiological fluids and form bonds with bone through the use of HA bone-like layers, leading to an effective interaction between the material surface and bone tissue [14].

Scaffolds used in bone tissue engineering are generally highly porous three dimensional structures that exhibit tailored porosity, pore size, interconnectivity, and mechanical properties. Additionally, the incorporation of nanotopographic features in the design of the scaffold is important in order to mimic the natural structure of bone. The main role of the scaffold, however, is to act as a substrate that allows cells to attach, 
proliferate, differentiate and organise in normal, healthy tissue as the structure degrades (see Figure 2.6) [14].

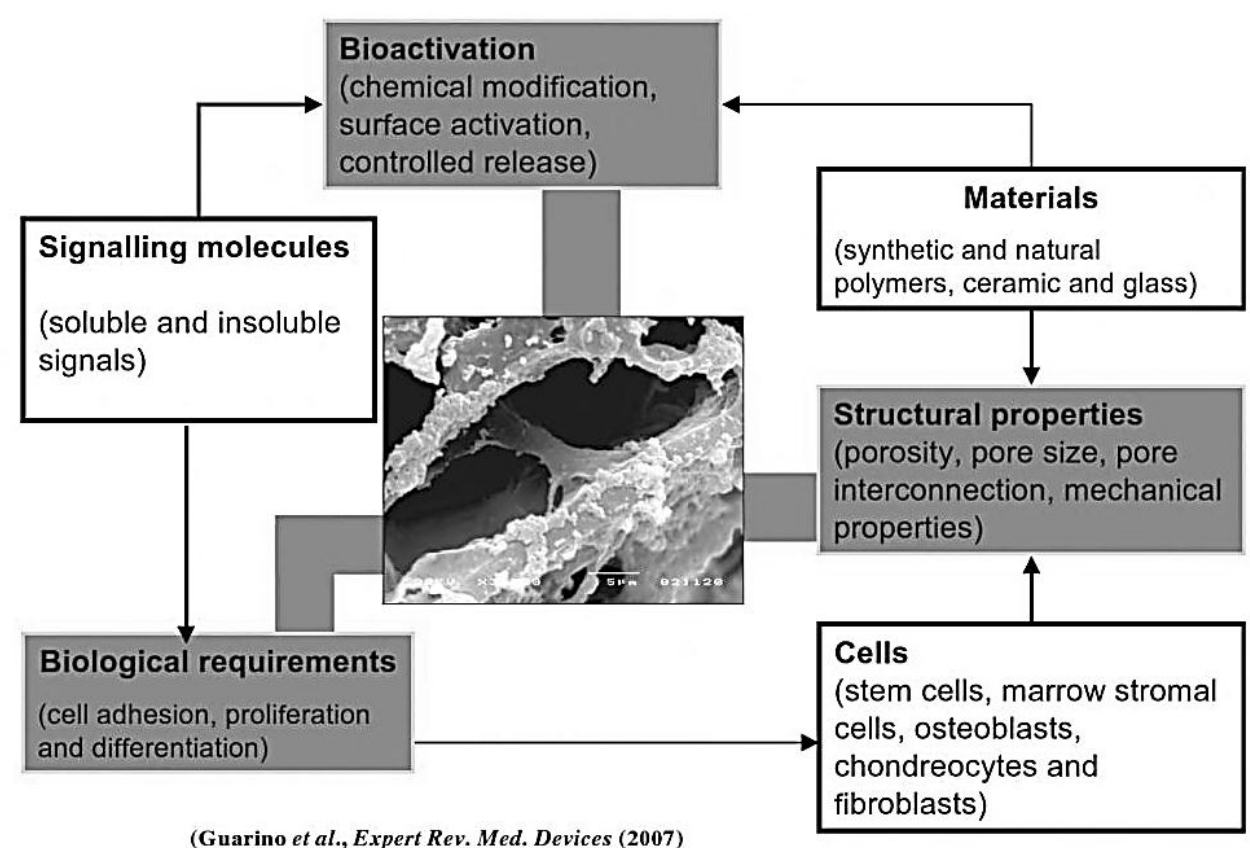

Figure 2.6: Important factors in the design of optimal scaffolds for bone tissue [14]

When designing scaffolds for orthopaedic implants, there are many different factors to consider. The criterion for selecting materials for implants include [14]:

- Osteoconductivity - avoid the formation of encapsulating tissue, encourage growth of bone tissue between scaffold and bone

- Biodegradation - this should be tailored to match the rate of regeneration of new tissue

- Time-dependant variation of mechanical strength and structural integrity - this is linked to the biodegradation of the material. The scaffold needs to provide mechanical stability in load bearing areas during an initial period of tissue growth. 
- Scaffold architecture - the resulting scaffold should possess an interconnected porous structure, porosity $>90 \%$ and pore diameters in the range of 300 to $500 \mu \mathrm{m}$ (necessary for cell seeding, tissue growth, vascularisation and nutrient delivery).

- Fabrication of complex shapes - match the bone structure and bone defects.

- Suitable for commercialisation - material synthesis and implant fabrication should be scalable and cost effective.

Since no one material has yet been found suitable to meet the above criteria for forming an implant, the development of composite implants containing biodegradable polymers and bioactive ceramics (e.g. HA or Bioglass ${ }^{\circledR}$ ) has become more popular as a method of fulfilling the requirements of orthopaedic implants [14].

\subsection{Materials for applications in biomedical implants}

Currently, there are several different materials being used in biomedical implants, the material selection of which is dependent on the application of the implant. Traditionally, for replacing hard tissue such as bone and cartilage, metal alloy implants are the most popular choice due to their fatigue resistance, hardness and corrosion resistance [7]. However, recent years have seen an increase in the scope of what is considered a suitable material for biomedical implants - Hench and Ethbridge have defined a biomaterial as: "a bioactive material $[\ldots]$ that elicits a specific biological response at the interface of the material which results in the formation of a bond between the tissues and the material" [8]. As such many new materials, especially polymers and ceramics, have been examined for their physiological compatibility. 
Biomaterials implanted in the human body elicit responses that fall under the following four categories:

1) Toxic materials - the surrounding tissue dies [19]

2) Bioinert materials - the material is non-toxic and biologically inactive; a fibrous tissue capsule forms around the material. These are characterised by their low reactivity with the body, and can co-exist with the surrounding tissue without apparent change. $[7,18,19]$

3) Bioactive materials - the material is non-toxic and biologically active; an interfacial bond forms between the material and tissue. These can form direct chemical ties with the surrounding tissue, and bone growth/tissue adhesion is promoted on the implant surface $[18,19]$. There are two classes of bioactive materials: osteoconductive materials that bond to hard tissue, stimulate bone growth on the surface of the bioactive material, and osteoproductive materials that stimulate the growth of new bone on the material, away from the implant surface, and can also bond to soft tissue such as gum cartilage [7].

4) Bioreabsorbable materials - the material is non-toxic and dissolves; the surrounding tissue replaces the dissolved materials, which are non-toxic and are eliminated/metabolized by the body. $[7,18,19]$

There are many different types of biomaterials, and they can be metallic, ceramic or polymeric in nature, with each offering their own unique features. As such, biomaterials can also be classified for different applications depending on their type and properties (see Table 2.1). 
Table 2.1: Classification, Applications and Features of Different Biomaterials

\begin{tabular}{|c|c|c|c|c|}
\hline System & Material & $\begin{array}{c}\text { Applicatio } \\
\mathbf{n}\end{array}$ & Features & $\begin{array}{c}\text { Reference } \\
\text { S }\end{array}$ \\
\hline \multirow[t]{3}{*}{ Metallic } & 316L SS & Structural & $\begin{array}{l}\text { Bioinert, low cost, easy to } \\
\text { manufacture }\end{array}$ & {$[18,20,21]$} \\
\hline & $\mathrm{Ti}-6 \mathrm{Al}-4 \mathrm{~V}$ & Structural & $\begin{array}{l}\text { Excellent biocompatibility, } \\
\text { passive oxide film }\end{array}$ & {$[20,21]$} \\
\hline & $\mathrm{Co}-\mathrm{Cr}-\mathrm{Mo}$ & Structural & $\begin{array}{l}\text { good wear resistance, passive } \\
\text { oxide film }\end{array}$ & {$[20,21]$} \\
\hline \multirow[t]{6}{*}{ Ceramic } & $\begin{array}{l}\text { Hydroxyapatite } \\
\text { (HA) }\end{array}$ & $\begin{array}{l}\text { Structural, } \\
\text { coatings }\end{array}$ & $\begin{array}{l}\text { Bioactive, similar to bone, } \\
\text { osteoconductive }\end{array}$ & {$[18-20]$} \\
\hline & $\begin{array}{l}\text { Halloysite } \\
\text { Nanotubes } \\
\text { (HNT) }\end{array}$ & $\begin{array}{l}\text { Structural, } \\
\text { coatings }\end{array}$ & $\begin{array}{l}\text { Low cost, biocompatible, drug } \\
\text { delivery }\end{array}$ & {$[22-24]$} \\
\hline & Alumina & $\begin{array}{l}\text { Structural, } \\
\text { coatings }\end{array}$ & Bioinert & [20] \\
\hline & Zirconia & $\begin{array}{l}\text { Structural, } \\
\text { coatings }\end{array}$ & Bioinert, highly wear resistant & {$[20]$} \\
\hline & Bioglass (BG) & $\begin{array}{l}\text { Structural, } \\
\text { coatings }\end{array}$ & Bioactive & {$[20]$} \\
\hline & $\begin{array}{l}\text { Tricalcium } \\
\text { phosphate (TCP) }\end{array}$ & $\begin{array}{l}\text { Structural, } \\
\text { scaffold }\end{array}$ & $\begin{array}{l}\text { Biocompatible, bioresorbable, } \\
\text { used in bone repair }\end{array}$ & {$[19,20]$} \\
\hline \multirow[t]{4}{*}{ Polymer } & Chitosan & $\begin{array}{l}\text { Coating, } \\
\text { scaffold }\end{array}$ & $\begin{array}{l}\text { Natural cationic } \\
\text { polysaccharide, reabsorbed by } \\
\text { body, antimicrobial, excellent } \\
\text { film-forming properties, low } \\
\text { cost }\end{array}$ & [25-28] \\
\hline & Hyaluronic acid & $\begin{array}{l}\text { Coating, } \\
\text { scaffold }\end{array}$ & $\begin{array}{l}\text { Natural anodic } \\
\text { polysaccharide, restore } \\
\text { damaged tissue, } \\
\text { biodegradable }\end{array}$ & {$[7,29]$} \\
\hline & $\begin{array}{l}\text { Poly-L- } \\
\text { Ornithine \& } \\
\text { Poly-L-Lysine } \\
\end{array}$ & $\begin{array}{l}\text { Coating, } \\
\text { scaffold }\end{array}$ & $\begin{array}{l}\text { Cathodic polymer, promotes } \\
\text { cell adhesion, selectively } \\
\text { permeable, cell encapsulation }\end{array}$ & {$[30-33]$} \\
\hline & PE, UHMWPE & Structural & $\begin{array}{l}\text { Bioinert, easy to manufacture, } \\
\text { low cost }\end{array}$ & [20] \\
\hline
\end{tabular}

\subsubsection{Metallic alloys}

All types of implants must be designed with the consideration that they will undergo some type of cyclic loading, as this causes the implant to fail at a much lower 
yield stress than normal. For biomedical implants, the fatigue life is the number of cycles it must survive for as well as the stress it is being subjected to (typically, an implant is expected to survive for $10^{7}$ to $10^{8}$ cycles) [7].

The hardness of the metal is also an important aspect as it determines the resistances to plastic deformation. Additionally, hardness also determines the wear of the material, which occurs when there is movement between two parts in contact with one another, and can cause the generation of undesirable debris [7].

Finally, corrosion of the implant is another aspect that must be taken into account, as corrosion of metal in the body, in addition to creating harmful products, can also cause the implant to fracture. As physiological fluids have an especially high concentration of corrosive components (see Figure 2.5), the effect of body fluids on metal is similar to that of warm, aerated seawater. Furthermore, the nature of the implant further exagerates the problem, as the implant can be composed of multiple parts with crevices whose spacing is large enough to let fluid enter but small enough to keep it stagnant, as well as parts in movement that come in contact and cause fretting. As such, a metallic biomedical implant can undergo galvanic, crevice (see Figure 2.7) or stress corrosion [7]. 


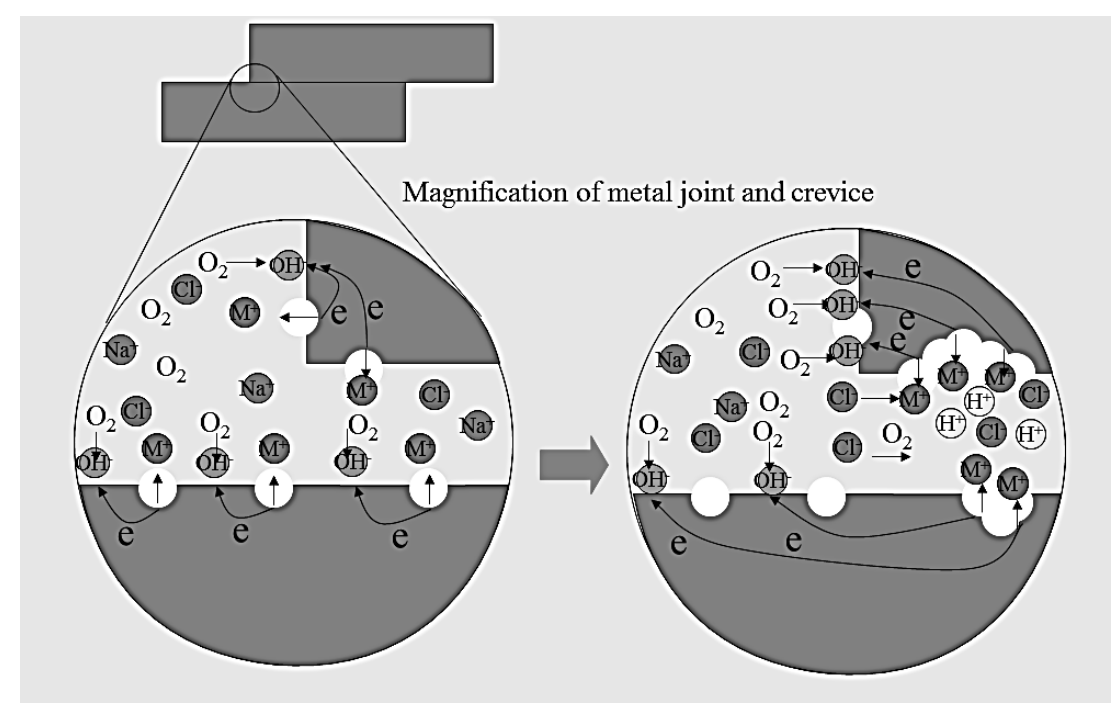

Figure 2.7: The mechanism of crevice corrosion [7]

Thus, for a metal to be used in a biomedical implant, it must possess adequate physical, mechanical and electrochemical properties. The three most popular choices are stainless steels 316L, titanium alloys and cobalt-chromium alloys as they meet these criteria and offer various advantages [7] (see Table 2.2).

Table 2.2: Properties and applications of metallic alloys in biomedical implants [7]

\begin{tabular}{|l|l|l|}
\hline Material & Properties & Application \\
\hline Stainless steel & Low cost fabrication & $\begin{array}{l}\text { Surgical wire (annealed), pin, } \\
\text { plate, screw, IM nail }\end{array}$ \\
\hline Titanium alloy & $\begin{array}{l}\text { High cost, low density and } \\
\text { modulus, excellent } \\
\text { osteointegration }\end{array}$ & $\begin{array}{l}\text { Surgical wire (annealed), pin, } \\
\text { plate, screws, IM nail }\end{array}$ \\
\hline $\begin{array}{l}\text { Co-Cr alloys } \\
\text { (wrought) }\end{array}$ & $\begin{array}{l}\text { High cost, high density and } \\
\text { modulus, difficult to fabricate }\end{array}$ & Surgical wire, IM nails \\
\hline
\end{tabular}




\subsubsection{Biopolymers for biomedical implants}

\subsubsection{Chitosan}

Chitosan (CHIT) is a nontoxic biopolymer derived from chitin, a naturally occurring polysaccharide found in the shells of crustaceans, such as shrimps and crabs. Given the large number of organisms that synthesize chitin, it is the second largest biopolymer in the world, after cellulose [25,34,35], the material that reinforces cell walls in plants (see Figure 2.8). Chitosan is of particular interest due to its low immunogenicity (the ability to produce a reaction from the immune system), which makes it attractive as a bio-polymer [25].

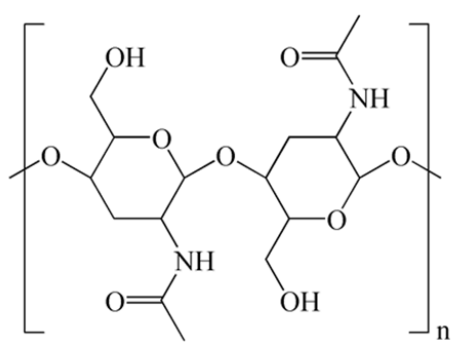

a

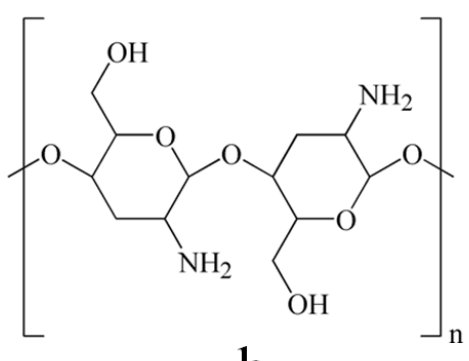

b

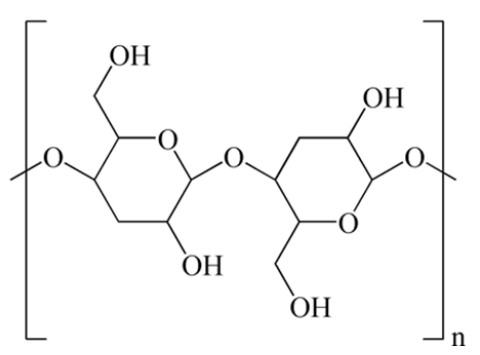

$\mathrm{C}$

Figure 2.8: Comparison of chemical structure of a) chitin b) chitosan and c) cellulose

Chitin is easily obtained from the shells of crabs and shrimps as a by-product of the food industry. From these, chitin is removed from the crustacean shells, which involves the removal of proteins and the dissolution of calcium carbonate. The chitin is then deacetylated in $40 \%$ sodium hydroxide at $120^{\circ} \mathrm{C}$ for $1-3$ hours, which results in $70 \%$ deacetylated chitosan (chitosan becomes soluble in aqueous media when the degree deacytelation reaches 50\%) [25,34]. The solubility of chitosan is attributed to the 
protonation of the $-\mathrm{NH}_{2}$ group to $\mathrm{NH}_{3}{ }^{+}$in an acidic media, at which point the polysaccharide is converted to a polyelectrolyte [34].

Unlike many other naturally occurring polysaccharides, which are neutral or acidic in nature, chitosan is a highly basic polysaccharide; in aqueous solutions it is cationic in nature and, due to its $-\mathrm{NH}_{3}{ }^{+}$groups interacting with metals, has excellent film forming abilities $[25,35,36]$.

Chitosan is further desirable for use in medical implants due to its antimicrobial properties. Studies on the antimicrobial properties of chitosan have revealed that it is effective in inhibiting growth of bacteria on a surface. Tests conducted by No et al. on the antibacterial activity of chitosan using multiple gram-positive and gram-negative bacterial organisms showed that chitosan limited the activity of the bacteria, though this was heavily dependent on the molecular weight of the chitosan used [26].

\subsubsection{Hyaluronic acid}

Hyaluronic acid (HYH; syn. hyaluronate, hyaluronan) is a naturally occurring large polysaccharide with small amounts of protein attached [9]. It is composed of a repeating linear disaccharide made up of N-acetyl-D-glucosamine and D-glucuronic acid [7,29]. HYH is present in all tissues and cartilage of vertebrates [29]. Commercially, hyaluronic acid is obtained from rooster combs, but it can also be obtained from genetically engineered bacteria [7].

In addition to being present in the ECM of cartilage and other tissues [7,37], it is also found in the aqueous humour of the eye and joints, where it plays an important role 
controlling fluid flow and acting as a viscoelastic dampening medium [7], and is used in connective tissue in bone [12] and is distributed across various organ in the body (see Table 2.3).

Table 2.3: Distribution of hyaluronan in various tissues for a rat [38]

\begin{tabular}{|l|c|c|c|}
\hline \multicolumn{1}{|c|}{ Boyd Part } & Weight $(\mathbf{g})$ & $\begin{array}{c}\text { Total HYH } \\
(\mathbf{m g})\end{array}$ & $\begin{array}{c}\text { Distribution HYH } \\
\text { in body (\%) }\end{array}$ \\
\hline Whole rat & 201 & 60.5 & 100 \\
\hline Skin & 40.2 & 33.8 & 56 \\
\hline Muscles and supporting & 35.7 & 4.69 & 8 \\
\hline $\begin{array}{l}\text { Skeleton } \\
\text { tissues }\end{array}$ & 57.6 & 16.2 & 27 \\
\hline Intestines and stomach & 15.8 & 0.50 & 1 \\
\hline Remaining internal organs & 43.4 & 5.25 & 9 \\
\hline
\end{tabular}

Due to its physiochemical properties, many different biological functions have been attributed to hyaluronic acid, such as:

- lubrication [29]

- water homeostasis [29]

- filtering effects [29]

- regulation of plasma protein distribution [29] and the environment in which cells exist [7]

As a naturally occurring polysaccharide, it is completely biodegradeable in vivo, which makes it particularly attractive as a material for creating composite implants involving hydrogels and living cells (most cells do not exist in crystalline matrixes of solutions, but hydrogels) [7], where it can act as a lubricant between joints. Furthermore, 
it is believed that hyaluronic acid forms a film between cartilage surfaces to protect them from frictional damage [29], and the basic structure of hyaluronic acid can be tailored depending on its application [7], making it a very versatile material.

Hyaluronic acid degrades within 2-5 days in the body if it is unmodified. If modified by esterification with hydrophobic groups or cross-linking, (which reduces water uptake and thus expansion), the degradability can be reduced, allowing hyaluronic acid to be tailored for specific applications [7].

\subsubsection{Poly-L-Lysine}

Poly-L-Lysine (PLL) is an polycationic amino acid that has been used for bioencapsulation [30,33,39], and is the most widely used biomaterial for cell encapsulation, having gained prominence in 1980 when the alginate-PLL microencapsulation procedure was developed by Lim and Sun, who sought a way to circumvent immune rejection in cell transplantation in the pancreas. Lim and Sun found that by using a microencapsulation procedure to completely enclose viable islets in the pancreas with a semipermeable membrane, they were able to prolong the survival of the islets both in vitro and in vivo [40]. Since then, PLL has been used for different applications, such as coatings for alginate beads for cell therapy [33] or poly-(lactide-coglycolide) (PLGA) microsphere scaffolds for nerve tissue engineering [39]. Recently, in addition to this, PLL is being investigated for use in scaffolds for bone regeneration [41].

PLL was used to coat PLGA microspheres by Nojehdehia et al. It was found that coatings of PLL formed a cross-linked network of the microspheres, and provided a 3D 
environment, enhancing the biological applications. Cellular functions such as cell attachment and differentiation were improved, and compared to smooth/rigid surfaces there was superior attachment and growth of adherent cells on surfaces that closely resembled the macromolecular structure of ECM [39].

Due to the fact that charged PLL is immunogenic (it provokes an immune response from the body, and can provoke an inflammatory response as well) [30,33], PLL-alginate beads were coated with a layer of alginate, creating an alginate-PLLalginate (APA) microcapsule to try and remedy this. However, even with this, the immunogenic nature of PLL could not be fully masked/neutralized [33].

Orive et al., who have studied the structure of APA microcapsules, have postulated that the best way to improve the biocompatibility of PLL would be on either focusing on properly balancing the net positive charge due to the $\mathrm{NH}_{3}{ }^{+}$, or finding a way to physically mask all of the PLL [33].

\subsubsection{Poly-L-Ornithine}

Poly-L-Ornithine (PLO) is a polycation similar in structure to PLL [30,42]. Like PLL, it is used in microencapsulation [30,32], in addition to being used as a coating that promotes cell adhesion [31]. Due to their similarity, it is viewed as a replacement to PLL, as the immunogenic properties of PLL can lead to inflammatory responses in the host tissue [30]. Like PLL, PLO is under investigation for the fabrication of composite materials for bone tissue regeneration - experiments by Zhen et al. show that like PLL, 
the addition of PLO to chitosan scaffolds improve its biocompatibility, though not to the extent of PLL [41].

In order to compare the two, Darrabie et al. carried out experiments that examined both PLO and PLL coatings on alginate microcapsules to compare the extent to which either polymer affected perm-selectivity and microbead swelling (the latter affects the mechanical strength of alginate microparticles). They found that the PLO coatings nearly eliminated bead swelling (see Figure 2.9), which increased the biocompatibility (bead swelling increases pore size to an undesirable extent), and that there was significantly less instances of broken capsules (see Figure 2.10) due to an increase in mechanical strength of the coating [30].

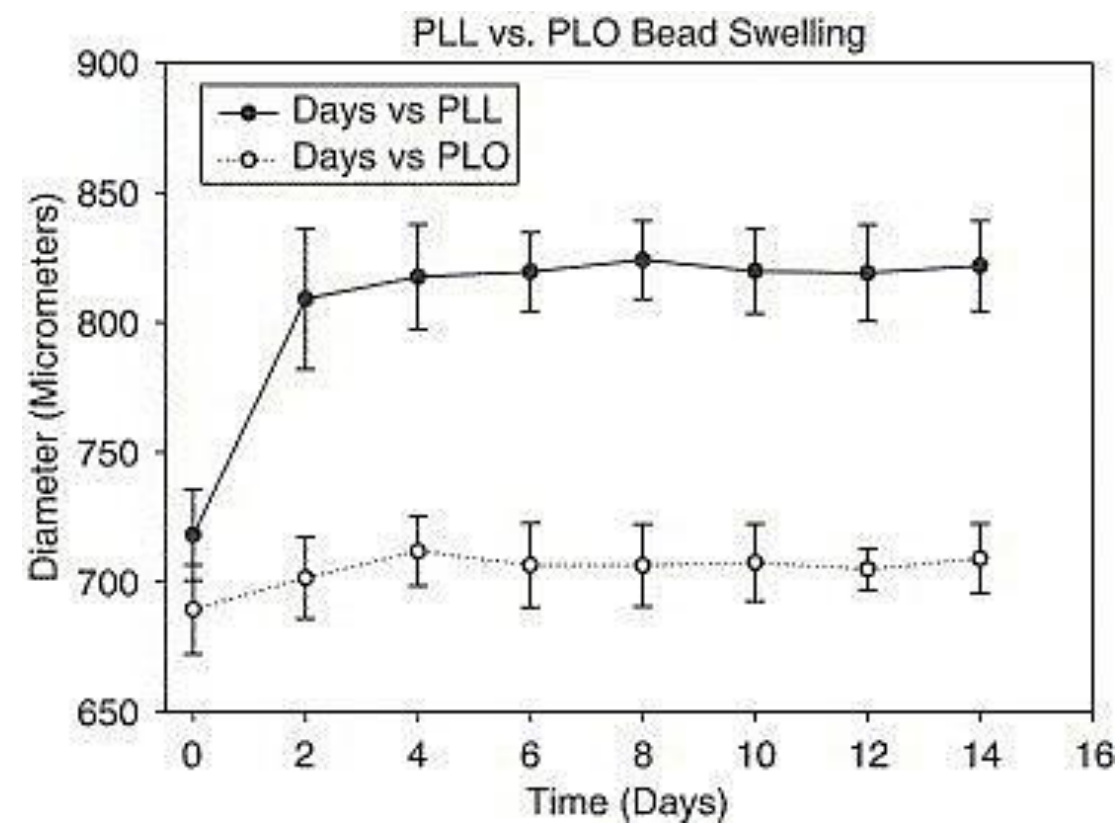

Figure 2.9: Changes in the diameter of alginate microcapsules during 14-day saline incubation at $37^{\circ} \mathrm{C}$. Capsules were coated with either PLL or PLO [30]. 


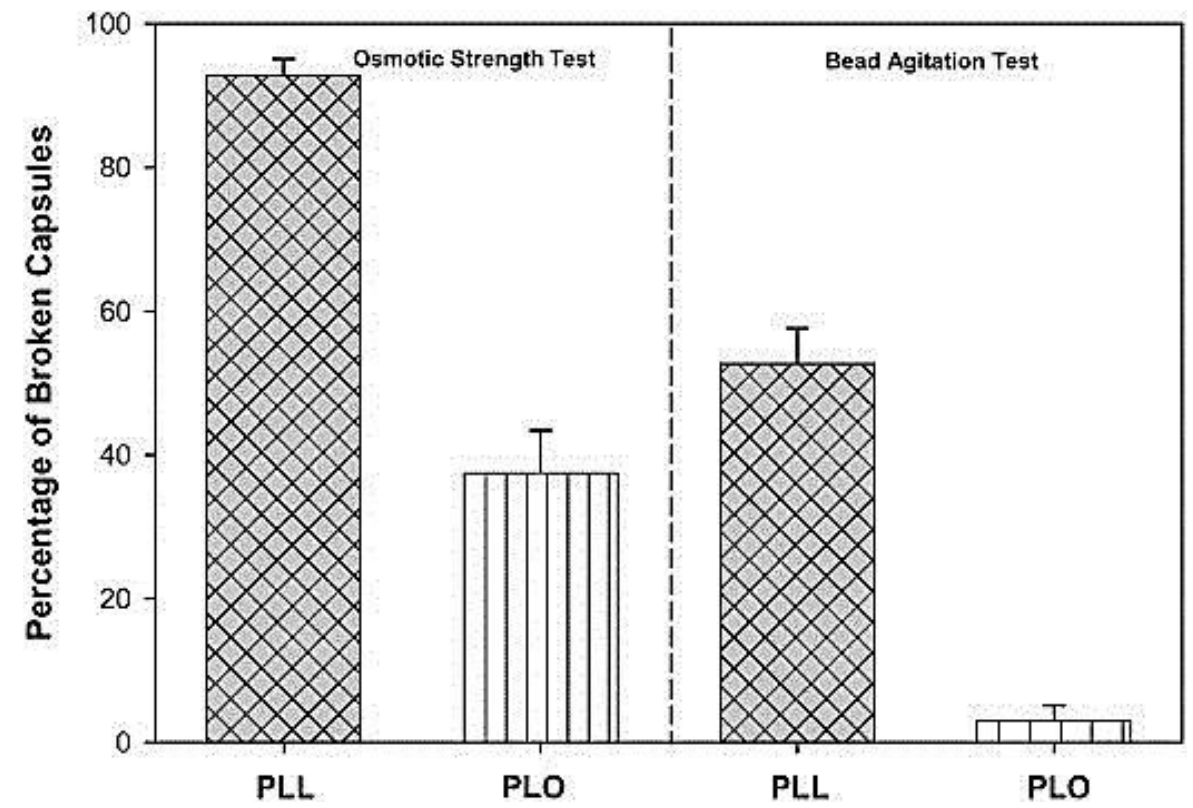

Figure 2.10: Effect of PLL and PLO coatings on microcapsule mechanical strength. Ruptured capsules were quantified following subjection to induced osmotic stress. Following $36 \mathrm{~h}$ of bead agitation, broken capsules in both PLL- and PLO-coated capsules were quantified [30].

\subsubsection{Polyacrylic acid}

Polyacrylic acid (PAA) is an organic binder used to improve adhesion between particles [43]. It is an anionic polymer composed of a repeating unit of acrylic acid. At a $\mathrm{pH}>4$, PAA carries a negative charge due to the deprotonated $\mathrm{COOH}$ groups, and below $\mathrm{pH} \sim 4$ PAA becomes protonated [44].

The effects of PAA could be seen in work by Nishimori et al. in 1996, who prepared films using PAA. They chose to use PAA as an acrylic binder when depositing silica particles by EPD onto stainless steel as polycarboxylic acids were expected to be best suited to co-deposit with particles due to the presence of $-\mathrm{COO}^{-}$under basic conditions, and PAA contains a large number of carboxylic groups. It was noted that compared to film produced without PAA, films with PAA were thicker and were shown to have no microcracks after drying (see Figure 2.11) [45]. 

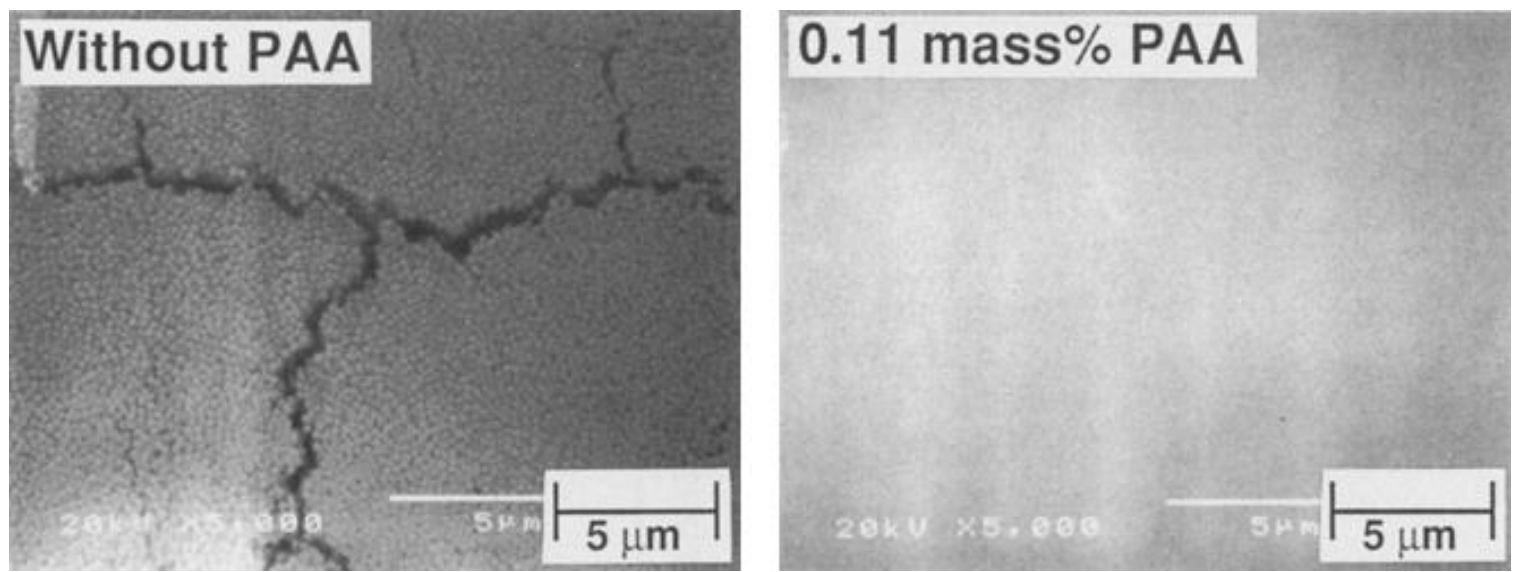

Figure 2.11: SEM photographs of the surface of the thick films prepared with and without PAA [45]

Additionally, Nishimori et al. noted that the addition of PAA had an effect on particle size as well as mass deposited, with particles of silica decreasing in size (see Figure 2.12) and the deposit mass increasing as the concentration of PAA increased (see Figure 2.13) [45].
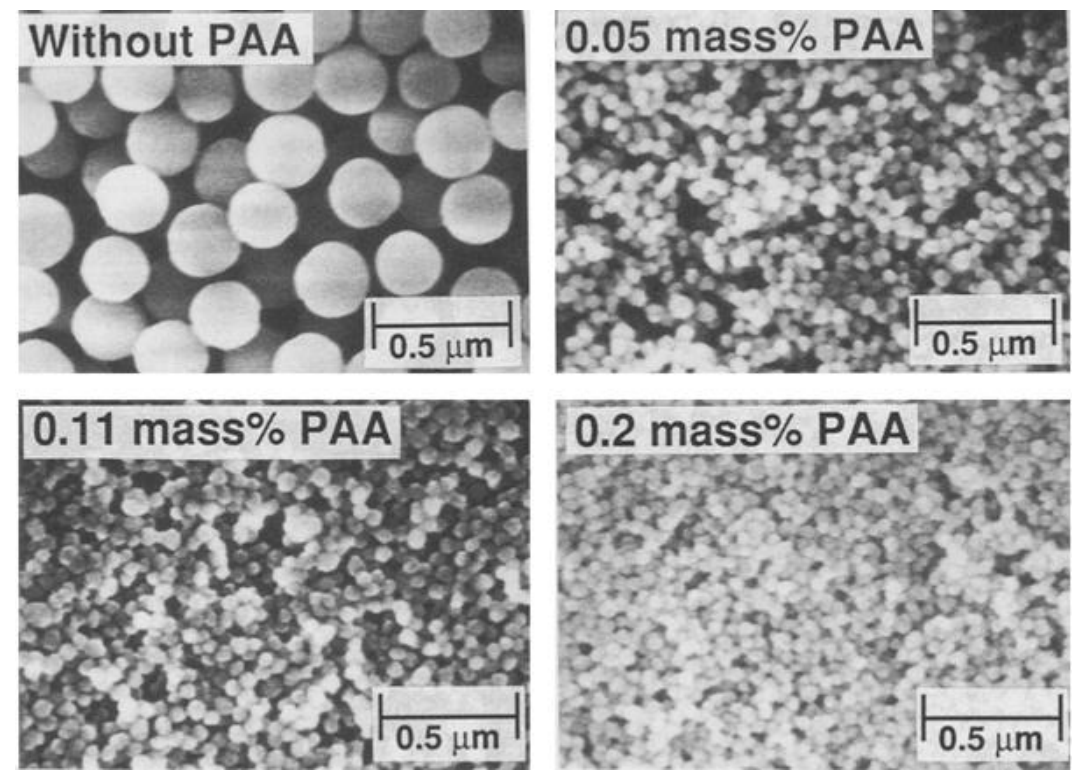

Figure 2.12: FE-SEM photographs of silica particles prepared with different amounts of PAA added [45] 


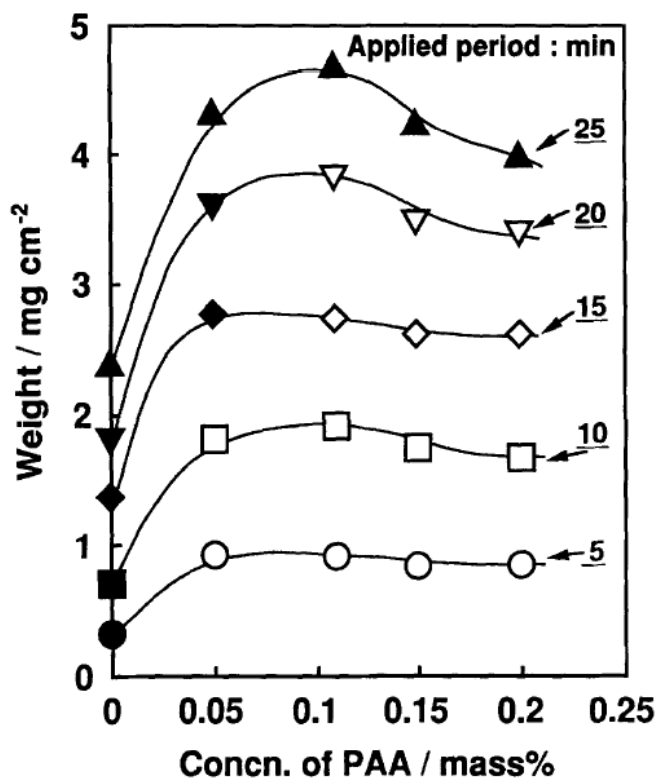

Figure 2.13: Weights of silica films deposited as a function of PAA added. Open marks indicate that there were no cracks on the surface of the films. Filled marks indicate that micro-cracks were observed by SEM [45].

Hasegawa et al. carried out similar experiments and observed similar results - an increase in deposited mass as PAA concentration increases, as well as no micro-cracks and thicker films [43].

More recently, PAA has been used to form coatings for biological applicationsSato et al. used PAA to coat CdS nanocrystals which were applied a biological labelling materials [46].

\subsubsection{Bioactive ceramics and apatites for biomedical implants}

\subsubsection{Halloysite Nanotubes}

Halloysite (HNT) is a two-layered clay mineral in the kaolin group, and is similar in structure and chemical composition to kaolinite $[24,47,48]$. It is a natural aluminosilcate that differs from other similar minerals in that it takes the shape of hollow 
nanotubes [24], with a diameter of 50 t0 $200 \mathrm{~nm}$ and lengths ranging from 0.02 to $30 \mu \mathrm{m}$ [48].
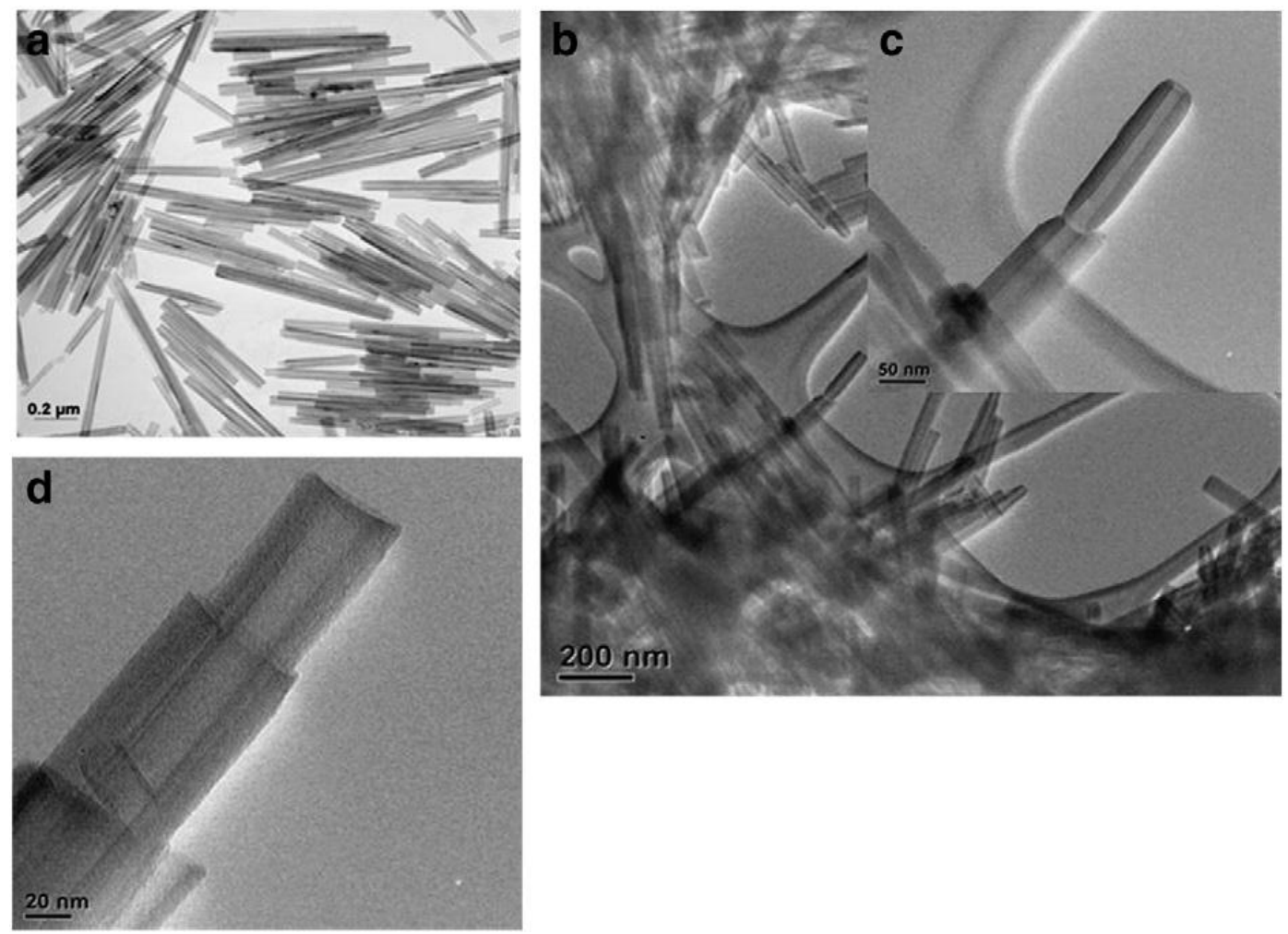

Figure 2.14: Halloysite from the CLA1 site in Maralinga Tjarutja in the Barton locality in South Australia [23].

Halloysite itself is composed of layers of octahedral alumina and tetrahedral silica separated by a layer of water (see Figure 2.15A). The ideal formula for halloysite is $\mathrm{Al}_{2} \mathrm{Si}_{2} \mathrm{O}_{5}(\mathrm{OH})_{4} \cdot \mathrm{nH}_{2} \mathrm{O}$, where $\mathrm{n}=0$ (indicating dehydrated halloysite with a basal spacing of $7 \AA$ ) or $n=2$ (indicating hydrated halloysite with basal spacing $10 \AA$ ) [48,49]. Intercalated water may occur between the repetitive two-layered sheets of the spiral wall [24]. Lattice mismatch between the aluminum and silicon layers causes strain, causes curving of the halloysite sheet, leading to its tubular form (see Figure 2.15B) $[47,49,50]$. 
Master Thesis

McMaster University
Imran A. Deen

Materials Science and Engineering

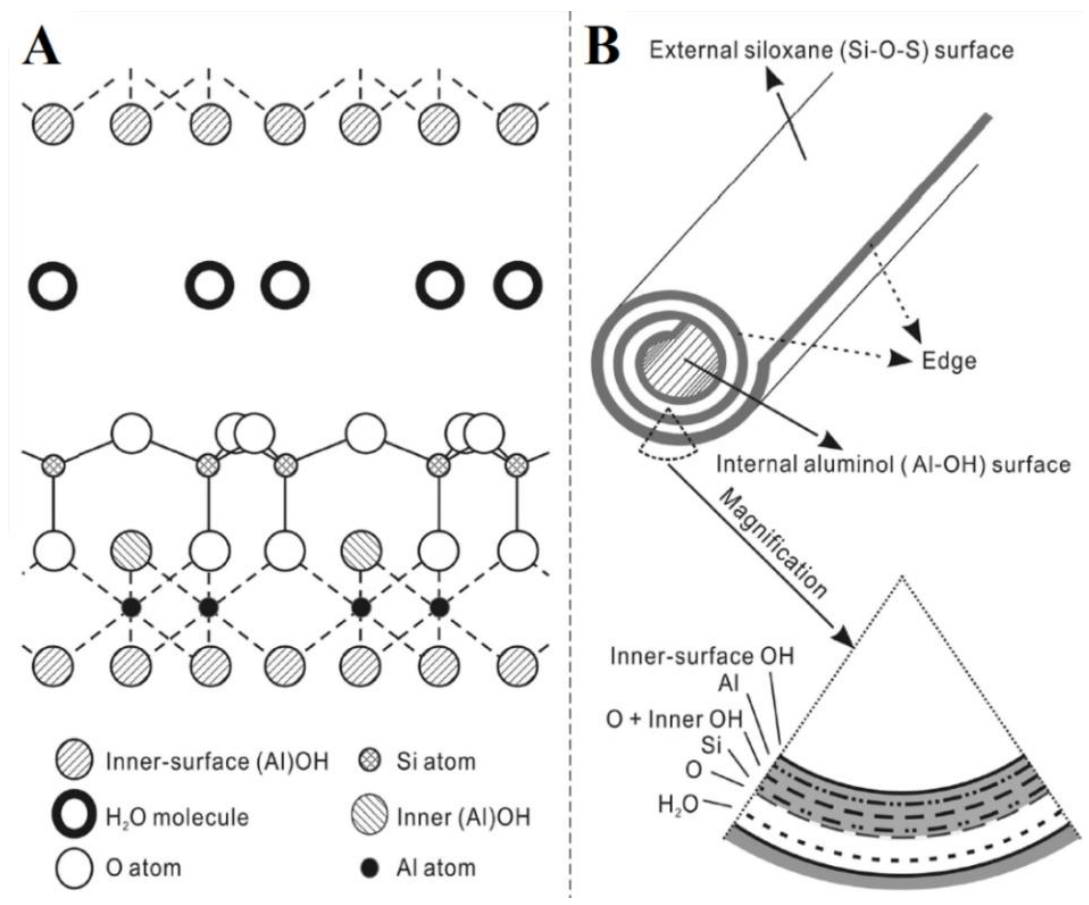

Figure 2.15: Structure of A) layers of halloysite and B) halloysite nanotube [49]

Halloysite is only slightly negative at low $\mathrm{pH}$ (see Figure 2.16) and shows a significant drop in potential before reaching a potential of $\sim-27 \mathrm{mV}$ at neutral $\mathrm{pH}$. This can be attributed to the silica component of halloysite being present at the outer surface, while the alumina is present mainly at the inner and edge surfaces [24]. 


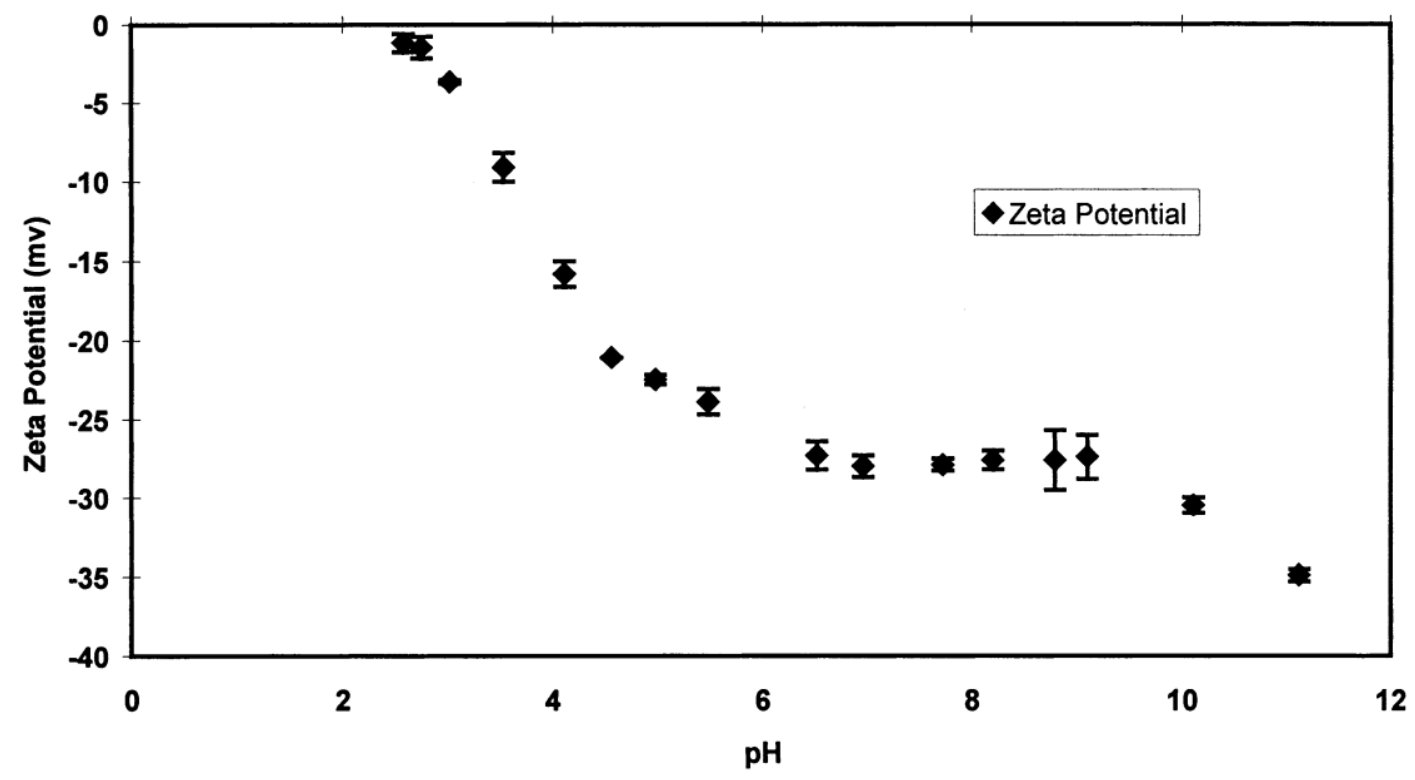

Figure 2.16: Zeta-potential plot for halloysite [24]

$\mathrm{X}$-ray diffraction (XRD) can be used to determine whether halloysite is hydrated, dehydrated, or partially hydrated by determining if there is a shift in the basal plane spacing. For example, XRD data for two samples show different peaks depending on whether or not the halloysite is hydrated (see Figure 2.17). In the sample from NZ, the basal spacing reflections show a sharp peak at $12.05^{\circ}$, which translates into a basal spacing of $7.35 \AA$. There is an absence of a peak at $8.76^{\circ}$, indicating the absence of $10 \AA$ spacing, which is present in the sample from Indiana. The sample from Indiana has peaks at $7 \AA$ and $10 \AA$, indicating it is partially hydrated, while the sample from NZ is dehydrated as it lacks a peak at $10 \AA$ [24]. 


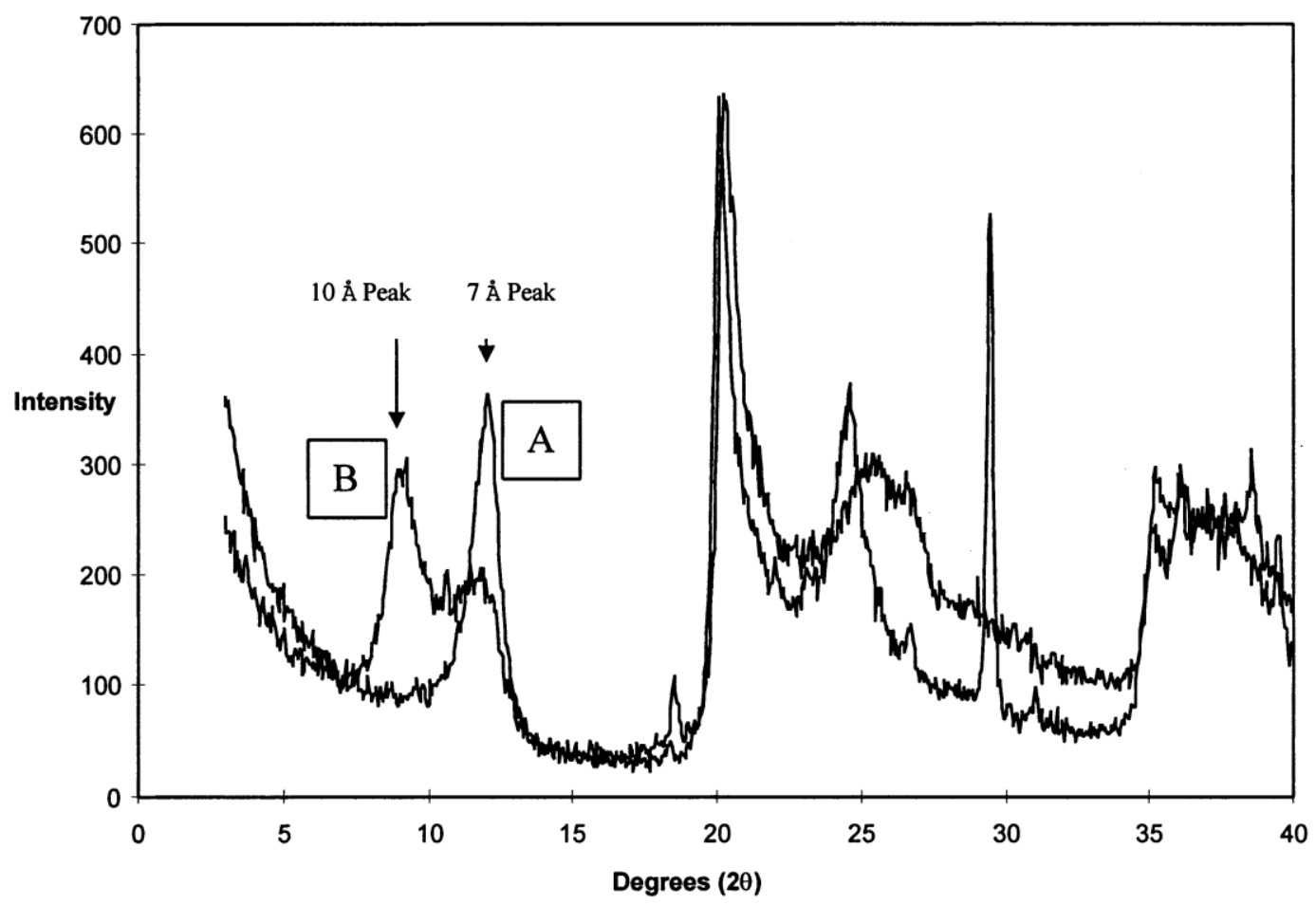

Figure 2.17: XRD patterns for halloysite from a) NZ and b) Indiana [24]

The inner and outer faces of the halloysite have a net negative charge, functioning as a polyvalent anion. Due to the shape and charge distribution of HNT, this could allow for extensive loading of agents by entrapping them in the lumen of tubules [24]. Clays themselves are common ingredients in pharmaceutical products - in the 1960s it was observed that oral absorption of several drugs was reduced by using clay-based intestinal absorbents or clay stabilizers. Furthermore, work by Cornejo-Garrido et al. shows that halloysite has anti-inflammatory properties, and is advantageous compared to other drugs in that its production is not tedious, hazardous, or expensive [23]. It is believed that hollow silica nanoparticles like halloysite are versatile materials that can be used for delivering drugs, proteins and genetic materials [22,23]. 


\subsubsection{Hydroxyapatite}

Apatites are a group of compounds that have similar structures but differ in their composition. In the body, bone, dentin and enamel all contain biological apatites, composed of the mineral phase of calcified tissue-these are normally referred to as calcium hydroxyapatite (HA) (chemical structure: $\mathrm{Ca}_{5}\left(\mathrm{PO}_{4}\right)_{3}(\mathrm{OH})$ ). Although biological apatites are similar to synthetically produced ones, they differ in composition, stoichiometry and physical and mechanical properties - biological HA is calciumdeficient due to various substitutions in regular HA lattice points, whereas regular HA has a specific composition and a well-defined crystal structure [51].

However, despite this difference, bioactive calcium phosphates, due to their close similarity to the structure and composition of bone, are seen as an effective precursor for bone substitutes [52]. Of these, HA, which is a natural calcium phosphate mineral, is seen as a leading bioactive ceramic that has previously found use as a method to improve the biocompatibility of titanium based implants [53] due to its similarity to bone apatite, which is the major component of the inorganic phase of bone and plays a key role in the calcification and reabsorption of bone [19].

Previous studies by Pang and Zhitomirsky have shown that HA nanoparticles show a needle-like morphology with the long axis of the needle corresponding to the caxis of hexagonal HA. The average length was approximately $200 \mathrm{~nm}$ with an aspect ratio of 8 (see Figure 2.18). Furthermore, the small size of the HA nanoparticles allowed for well-dispersed suspensions that remained stable for 1-2 days before sedimentation [54]. 


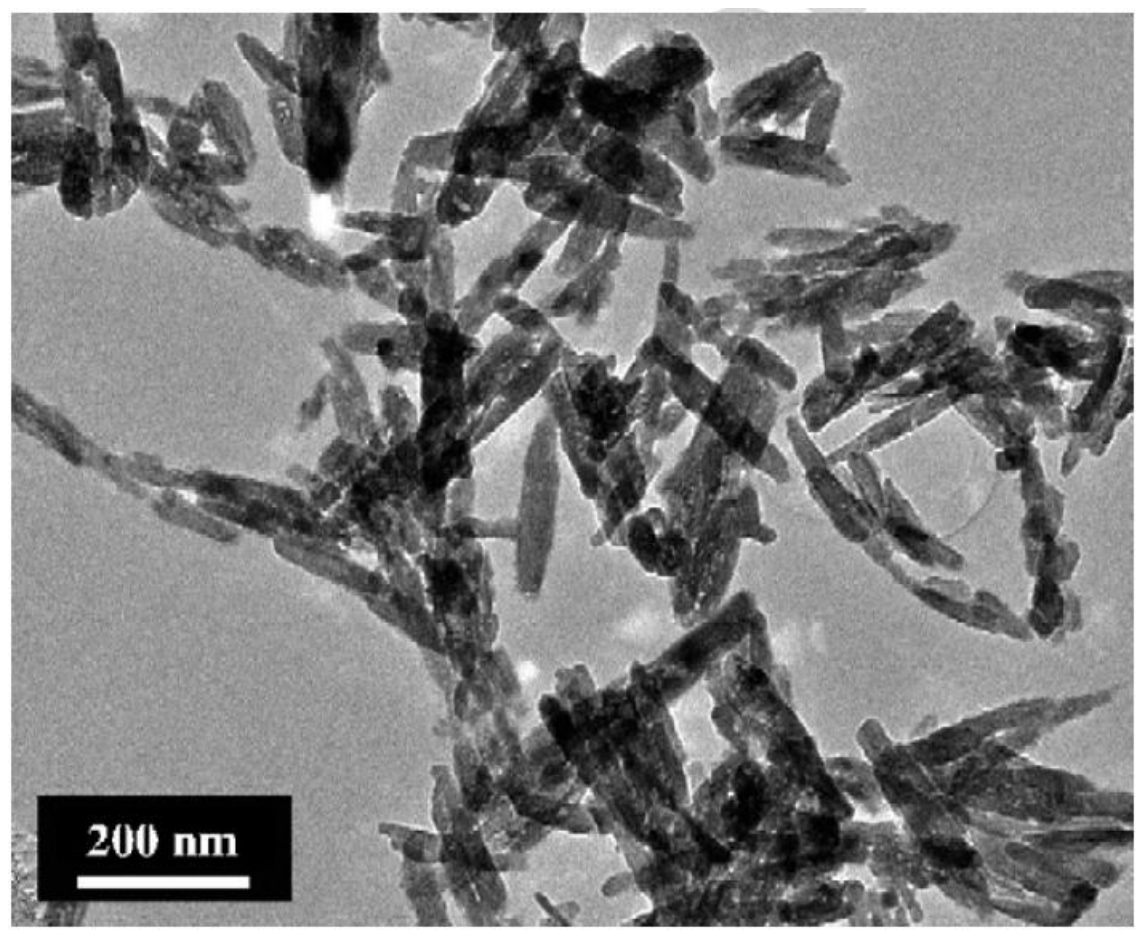

Figure 2.18: TEM image of the HA nanoparticles [54]

Because of its chemical and crystallographic similarity to the carbonated apatite in human bone, HA is a choice material for hard tissue repair [14]. Hydroxyapatite was incorporated into composite scaffolds as early as 1995 when Attawia et al. prepared a porous poly(lactide-co-glycolide) (PLGA)/HA scaffold, where it was observed that cells were maintaining their phenotype (observable characteristics and traits, such as morphology) and were proliferating on the surface as well as migrating inside the pores of the scaffold [55]. Additionally, Sui et al. found that another polymer, poly-L-lactic acid (PLLA), could be used to fabricate a nanofibrous polymer/HA hybrid membrane that had enhanced cell adhesion. Furthermore, they found that compared to PLLA alone, the presence of $\mathrm{HA}$ was able to slow the composite degradation and maintain the $\mathrm{pH}$ of the solution, which preserved cell viability and growth $[14,56]$. 


\subsection{Composite biomedical implants}

As has been previously demonstrated, there are many different materials that display good biological properties for physiological applications. However, individually, each of these materials has certain drawbacks that make them ill-suited for the creation of a biological implant by themselves. For example, metallic alloys, while possessing good mechanical properties, are typically bioinert and might face rejection from the body. Biopolymers and bioceramics have good biological properties but lack the mechanical strength to undergo multiple cycles of load-bearing situations. The best solution to this problem is to use biopolymers and bioceramics as a coating on alloys, which combine the strength of the substrate with the advantages of the biomaterials to fabricate a composite implant.

A composite implant is one which uses two or more distinct materials (metallic, ceramic or polymeric), separated by an interface. Unlike previous implants made of a single material, composite implants are advantageous in that they can be tailored according to the desired requirements of the patient, including mechanical, chemical, biological and physical needs $[14,19]$. For example, some of the advantages of composite implants include [14]:

- developing implants with improved mechanical properties due to the inclusion of inorganic materials

- controlled degradation of organic phases 
- controlling the topography of the material with the incorporation of nanosized or microsized particles

Because of their versatility, composite implants are being increasingly researched in the field of tissue engineering as a way of creating the next generation of biomedical implants as they offer numerous advantages of traditional implants in terms of integration with the body $[16,19]$.

\subsection{Electrophoretic Deposition}

Electrophoretic deposition (EPD) can trace its origin back to 1808, when Prof. Reuss of Moscow university discovered electrophoresis and electroosmosis (the movement of particles or liquids, respectively, under an applied electric field) [57]. Under the right conditions, when an external electric field is applied to a colloidal suspension or a solution, the charged particles present will migrate towards one of the electrodes, a phenomenon known as electrophoresis. After these particles reach the electrode, they form a coherent deposit at the surface, which is the basis of EPD [58,59]. Electrophoretic deposition is a widely used method of depositing films of ceramic and organoceramic materials from colloidal dispersions [58]. In recent years, EPD has gained popularity as a method of creating thin, composite films due to its versatility, low cost and ease of manufacturing [60].

While EPD falls under the definition of electrochemical deposition, it differs in several aspects from the more commonly known process of Electrolytic Deposition (ELD) (see Table 2.4). The most important difference between the two techniques is that 
the material to be deposited need not be electrically conductive [61] and the particles can be much larger, and the resulting films are much thicker [62].

Table 2.4: Characteristics of different electrodeposition techniques

\begin{tabular}{|l|l|l|l|}
\hline \multicolumn{1}{|c|}{ Property } & \multicolumn{1}{c|}{ ELD } & \multicolumn{1}{c|}{ EPD } & References \\
\hline Moving species & Ions & Solid particles & {$[60]$} \\
\hline $\begin{array}{l}\text { Charge transfer on } \\
\text { deposition }\end{array}$ & Ion reduction & None & {$[60]$} \\
\hline $\begin{array}{l}\text { Required } \\
\text { conductance of } \\
\text { liquid medium }\end{array}$ & High & Low & {$[60]$} \\
\hline Preferred liquid & water & organic & {$[60]$} \\
\hline Film thickness & $10^{-3}-3.16 \mu \mathrm{m}$ & $1-5.6 \times 10^{3} \mu \mathrm{m}$ & {$[62]$} \\
\hline Deposit formation & Redox reaction & Particle coagulation & {$[58,62]$} \\
\hline
\end{tabular}

\subsubsection{Deposition process}

During EPD, when particles are dispersed in a polar solvent or electrolytic solution, the surface of the particles develops an electrical charge through one or more of the following mechanisms [58]:

1) Preferential dissolution

2) Deposition of charges of charged species

3) Preferential reduction

4) Oxidation

5) Adsorption of charged species such as polymers

Afterwards, the charged surface will be electrostatically attracted to oppositely charge species in the solution (i.e. counter-ions) and a combination of electrostatic forces, Brownian motion and osmotic forces will result in a double-layered structure. 


\subsubsection{Deposition Mechanics}

The exact mechanism of deposition is not entirely understood, and as such there have been multiple theories as to how it occurs. Hamaker and Verwey were the first to attempt to explain the phenomena in 1940 by suggesting that the formation of deposits by electrophoresis was similar to sediments caused by gravitation in nature. The primary function of the electric field was to move particles toward the electrode to accumulate, which exerted enough force to overcome interparticle repulsion. The accumulation led to pressure exerted by the outer layer, which allowed for the formation of a deposit [63].

In 1954 Koelmans and Overbeek proposed an electrochemical method of deposit formation based on the DLVO theory; an increase of electrolyte concentration induced coagulation in the system, the deposit then formed as a result of particle flocculation and the resultant reduced zeta potential near the electrode [64]. While this mechanism works when the electrode generates $\mathrm{OH}^{-}$ions, it is invalid when there is no increase in electrolyte concentration near the electrode [60].

A charge neutralization method was later proposed by Grillon et al. in 1992, who suggested that particles would neutralize when they came in contact with the electrode and become static [65]. While this mechanism explained the deposition at the initial stage of deposition from dilute suspensions, it failed for a) EPD for long times (thick films), b) when particle-electrode processes are prevented (e.g. semi-permeable membrane induces deposition between the electrodes), and c) when electrochemical reactions alter the $\mathrm{pH}$ near the electrode [60]. 
A complete explanation of the phenomenon of electrophoresis was offered by Sarkar and Nicholson in 1996 based on the DLVO theory, which accounted for the discrepancies of previous theories. Sarkar and Nicholson considered the movement of a positively charged oxide particle. In the absence of any external force, only the DLVO force $\left(\mathrm{F}_{\mathrm{T}}\right)$ is present. They considered an external DC electric field $\left(\mathrm{F}_{\mathrm{E}}\right)$ applied, and a particle at the depositing electrode, with a second particle approaching (see Figure 2.19). The applied electric field then resulted in a modified force $\left(\mathrm{F}_{\mathrm{M}}\right)$ on the particle:

$$
\mathrm{F}_{\mathrm{M}}=\mathrm{F}_{\mathrm{T}}+\mathrm{F}_{\mathrm{E}}
$$

If the applied field exerts a force greater than the mutual repulsive force, the two particles will coagulate at the electrode [66].

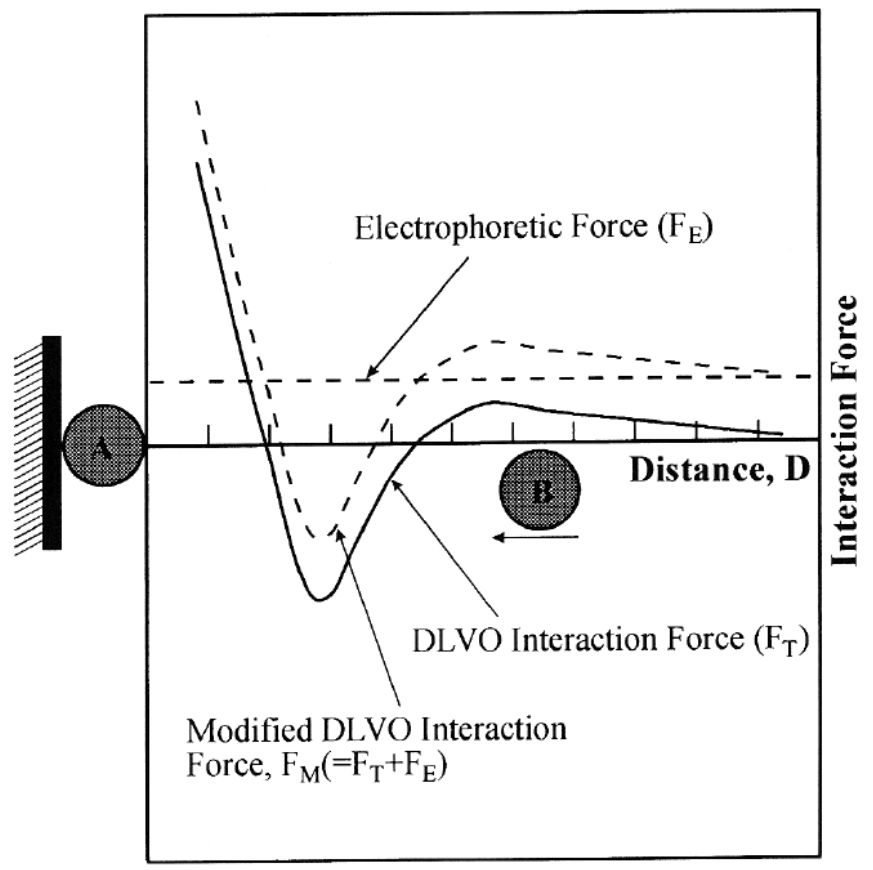

Figure 2.19: Schematic of the force between two particles in suspension as a function of separation [66] 
Furthermore, if a positively charged particle moves towards the cathode in an EPD cell, the lyosphere system (the counter-ions surrounding the particle forming the diffuse double layer) is distorted by fluid dynamics and the electric field, and thins ahead of the particle (see Figure 2.20) [66].
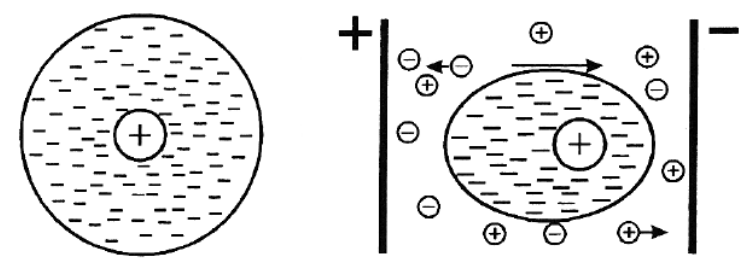

LOCAL LYOSPHERE THINNING

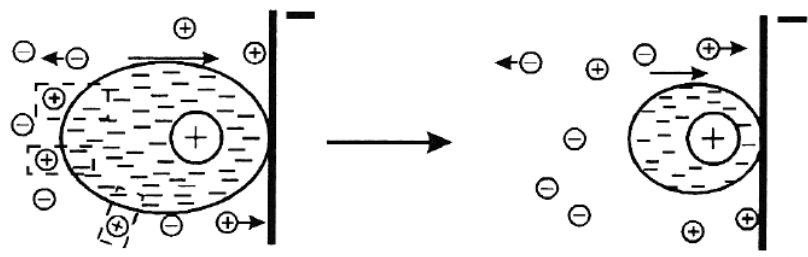

COAGULATION
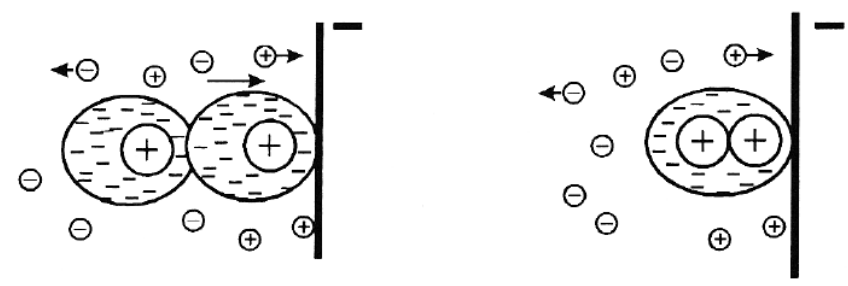

Figure 2.20: Schematic of the deposition mechanism by lyosphere distortion and thinning [66]

Cations in the liquid will also move with the particle, and the counter-ions will react with them. As a result of this chemical reaction, the double layer around the tail of the particle thins, and an incoming particle (which has a thin double layer ahead of itself) can approach close enough that London Van der Waals forces allows for coagulation/deposition at the electrode [66]. 


\subsubsection{Deposition of polymers}

The classical colloidal theories that describe electrostatic forces between solid particles in suspension can also be used to describe polymers. As outlined above, when a solid particle is immersed in a solvent, it acquires a charge; the same is true for many polymers. In a non-aqueous medium, dissociation and ionization or surface groups is the most likely mechanism. The particles react with either $\mathrm{H}^{+}$or $\mathrm{OH}^{-}$and undergo proton association or disassociation as follows $[62,67]$ :

$$
\begin{gathered}
(\mathrm{M} / \mathrm{P})-\mathrm{OH}+\mathrm{H}^{+} \rightarrow\left(\mathrm{M} / \mathrm{P}-\mathrm{OH}_{2}\right)^{+} \\
(\mathrm{M} / \mathrm{P})-\mathrm{OH}+\mathrm{OH}^{-} \rightarrow(\mathrm{M} / \mathrm{P}-\mathrm{O})^{-}+\mathrm{H}_{2} \mathrm{O}
\end{gathered}
$$

Where $(\mathrm{M} / \mathrm{P})$ is the metal or polymer constituent of the particle.

\subsubsection{DLVO theory}

Named after Derjaguin and Landau, Verwey and Overbeek, the DLVO theory describes the interaction between two particles (which are electrostatically stabilized in a suspension), as a combination of van der Waals attraction potential and electrostatic repulsion potential (see Figure 2.21) [58,62]:

$$
\mathrm{V}_{T}=\mathrm{V}_{A}+\mathrm{V}_{R}
$$

Where $V_{T}$ is the total interaction, $V_{A}$ is the van der Waals attraction, and $V_{R}$ is the electrostatic repulsion. 


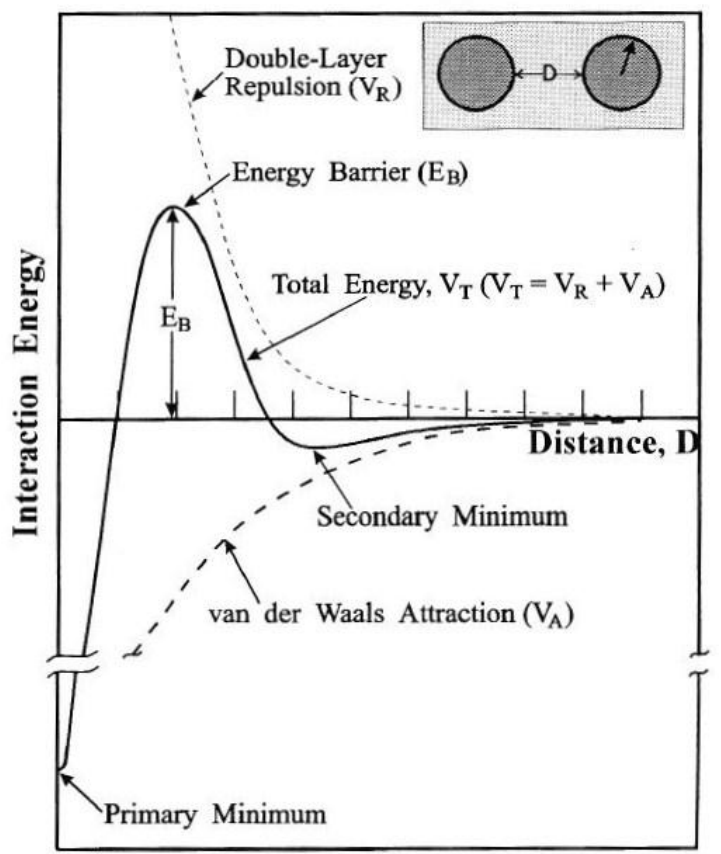

Figure 2.21: Energy of interaction between two particles [66]

The attractive force of the London-van der Waals' interaction can be described by the following $[58,62]$ :

$$
V_{A}=-\frac{A}{6}\left[\frac{2 r^{2}}{S^{2}+4 r S}+\frac{2 r^{2}}{S^{2}+4 r S+4 r^{2}}+\ln \left(\frac{S^{2}+4 r S}{S^{2}+4 r S+4 r^{2}}\right)\right]
$$

Where $A$ is Hamaker's constant (positive, on the order of $10^{-19}$ to $10^{-20}$ ), $r$ is the radius of the particles, and $S$ is the distance between the particles. This can be further simplified if the separation distance between the particles is significantly higher than their radii, i.e., if $S>r[58,62]:$

$$
V_{A}=-\frac{A r}{12 S}
$$

The repulsive energy, $V_{R}$, is described by [58]: 


$$
V_{R}=2 \pi \varepsilon_{r} \varepsilon_{0} r E^{2} e^{-\kappa S}
$$

The Debye-Hückel length, $\kappa$, (the length over which significant charger separation can occur), is described by the following equation [58]:

$$
\kappa=\sqrt{\frac{F^{2} \sum_{i} C_{i} Z_{i}^{2}}{\varepsilon_{r} \varepsilon_{0} R_{g} T}}
$$

Where $F$ is Faraday's constant, $\varepsilon_{\mathrm{o}}$ is the permittivity of vacuum, $\varepsilon_{\mathrm{r}}$ is the dielectric constant of the solvent, $E$ is the electric potential of the particle, $C_{i}$ is the concentration of the counter ions of type $i$, and $Z_{i}$ is the valence of the counter ions of type $i$.

This interaction/stabilization is described by the DLVO theory. When using DLVO theory to describe electrostatic stabilization of particles, it is important to note that it makes the following important assumptions [58]:

1) Infinite flat solid surface.

2) Uniform surface charge density.

3) No redistribution of surface charge (i.e. the surface electric potential remains constant).

4) No change of concentration profiles of both counter ions and surface charge determining ions (i.e. the electric potential remains unchanged).

5) Solvent exerts influence via dielectric constant only (i.e. no chemical reactions between the particles and solvent). 
While these assumptions are far from reality, the DLVO theory works well in describing particle stabilization in spite of this, and is widely accepted to describe charged colloidal suspensions [58].

\subsubsection{The Double layer}

When a solid surface establishes a charge, an electrostatic force develops between the solid surface and any charged species in the proximity to the surface. Meanwhile, Brownian motion and entropic force homogenize the distribution of various species in the solution, in which there are both charged ions (that determine the surface charge) and counter-ions (oppositely charged to the charged ions). However, while charge neutrality is maintained, the concentration of ions and counter-ions in proximity to the charged surface varies. Thus, the distribution of both positive and negative ions is controlled by the following [58]:

- Coloumbic/electrostatic force

- Entropic force or disruption

- Brownian motion

The result of the above forces, when combined, is that the concentration of counter ions is highest near the surface and decreases with distance, while the concentration of charge determining ions changes in the opposite manner. This inhomogeneous distribution of ions close to the surface results in the creation of the double layer (see Figure 2.22), which is composed of the Stern and Gouy (diffuse double) layers, which are separated by the Helmholtz plane [58]. 


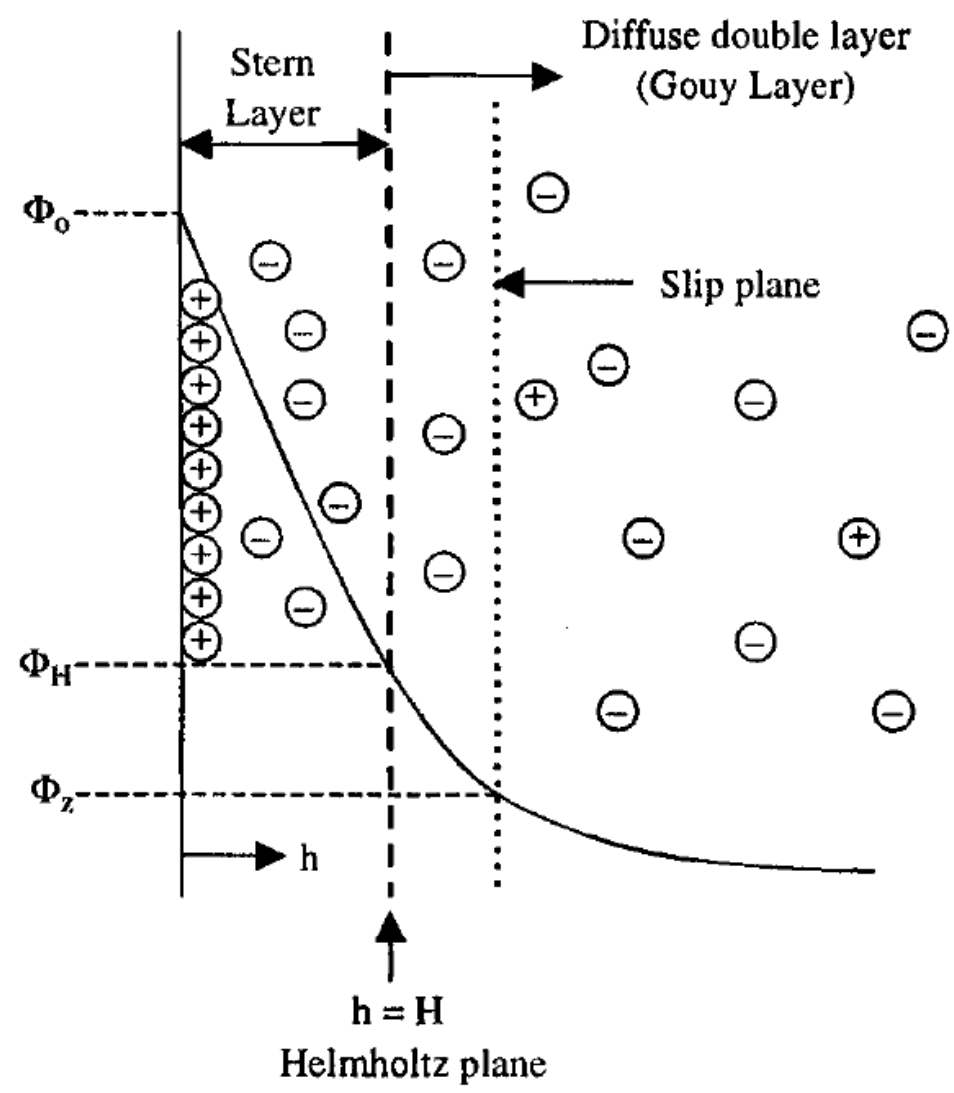

Figure 2.22: Structure of the double layer structure and distribution of potential (surface charge is assumed to be positive) [58]

The electric potential drops linearly in the Stern layer through the tightly bound layer of solvent and counter ions until it reaches the Helmholtz plane. Afterward, in the Gouy layer, the electric potential drops according to the following [58,60]:

$$
E \propto e^{-\kappa(h-H)}
$$

Where $\mathrm{h} \geq \mathrm{H}$ is the Stern layer, $\mathrm{H}$ is the Helmholtz plane, and $1 / \kappa=$ the Debye-Hückel length.

From Section 2.6.1.3, $\kappa$ was expressed as directly proportional to the concentration and valence of the ions, and inversely proportional to the dielectric 
constant. This indicates that the electric potential at the surface drops with increased concentration and valence state of counter ions, and increases with an increased dielectric constant [58].

\subsubsection{Deposition kinetics}

Deposition kinetics were first described in 1940 by Hamaker, who theorised that the mass of deposition was directly proportional to the time of deposition, and proposed a linear relationship known as the Hamaker equation [68]:

$$
M=\mu E t S C_{S}
$$

Where $C_{s}$ is concentration of colloidal particles, $E$ is the electric field, $t$ is the deposition time, $\mu$ is the particle mobility and $S$ is the surface of electrode. Given many variables held constant, Equation 2-9 can be simplified:

$$
M=\underbrace{\mu E S C_{S}}_{\text {constant }} t=k t
$$

Where $\mathrm{k}=\mu \mathrm{ESC}_{\mathrm{s}}$. However, this model ignored the change of concentration during deposition. In 1994, Zhang et al. derived a kinetic equation [69] that accounted for the change in concentration over time. This model was further refined to take into account the effect of voltage drop as the deposited film increased (see Figure 2.23). 


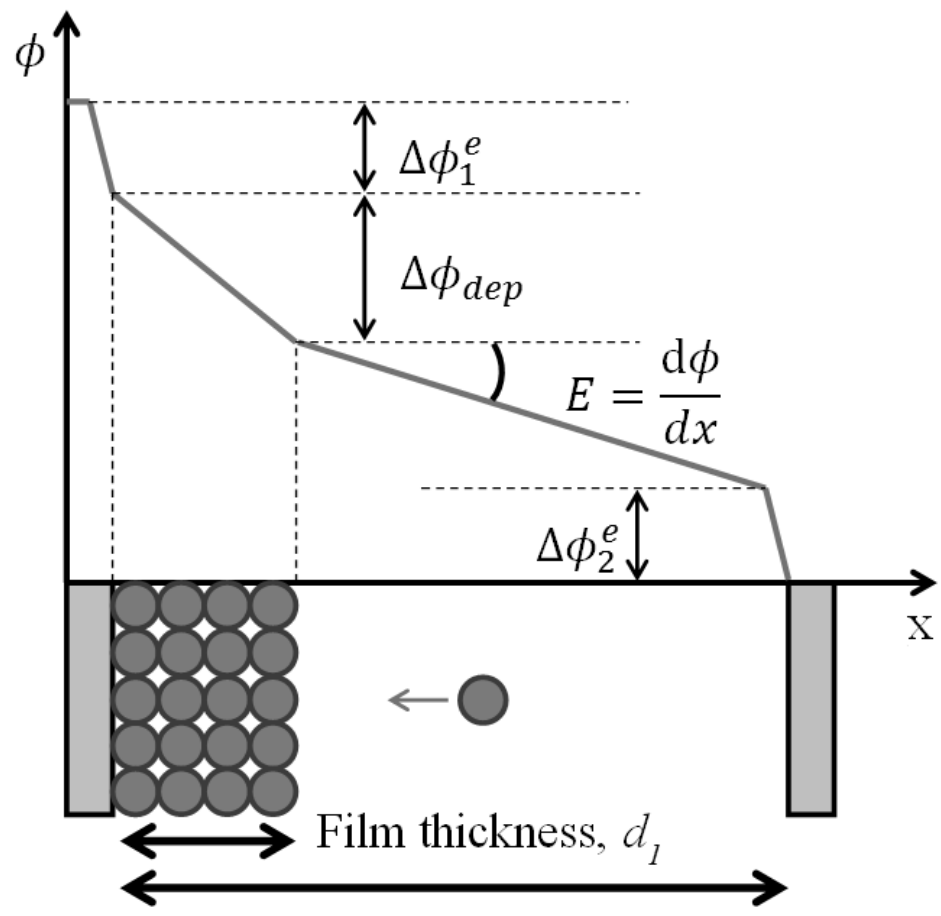

Electrode spacing, $d$

Figure 2.23: Evolution of the potential in the deposition cell during EPD. [59]

The potential drop in and EPD cell between the electrodes can be described by the following expression [59]:

$$
V_{a}=\Delta \phi_{1}+I R_{d e p} d_{1}+I R_{s}\left(d-d_{1}\right)+\Delta \phi_{2}
$$

where $V_{a}$ is the applied potential, $I$ is the current, $R_{\text {dep }}$ and $R_{s}$ are the resistance per unit length over the deposit and solution, $d$ is the electrode separation, $d_{l}$ is the thickness of the deposit and $\Delta \phi_{i}=$ potential drop at one electrode. As deposit forms, it replaces an equal thickness of suspension and the total resistance of system changes [59].

Thus, there are four basic models that describe the different conditions under which EPD occurs (see Table 2.5 and Figure 2.24) [66]. 
Table 2.5: Deposition kinetics for various conditions

\begin{tabular}{|c|c|c|c|}
\hline Model & Parameters & Equation & \\
\hline I & $\begin{array}{l}\text { Constant } \\
\text { current/constant } \\
\text { concentration } \\
\end{array}$ & $w(t)=k w_{0} t$ & $(2-12)$ \\
\hline II & $\begin{array}{l}\text { Constant } \\
\text { current/variable } \\
\text { concentration }\end{array}$ & $w(t)=w_{0}\left(1-e^{-k t}\right)$ & $(2-13)$ \\
\hline III & $\begin{array}{l}\text { Constant } \\
\text { voltage/constant } \\
\text { concentration } \\
\end{array}$ & $R^{\prime} w^{2}+L w(t)+k^{\prime} w_{0} V_{a} t=0$ & $(2-14)$ \\
\hline IV & $\begin{array}{l}\text { Constant } \\
\text { voltage/variable } \\
\text { concentration }\end{array}$ & $\begin{array}{c}R^{\prime} w(t)+\left(R^{\prime} w_{0}+L\right) \ln \left(\frac{w_{0}-w(t)}{w_{0}}\right) \\
+k^{\prime} V_{a} t=0\end{array}$ & $(2-15)$ \\
\hline
\end{tabular}

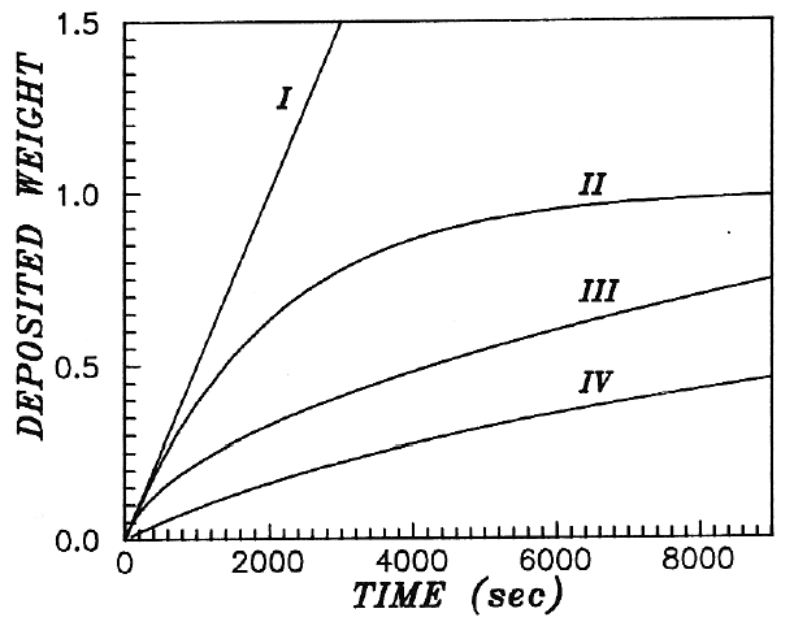

Figure 2.24: Deposited weight (fraction of initial weight of solid in the suspension) for different conditions [66]

\subsubsection{Factors affecting deposition}

Electrophoretic deposition relies on the mechanism of charged particles forming a coherent deposit on an electrode under an electric field. As such, EPD relies on several different parameters related to what is desired in the properties and characteristics of the film. Factors such as the type of solvent used, the properties of the particles to be 
deposited, the deposition conditions and the substrate itself all play a large role in the EPD process $[58,60]$.

\subsubsection{Choice of solvent}

Solvents, which are either aqueous (i.e $\mathrm{H}_{2} \mathrm{O}$ ) or non-aqueous/organic, can be grouped into either protic (able to exchange protons) or aprotic (unable to exchange protons) categories. Furthermore, different solvents have different properties that affect EPD, as they affect the dielectric constant, conductivity and viscosity of the suspension (see Table 2.6).

Table 2.6: List of solvents used in EPD and their properties

\begin{tabular}{|l|c|c|c|c|c|}
\hline \multicolumn{1}{|c|}{ Solvent } & Formula & $\begin{array}{c}\text { Viscosity }(\boldsymbol{c P}) \\
\left(\mathbf{1 0}^{-3} \mathbf{N s m}^{-2}\right)\end{array}$ & $\begin{array}{c}\text { Dielectric } \\
\text { constant }\end{array}$ & Type & References \\
\hline Acetic acid & $\mathrm{C}_{2} \mathrm{H}_{4} \mathrm{O}_{2}$ & 1.056 & 6.2 & Protic & {$[58,70]$} \\
\hline Acetone & $\mathrm{C}_{3} \mathrm{H}_{6} \mathrm{O}$ & 0.3087 & 20.7 & Aprotic & {$[58,60]$} \\
\hline Ammonia & $\mathrm{NH}_{3}$ & & 16.9 & Protic & {$[58]$} \\
\hline Benzene & $\mathrm{C}_{6} \mathrm{H}_{6}$ & $0.649\left(20^{\circ} \mathrm{C}\right)$ & 2.3 & Aprotic & {$[58,70]$} \\
\hline Chloroform & $\mathrm{CHC}_{3}$ & $0.514\left(30^{\circ} \mathrm{C}\right)$ & 4.8 & Aprotic & {$[58,70]$} \\
\hline Diethyl ether & $\mathrm{C}_{4} \mathrm{H}_{10} \mathrm{O}$ & 0.224 & 4.3 & Aprotic & {$[58,70]$} \\
\hline Ethanol & $\mathrm{C}_{2} \mathrm{H}_{5} \mathrm{OH}$ & 1.0885 & 24.55 & Protic & {$[58,60]$} \\
\hline Ethylene glycol & $\mathrm{C}_{2} \mathrm{H}_{6} \mathrm{O}_{2}$ & 16.265 & 37.7 & Protic & {$[60,71]$} \\
\hline Formamide & $\mathrm{CH}_{3} \mathrm{ON}$ & $2.296\left(30^{\circ} \mathrm{C}\right)$ & 110 & Protic & {$[58]$} \\
\hline Methanol & $\mathrm{CH}_{3} \mathrm{OH}$ & 0.557 & 32.6 & Protic & {$[58,60]$} \\
\hline Pyridine & $\mathrm{C}_{5} \mathrm{H}_{5} \mathrm{~N}$ & 0.879 & 14.2 & Aprotic & {$[58,70]$} \\
\hline Water & $\mathrm{H}_{2} \mathrm{O}$ & 0.890 & 78.5 & Protic & {$[58,70]$} \\
\hline
\end{tabular}

Previous experiments have shown that the dielectric constant of the solvent affects EPD. Powers, who investigated the deposition of beta-alumina in organic media, found that EPD produced deposits only with a liquid where the dielectric constant was within 15-25 (see Figure 2.25) [72]. Too low of a dielectric constant causes EPD to fail because 
there is insufficient dissociative power, whereas if the dielectric constant is too high there is a high ionic concentration in the suspension, which reduces the size of the double layer region and consequently electrophoretic mobility [60].

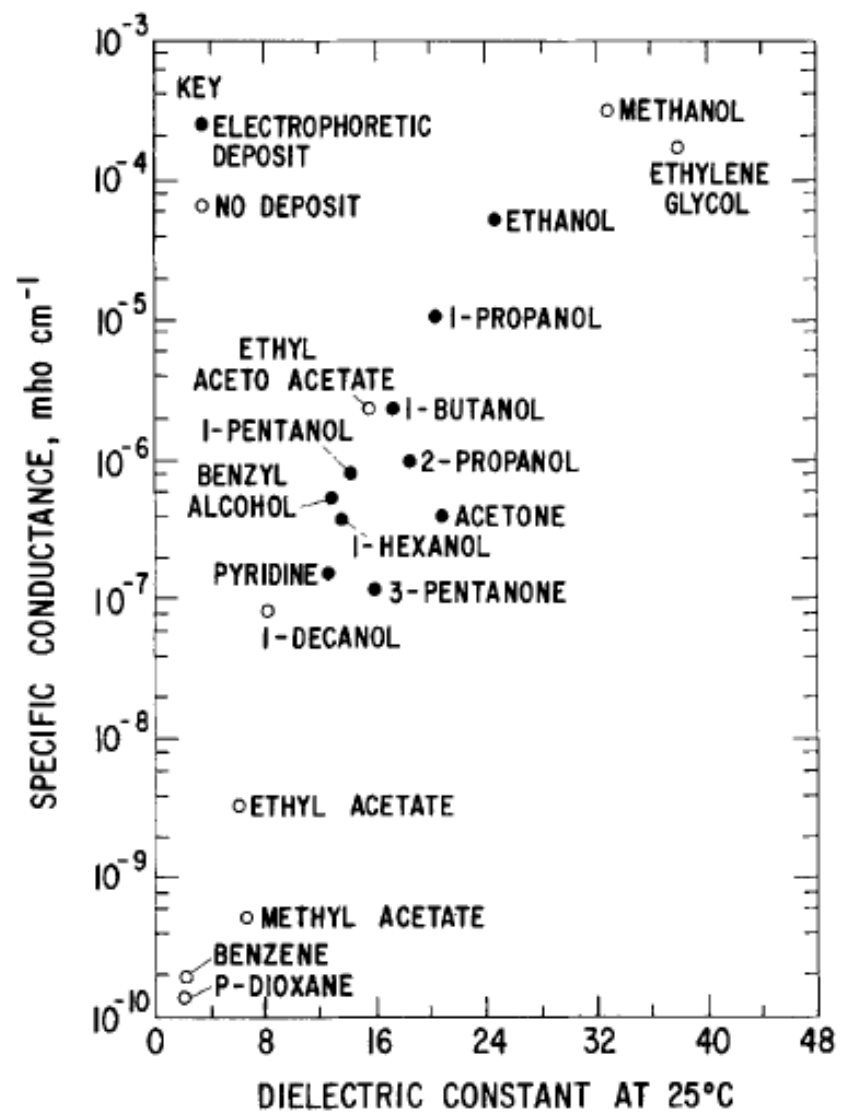

Figure 2.25: The electrical conductivity of suspensions vs. the dielectric [72]

For optimum conditions, a suspension with low viscosity, high dielectric constant and low conductivity is desired [60].

\subsubsection{Particles in the suspension}

In order for EPD to be successful, the stability of the suspension is paramountparticles need to be completely dispersed and stable in order to form a uniform deposit. Particle size plays a larger role here, as the larger/heavier the particle, the more likely 
gravitational forces will overcome the electrostatic forces and lead to sedimentation. Suspensions where the particles are not stable and sediment will lead to a non-uniform deposit, where the bottom is thicker than the top [60]. A well-dispersed suspension is necessary in order to avoid flocculation or coagulation of the particles in the suspension, which result in a non-uniform film (see Figure 2.26) [73].

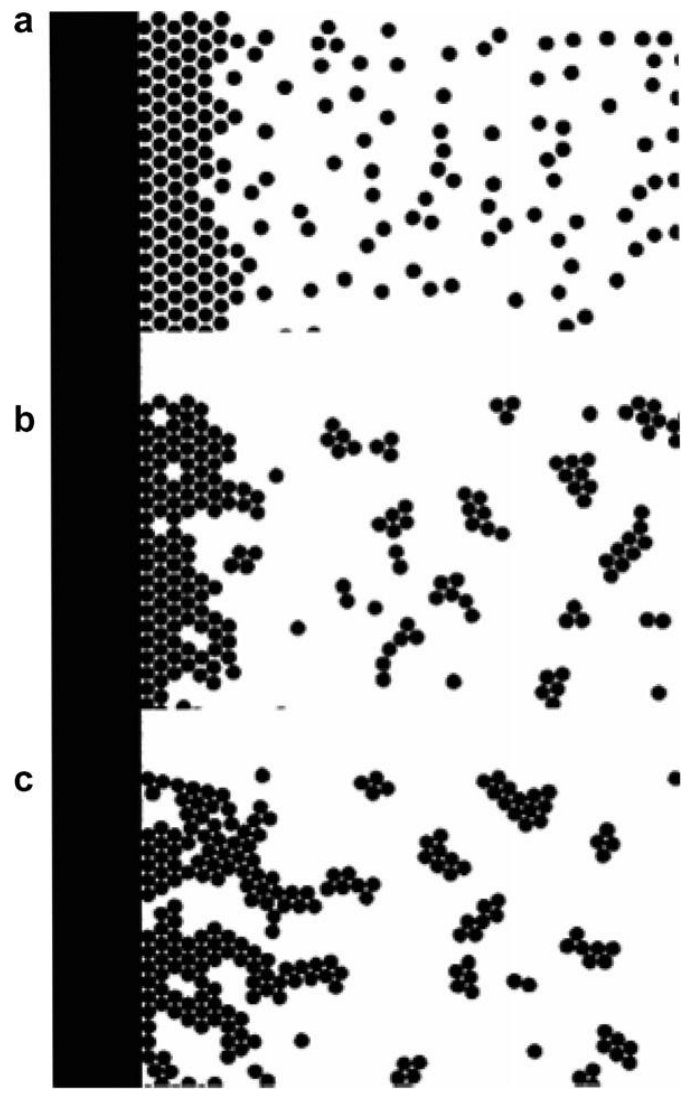

Figure 2.26: Particle distribution structures in the Nerst layer: a) stable state, b) flocculated state, c) coagulated state [73]

Furthermore, the zeta potential of particles plays an important role in their deposition. In Section 2.6.2, it was shown that the deposit mass was directly proportional to its electrophoretic mobility. This can be further broken down to include the zeta potential of the particle. Using Smoluchowski's formula the electrophoretic mobility for 
large particles, where the radius is large compared to the Debye length, $1 / \kappa$, can be described using the following equation [74]:

$$
\mu=\frac{\varepsilon \varepsilon_{0} \zeta}{\eta}
$$

For particles smaller than the Debye length, the electrophoretic mobility is instead described by Hückel's formula [74]:

$$
\mu=\frac{2 \varepsilon \varepsilon_{0} \zeta}{3 \eta}
$$

Where $\mu$ is the electrophoretic mobility, $\zeta$ is the zeta potential, $\eta$ is the viscosity of the liquid, $\varepsilon$ is the relative permittivity of the liquid, and $\varepsilon_{0}$ is the permittivity of vacuum.

\subsubsection{Deposition conditions}

Deposition time and applied voltage are both parameters that can be easily controlled in order to influence deposition. As seen in Section 2.6.2, a simplified relationship between the mass deposited and different parameters was proposed by Hamaker, who was the first to suggest that the mass of the deposit was directly proportional to the applied voltage and time elapsed [68]. Wang et al., who deposited $\mathrm{ZnO}$ using $\mathrm{EPD}$, noted that the thickness of the film increased with increasing voltage, and that the thickness increased rapidly as time progressed before reaching a plateau (see Figure 2.27). 


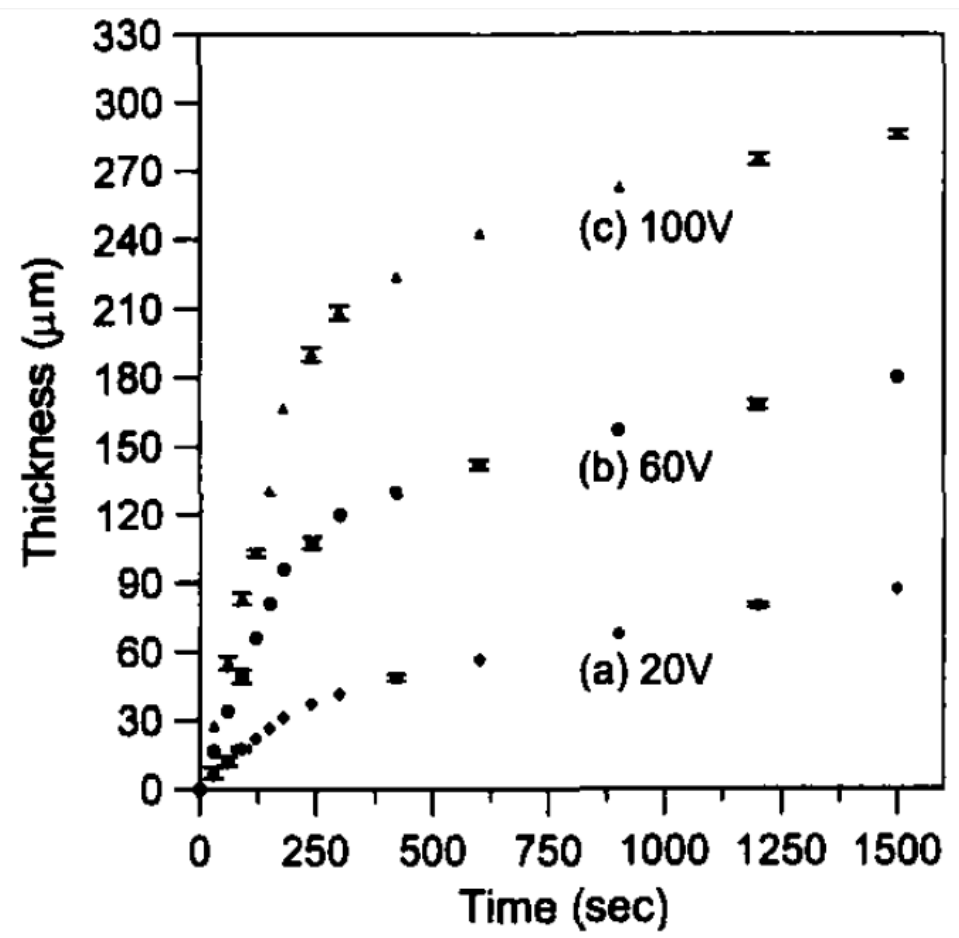

Figure 2.27: Relationship between thickness and deposition time for $\mathrm{ZnO}$ coatings deposited on copper electrode at (a) 20, (b) 60, and (c) $100 \mathrm{~V}[75]$

\subsubsection{Advantages of EPD}

The creation of biocomposites is not a new idea, with many different methods having been employed in the past. For example, HA has been deposited on dense metallic and ceramic substrates using industrial and laboratory techniques such as plasma spraying, electrophoretic deposition, sputtering and hot isostatic pressing.

While there are many different methods of creating films, each with their own advantages and disadvantages (see Table 2.7 and Figure 2.28), there are several requirements for depositing biomaterials onto medical implants to fabricate composite coatings that the deposition technique must be able to meet in order to be considered [76]: 
- The material should not be damaged or altered (chemically or structurally), during the coating process.

- The mechanical properties of the substrate material should not be adversely affected by the coating process.

- The adherence between the coating and substrate should be sufficient to insure interfacial failure does not occur during the implant's lifetime.

- The added expense of the coating process should not significantly increase the cost of the implant.

Table 2.7: Comparison of Deposition Methods

\begin{tabular}{|c|c|c|c|}
\hline Technique & Advantages & Disadvantages & References \\
\hline Dip Coating & $\begin{array}{l}\text { Inexpensive, quick, coat } \\
\text { different shapes }\end{array}$ & $\begin{array}{l}\text { Non-uniform film } \\
\text { (concentration gradient from } \\
\text { top to bottom) high sintering } \\
\text { temperatures }\end{array}$ & {$[58,76]$} \\
\hline $\begin{array}{l}\text { Sputter } \\
\text { Coating }\end{array}$ & $\begin{array}{l}\text { Uniform coating } \\
\text { thickness on flat } \\
\text { substrates, mixture of } \\
\text { elements/compounds } \\
\text { remain the same }\end{array}$ & $\begin{array}{l}\text { Expensive, complex and time } \\
\text { consuming process, cannot } \\
\text { coat complex shapes }\end{array}$ & {$[58,76]$} \\
\hline $\begin{array}{l}\text { Hot Isostatic } \\
\text { Pressing }\end{array}$ & Produces dense coatings, & $\begin{array}{l}\text { high temperature required, } \\
\text { complex equipment, cannot } \\
\text { form complex coatings }\end{array}$ & {$[76]$} \\
\hline $\begin{array}{l}\text { Electrophoretic } \\
\text { Deposition }\end{array}$ & $\begin{array}{l}\text { Uniform coating, rapid } \\
\text { deposition, coat complex } \\
\text { substrates, simple process }\end{array}$ & $\begin{array}{l}\text { Difficult to produce crack- } \\
\text { free coatings, high sintering } \\
\text { temperatures for ceramics }\end{array}$ & [77-80] \\
\hline $\begin{array}{l}\text { Thermal } \\
\text { Spraying }\end{array}$ & $\begin{array}{l}\text { High deposition rates, } \\
\text { low cost }\end{array}$ & $\begin{array}{l}\text { Adhesiveness varies, change } \\
\text { in chemical structure, line of } \\
\text { sight technique, high temp. } \\
\text { cracks }\end{array}$ & [81-84] \\
\hline Sol-Gel & $\begin{array}{l}\text { Can coat complex shapes, } \\
\text { low processing temp, } \\
\text { cheap }\end{array}$ & $\begin{array}{l}\text { Time intensive, change } \\
\text { crystal structure, cracks, may } \\
\text { require high temp. }\end{array}$ & [85-87] \\
\hline
\end{tabular}




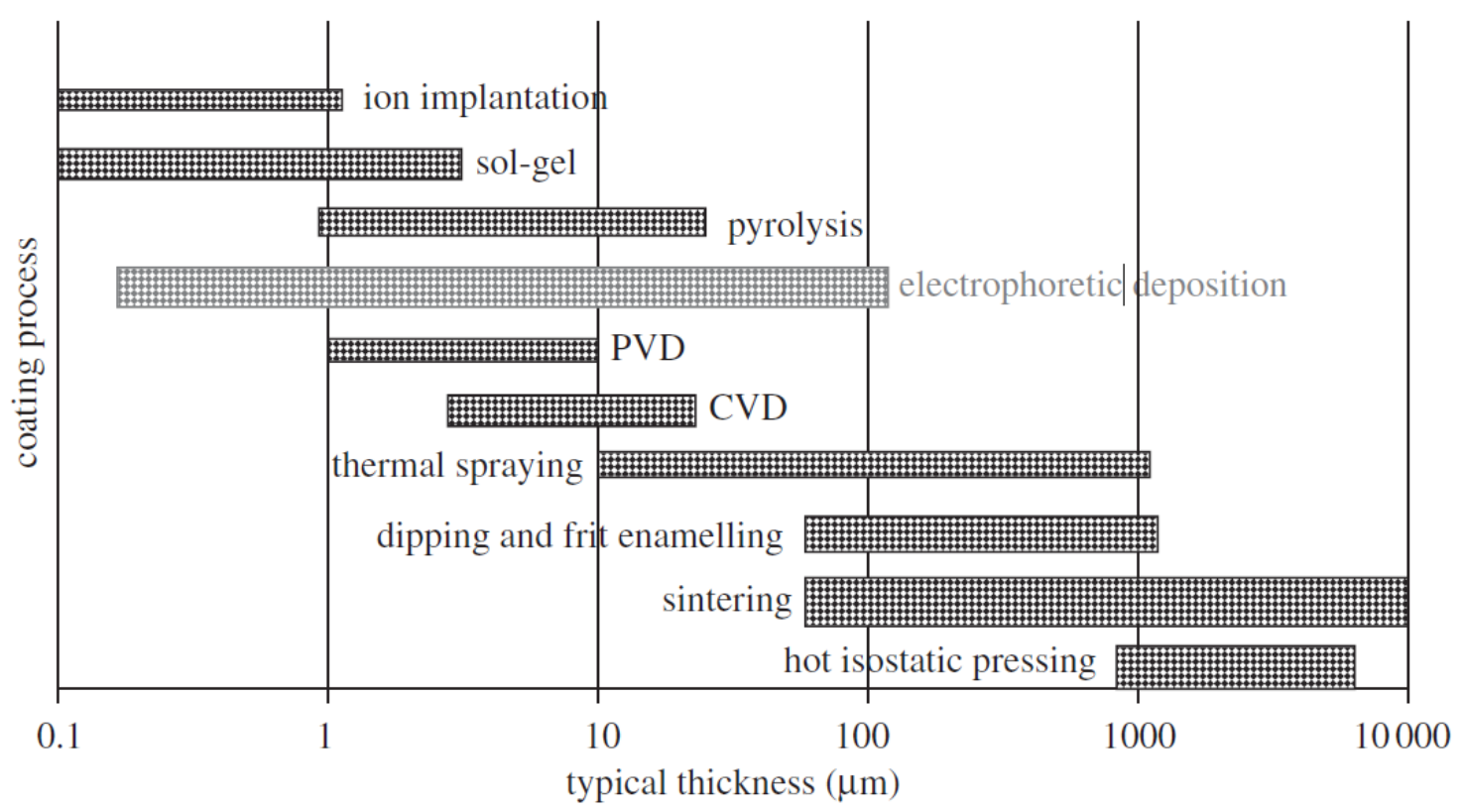

Figure 2.28: Typical thickness of coatings obtained by different process methods [21]

Electrophoretic deposition is well-suited for the purpose of creating composite films on complex substrates. Compared to other deposition techniques, EPD is very versatile as it can be modified depending on the application. It can deposit coatings of variable thicknesses (see Figure 2.28) at room temperature as well as deposit multicomponent films using relatively inexpensive equipment. Additionally, EPD is capable of deposition on flat, cylindrical, or any other shaped surface $[60,88,89]$ without damaging the particles to be deposited. The addition of polymers in EPD negates its disadvantages as well, as sintering is no longer needed to fabricate ceramic films and drying can be done at room temperature. Furthermore, the creation of multilayered, specialized films is possible - EPD of composites offers advanced functionality in the application of biomedical implants [88]. 


\section{Objective}

The primary objective of this work is to prove the feasibility of deposit biocomposite coatings with advanced functionality for biomedical implants using new materials biocompatible with human physiology. As such, there are two main components to this project:

1. Prove the feasibility of depositing composite films containing HNT by EPD, which has not been reported in literature. Following this, it is to be shown that HNT and HA can be used to successfully fabricate composite and multilayer films.

2. Investigate the characteristics of coatings deposited from different biopolymers (chitosan, hyaluronic acid, PLO, PLL, PAA) containing varying amounts of HNT and/or HA. Using the different experimental techniques outlined below (see Section 4.3 and Section 4.4), analyze the composition, morphology, structure and electrochemical properties of the EPD coatings. Additionally, investigate the EPD kinetics of biopolymer and biocomposite films, as well as the effect varying concentration of the polymer or ceramic has on the deposition rate. 


\section{Experimental Procedures}

\subsection{Materials Used}

\subsubsection{Commercially supplied materials}

The materials listed below (see Table 4.1) were used over the course of this project to deposit biocomposite coatings:

Table 4.1: Materials for biocomposite coatings

\begin{tabular}{|c|c|c|}
\hline Material & Supplier & Specification \\
\hline Chitosan & Sigma-Aldrich & $\begin{array}{l}\text { Chitosan from shrimp shells, practical grade, } \geq 75 \% \\
\text { deacetylated, } M_{W}=150,000-200,000\end{array}$ \\
\hline $\begin{array}{l}\text { Sodium } \\
\text { hyaluronate }\end{array}$ & Sigma-Aldrich & $\begin{array}{l}\text { Hyaluronic acid sodium salt from Streptococcus } \\
\text { equi, solubility: } \mathrm{H}_{2} \mathrm{O}, 5 \mathrm{mg} / \mathrm{mL} \text {, total impurities: } \\
\leq 1 \% \text { protein }\end{array}$ \\
\hline $\begin{array}{l}\text { Poly-L- } \\
\text { ornithine }\end{array}$ & Sigma-Aldrich & $\mathrm{M}_{\mathrm{W}}>100,000\left(\mathrm{M}_{\mathrm{W}, \mathrm{VIS}}=153,500\right)$ \\
\hline Poly-L-lysine & Sigma-Aldrich & $\mathrm{M}_{\mathrm{W}}=150,000-300,000\left(\mathrm{M}_{\mathrm{W}, \mathrm{VIS}}=116,580\right)$ \\
\hline Polyacrylic acid & Sigma-Aldrich & $\sim 0.1 \%$ cross-linked, $\mathrm{M}_{\mathrm{V}} \sim 1,250,000$ \\
\hline $\begin{array}{l}\text { Halloysite } \\
\text { Nanotube }\end{array}$ & Sigma-Aldrich & $\begin{array}{l}30-70 \mathrm{~nm} \times 1-3 \mu \mathrm{m}, \text { nanotube, } 1.26-1.34 \mathrm{~mL} / \mathrm{g} \\
\text { pore volume, } 64 \mathrm{~m}^{2} / \mathrm{g} \text { surface area }\end{array}$ \\
\hline Hydroxyapatite & Lab prepared & $\begin{array}{l}\text { Needle-shaped nanoparticles, } 150-200 \mathrm{~nm} \text { length } \\
\text { aspect ratio: } 8\end{array}$ \\
\hline Acetic acid & $\begin{array}{l}\text { Caledon } \\
\text { Laboratories } \\
\text { Ltd. }\end{array}$ & Reagent grade \\
\hline Ethanol & $\begin{array}{l}\text { Commercial } \\
\text { Alcohol Inc. }\end{array}$ & Reagent grade \\
\hline $\begin{array}{l}\text { Hydrochloric } \\
\text { acid }\end{array}$ & $\begin{array}{l}\text { Caledon } \\
\text { Laboratories } \\
\text { Ltd. }\end{array}$ & Reagent grade \\
\hline $\mathrm{NaCl}$ & $\begin{array}{l}\text { Caledon } \\
\text { Laboratories } \\
\text { Ltd. }\end{array}$ & Reagent grade \\
\hline $\mathrm{KCl}$ & $\begin{array}{l}\text { Caledon } \\
\text { Laboratories } \\
\text { Ltd. }\end{array}$ & Reagent grade \\
\hline $\mathrm{CaCl}_{2}$ & Caledon & Reagent grade \\
\hline
\end{tabular}




\begin{tabular}{|l|l|l|}
\hline & $\begin{array}{l}\text { Laboratories } \\
\text { Ltd. }\end{array}$ & \\
\hline
\end{tabular}

\subsubsection{Synthesis of hydroxyapatite nanoparticles}

Hydroxyapatite nanoparticles were prepared for deposition by chemical precipitation. A wet chemical method for the fabrication of HA was described in literature. The method was based on the use of $\mathrm{Ca}(\mathrm{NO})_{3} \bullet 4 \mathrm{H}_{2} \mathrm{O}$ (Aldrich), $\left(\mathrm{NH}_{4}\right)_{2} \mathrm{H}_{2} \mathrm{PO}_{4}$ (Merck) and $\mathrm{NH}_{4} \mathrm{OH}$ (Palacid) [90].

Aqueous solutions of $\mathrm{Ca}(\mathrm{NO})_{3} \bullet 4 \mathrm{H}_{2} \mathrm{O}(1.0 \mathrm{M})$ and $\left(\mathrm{NH}_{4}\right)_{2} \mathrm{H}_{2} \mathrm{PO}_{4}(0.6 \mathrm{M})$ were prepared. At a temperature of $70^{\circ} \mathrm{C},\left(\mathrm{NH}_{4}\right)_{2} \mathrm{H}_{2} \mathrm{PO}_{4}$ was slowly added to $\mathrm{Ca}(\mathrm{NO})_{3} \bullet 4 \mathrm{H}_{2} \mathrm{O}$ while the $\mathrm{pH}$ was adjusted to 11 through the addition of $\mathrm{NH}_{4} \mathrm{OH}$. The resulting solution was stirred for 8 hours at $70^{\circ} \mathrm{C}$ and 24 hours at room temperature. The resulting $\mathrm{Ca}_{10}\left(\mathrm{PO}_{4}\right)_{6}(\mathrm{OH})_{2}(\mathrm{HA})$ precipitate that formed was washed with water and then with isopropyl alcohol [90].

\subsection{Electrophoretic Deposition Process}

\subsubsection{Solution Preparation}

All materials were prepared using either a mass balance capable of measurements accurate to 1/1000 grams (Mettler Toledo PR803 Balance) or 1/100 000 grams (Mettler Toledo AX105 DeltaRange)

Bioceramics in solution were dispersed using an ultrasonicator (VWR Ultrasonic Cleaner 150T) 
For chitosan, a stock solution of $3 \mathrm{gL}^{-1}$ was prepared by combining $3 \mathrm{~g}$ of chitosan with $6 \mathrm{~mL}$ acetic acid in a $1 \mathrm{~L}$ flask and topping it off with water. The solution was then stirred for $24 \mathrm{~h}$.

For the deposition of chitosan, a solution of $0.5 \mathrm{gL}^{-1}$ chitosan solution was prepared in a mixed ethanol-water solvent (17\% water). HNT and/or HA were weighed and added to the solution to achieve a concentration of 0.3 or $0.6 \mathrm{gL}^{-1} \mathrm{HNT}$ and 0.5 or 1.0 $\mathrm{gL}^{-1} \mathrm{HA}$. The solution was then ultrasonicated to achieve homogeneity.

For the deposition of HYH, a solution of $1.0 \mathrm{gL}^{-1}$ sodium hyaluronate (HYNa) was synthesized in a mixed solvent, containing $30 \% \mathrm{H}_{2} \mathrm{O}$ and $70 \%$ ethanol. $\mathrm{H}_{2} \mathrm{O}$ was added first, then HYNa, then the two were mixed until the HYNa fully dissolved, at which point ethanol was added slowly. HNT and/or HA were then added as required, and the solution was ultrasonicated.

Solutions of PLO and PLL were synthesized in the same manner as HYNa (30\% water and $70 \%$ ethanol). Solutions for PAA were synthesized by dissolving PAA in pure water and adding a few drops of $8 \mathrm{gL}^{-1} \mathrm{NaOH}$ to adjust $\mathrm{pH}$.

\subsubsection{Experimental set-up for deposition}

EPD was performed using a constant voltage power supply (Amersham Biosciences EPS 2A200). Coatings were deposited either anodically of cathodically onto cleaned 304 stainless steel substrates using Pt counterelectrodes (see Figure 4.1). 


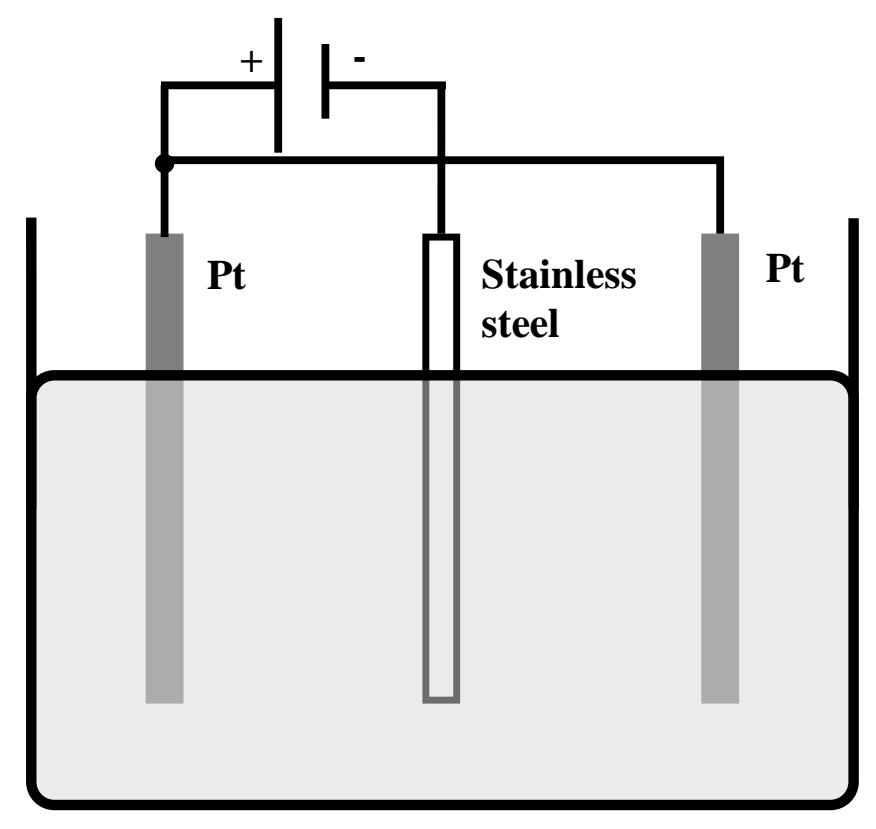

Figure 4.1: Schematic diagram of an EPD cell for cathodic deposition

The stainless steel substrate $(2.5 \mathrm{~cm} \times 5 \mathrm{~cm})$ was centered in the middle of the cell, with platinum counterelectrodes $(2.5 \mathrm{~cm} \times 5 \mathrm{~cm}$ each $)$ at a distance of $1.5 \mathrm{~cm}$ from either side. The volume of the cell varied from 50 to $300 \mathrm{~mL}$, though typically a $300 \mathrm{~mL}$ bath was used.

\subsubsection{Electrophoretic deposition procedure}

Anodic and cathodic deposition was carried out using a power supply (Amersham Biosciences EPS 2A200) using a constant voltage in the range of 5 to $40 \mathrm{~V}$ to provide a DC electric field for electrophoresis. The current density ranged from 1 to $12 \mathrm{~mA} \cdot \mathrm{cm}^{-2}$. Deposition times ranged from 2 to 30 minutes to obtain various thicknesses. Multilayers were fabricated by removing the substrate from one solution and immediately starting deposition in another. Immediately after deposition, the films were removed from the bath and left to dry in air at room temperature. 


\subsection{Materials and Film Characterization}

\subsubsection{TGA/DTA}

Thermogravimetric Analysis (TGA) and Differential Thermal Analysis (DTA) are methods of analysing materials properties over an increasing temperature range. TGA is used to quantify the amount of volatile material present in a sample by recording the mass loss vs. increasing temperature. In addition to TGA, DTA is used to record endothermic and exothermic peaks over a temperature range, and corresponds to the energy released or absorbed by the specimen, which can be attributed either to chemical reactions or phase transformations in the sample.

TGA/DTA was carried out using a thermoanalyzer (Netzsh STA-409) in air between 20 to $1000^{\circ} \mathrm{C}$ at a heating rate of $5^{\circ} \mathrm{C} \cdot \mathrm{min}^{-1}$.

Tests were carried out using films formed during deposition, which were subsequently scraped off the stainless steel substrate and left to dry in air. Additional tests were carried out individually on materials as-received from the supplier. By comparing the results obtained from composite films to their individual components, it was possible to determine the amount of each material present in the coating.

\subsubsection{XRD}

X-Ray Diffraction (XRD) was used to analyse the phase content in minerals, materials and composite films. XRD was carried out using a diffractometer (Nicholet 12) using monochromatized $\mathrm{Cu}-\mathrm{K} \alpha$ radiation at a scanning speed of $0.5^{\circ} \cdot \mathrm{min}^{-1}$. Analysis was 
done on starting materials (HNT, HA), pure polymer films (CHIT, HYH) and composite films (CHIT, HYH films containing HNT, HA).

Samples were prepared for analysis by removing the deposit off the stainless steel substrates after EPD and letting the deposit dry in air at room temperature for 24 hours, after which it was sent for XRD analysis.

\subsubsection{Electron Microscopy}

\subsubsection{Scanning Electron Microscopy}

A Scanning Electron Microscope (SEM) is a type of electron microscope that directs a high-energy beam of electrons in a raster pattern to obtain an image. A FE-SEM (Field Emission Scanning Electron Microscope) (JEOL JSM7000F FE-SEM) was used in order to view the morphology and structure of the deposits. Samples were obtained by depositing films on stainless steel substrates as described in Section 4.2.2. Small pieces of coated stainless steel were then cut from the substrate. These pieces were then glued to an SEM stub that had been covered with double-sided copper tape to prevent the samples from moving. Silver paste was then applied to the sample (see Figure 4.2) to ensure adhesion as well as conductivity. 


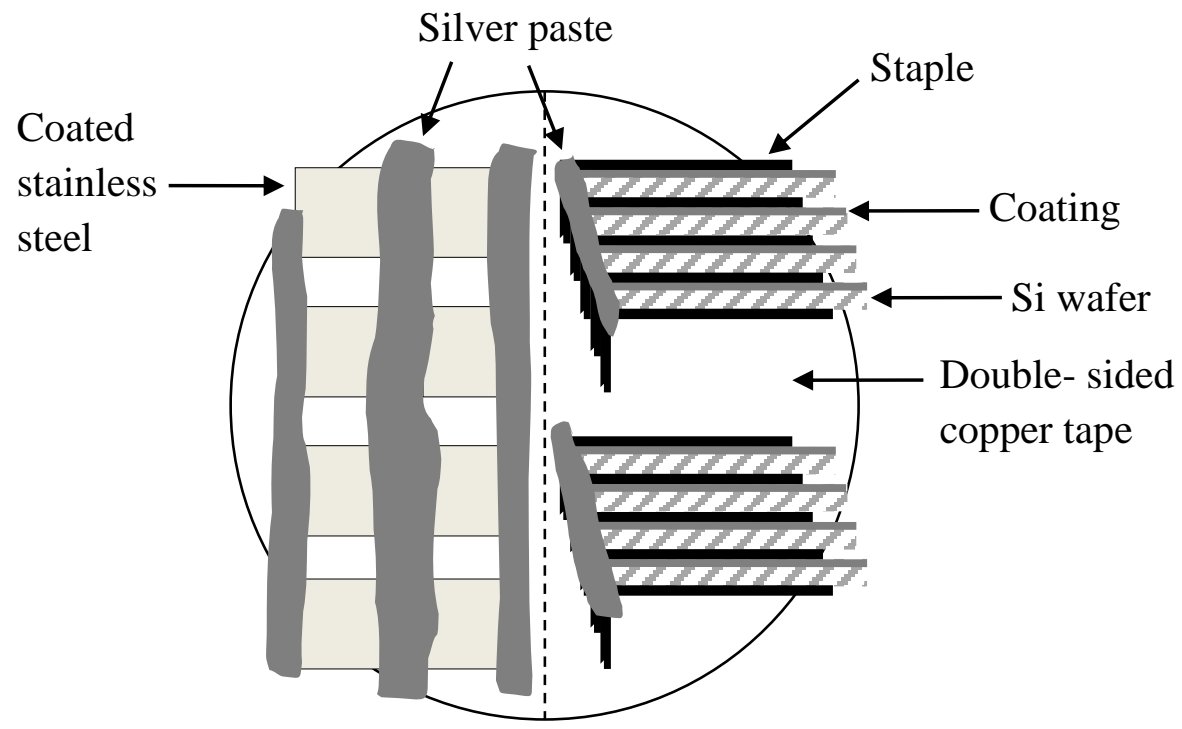

Figure 4.2: Example of sample holder prepared for SEM

In order to obtain cross-sections of the deposited films, platinized silicon wafers were used as substrates during EPD. Copper tape was used to attach silicon wafers to the stainless steel (see Figure 4.3) and ensure conductivity between the electrode and platinum surface. After deposition, the wafers were removed and a tungsten carbide scribe was used to break off slivers from the wafer. The slivers of silicon were then placed on the SEM stub between staples to ensure they stood perpendicular to the surface and that the cross-section was visible. Silver paste was used to help keep the samples in place and was applied to the surface of the cross-section (see Figure 4.2) in order to ensure the grounding and conductivity of the sample. 


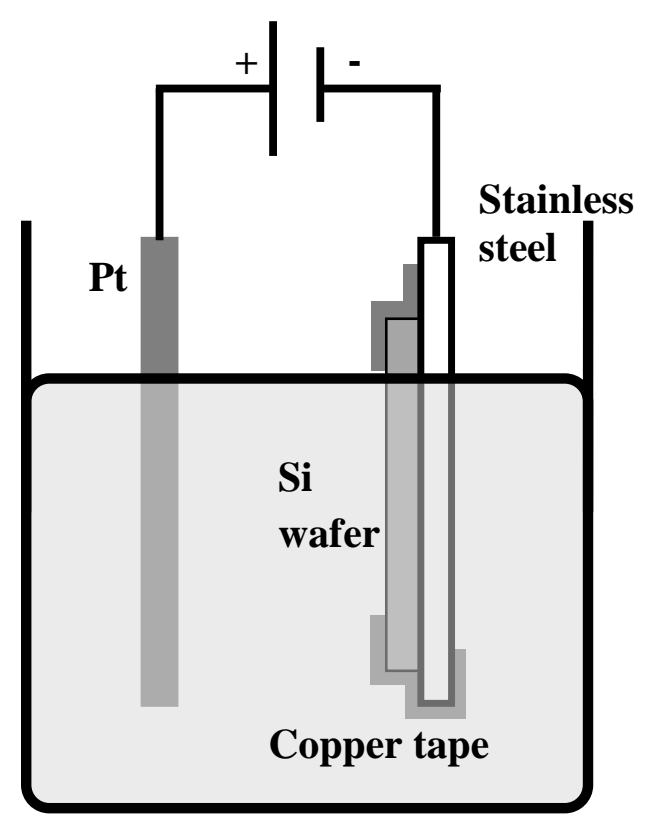

Figure 4.3: Schematic diagram of an EPD cell for cathodic deposition on a Si wafer

In order to improve the conductivity, $5 \mathrm{~nm}$ of Pt was deposited on the samples using a sputter coating system (Gatan Model 682 Precision Etching Coating System). In addition, the silver paste was also used to ground all the samples in order to ensure the conductivity of the sample in order to minimize charging at the surface

The SEM was operated using a working distance of $6 \mathrm{~mm}$, with the acceleration voltage set between 3 to $5 \mathrm{kV}$ and along with a probe current of 5 to $8 \mathrm{~mA} \cdot \mathrm{cm}^{-2}$. Due to the sensitive nature of the polymer coatings, using higher acceleration voltages proved unfeasible as they badly damaged the polymer, causing cracking of the sample. While lower beam energy did preserve the sample, it still led to some damage, so any focusing/aligning of the beam was done to the side of the site being analysed. 


\subsubsection{Transmission Electron Microscopy}

Transmission Electron Microscopy (TEM) was used to view individual halloysite nanotubes. By using TEM, HNT could be examined at the atomic level. A TEM (JEOL JEM-2010F) was used to view the HNT, as well as to carry out High Resolution Transmission Electron Microscopy (HR TEM).

Samples were prepared by creating an ethanol solution and adding HNT. The solution was then further diluted and a drop was placed on a TEM sample holder. The sample holder was composed of a porous carbon film held together by a copper grid (see Figure 4.4).

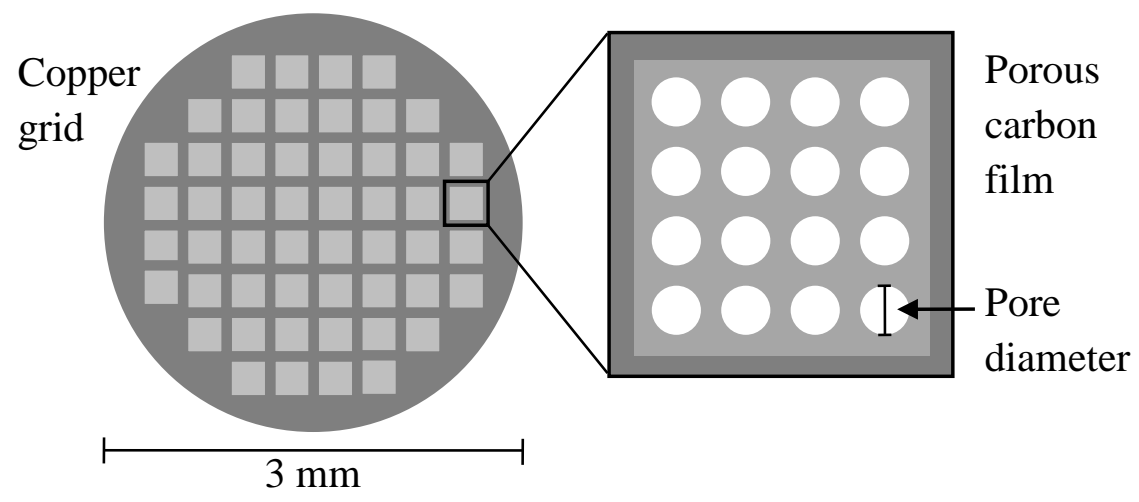

Figure 4.4: Schematic of a standard TEM sample holder

\subsubsection{Measuring deposition yield of EPD}

The deposition yield by EPD was investigated using a Quartz Crystal Microbalance (QCM) (Princeton Applied Research QCM922) for measuring the mass deposited versus time. The set-up was similar to the EPD cell in Section 4.2.2, with a DC power supply (Keithley Model 2400 General-Purpose SourceMeter) supplying a constant voltage of $4 \mathrm{~V}$. The QCM was hooked up to a computer running WinEchem software that 
recorded the resonance change of the quartz crystal (see Figure 4.5 for full set-up). A small sheet of platinum was used for the counter-electrode.

The QCM was connected to the EPD cell. Special electrodes made of a piezoelectric material had to be used to measure the change in resistance and frequency as deposition proceeded.

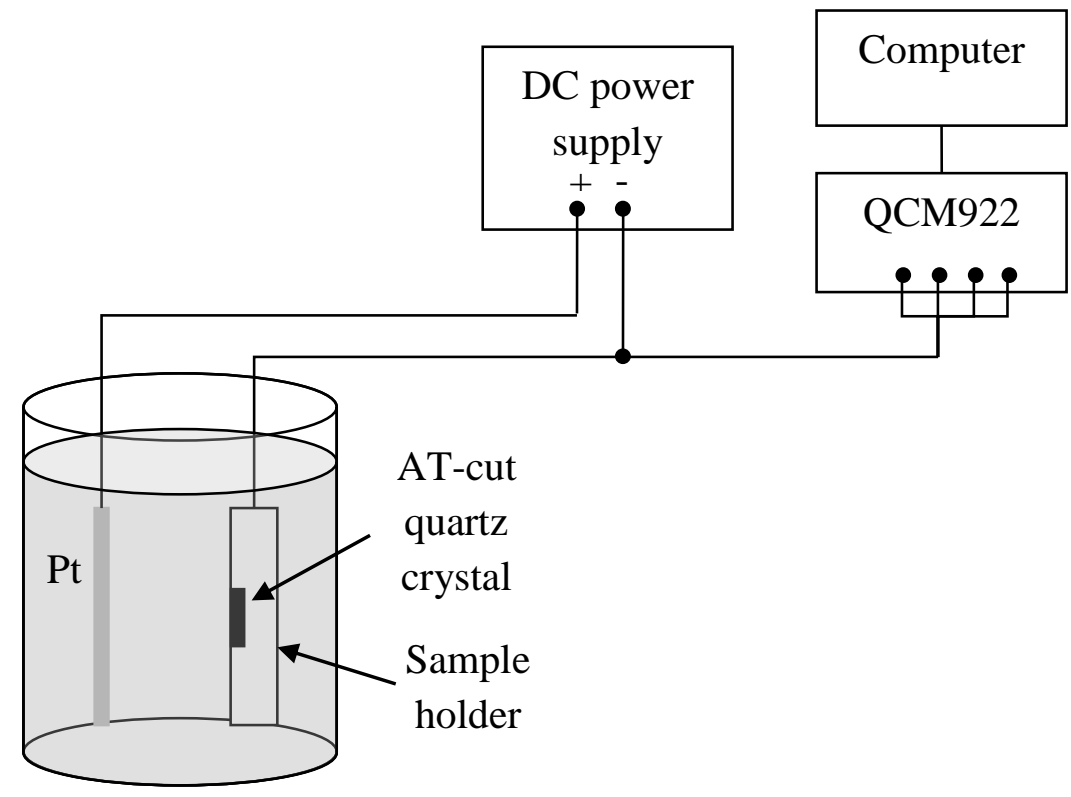

Figure 4.5: Schematic of the QCM set-up for cathodic deposition yield measurement

Due to the sensitive nature of the QCM, only solutions of very low concentrations could be used. Polymer concentration was in the range of 0.1 to $0.3 \mathrm{gL}^{-1}$ with HNT concentration ranging from 0 to $0.1 \mathrm{gL}^{-1}$.

The deposition yield was analysed by obtaining the change in mass ( $\Delta$ mass) was obtained from analysing the change in frequency $(\Delta f)$ of the quartz crystal using the Sauerbrey equation: 


$$
\Delta f=-\frac{2 f_{0}^{2} \Delta m}{A \sqrt{\mu_{q} \rho_{q}}}
$$

The Sauerbrey equation can be rearranged to obtain mass deposited as a function of frequency:

$$
\Delta \operatorname{mass}=-\Delta f \times \frac{A \sqrt{\mu_{q} \rho_{q}}}{2 f_{0}^{2}}
$$

Where $\mu_{q}$ is the AT-cut quartz crystal constant $\left(2.947 \times 10^{11} \mathrm{~g} / \mathrm{cm} \cdot \mathrm{sec}^{2}\right), \rho_{q}$ is the Quartz crystal density $\left(2.648 \mathrm{~g} / \mathrm{cm}^{3}\right), f_{0}$ is the Reference frequency $(9.00 \mathrm{MHz})$, and $A$ is the Quartz crystal surface area $\left(0.196 \mathrm{~cm}^{2}\right)$, which gives the following:

$$
\Delta \operatorname{mass}=-\Delta f \times \frac{0.196 \sqrt{2.947 \times 10^{11} \times 2.648}}{2 \times\left(9 \times 10^{6}\right)^{2}}=-\Delta f \times 1.06878 \times 10^{-9}
$$

For all QCM experiments done, the mass deposited can then be found using the following:

$$
\Delta \operatorname{mass}=-1.06878 \times 10^{-9} \Delta f
$$

\subsection{Electrochemical characterization}

The functional properties of the coatings were studied using a potentiostat (Princeton Applied Research PARSTAT 2273) connected to a standard three electrode cell and controlled through a computer using specialized software (Advanced Measurement Technology Inc., PowerSuite 2.58) A simulated body fluid (SBF), Ringer's solution ( $\mathrm{NaCl} 8.6 \mathrm{~g} / \mathrm{l}, \mathrm{CaCl}_{2} 0.33 \mathrm{~g} / \mathrm{l}, \mathrm{KCl} 0.30 \mathrm{~g} / \mathrm{l}$ [91-93]), degassed using nitrogen gas, 
was used for all the electrochemical studies. The counter-electrode was platinum and the reference electrode was a Standard Calomel Electrode (SCE).

Linear polarization tests were conducted between -250 and $+250 \mathrm{mV}$ vs SCE at a scan rate of $1 \mathrm{mV} \cdot \mathrm{s}^{-1}$. An initial open circuit delay of $60 \mathrm{~s}$ was used to stabilize the film, and a $50 \mathrm{~Hz}$ filter was applied to the tests. 


\section{Experimental Results and Discussion}

\subsection{Characterization of halloysite}

Samples of HNT were characterized using some of the above techniques prior to deposition to determine their properties. Halloysite was analysed under TEM and SEM (see Figure 5.1 and Figure 5.2). The analysis of TEM results showed that HNT have a uniform structure consisting of an inner diameter of 10-20 nm and an outer diameter of 40-80 $\mathrm{nm}$. The SEM analysis showed that the length of HNT varied, but was typically in the range of 0.5 to $5 \mu \mathrm{m}$.
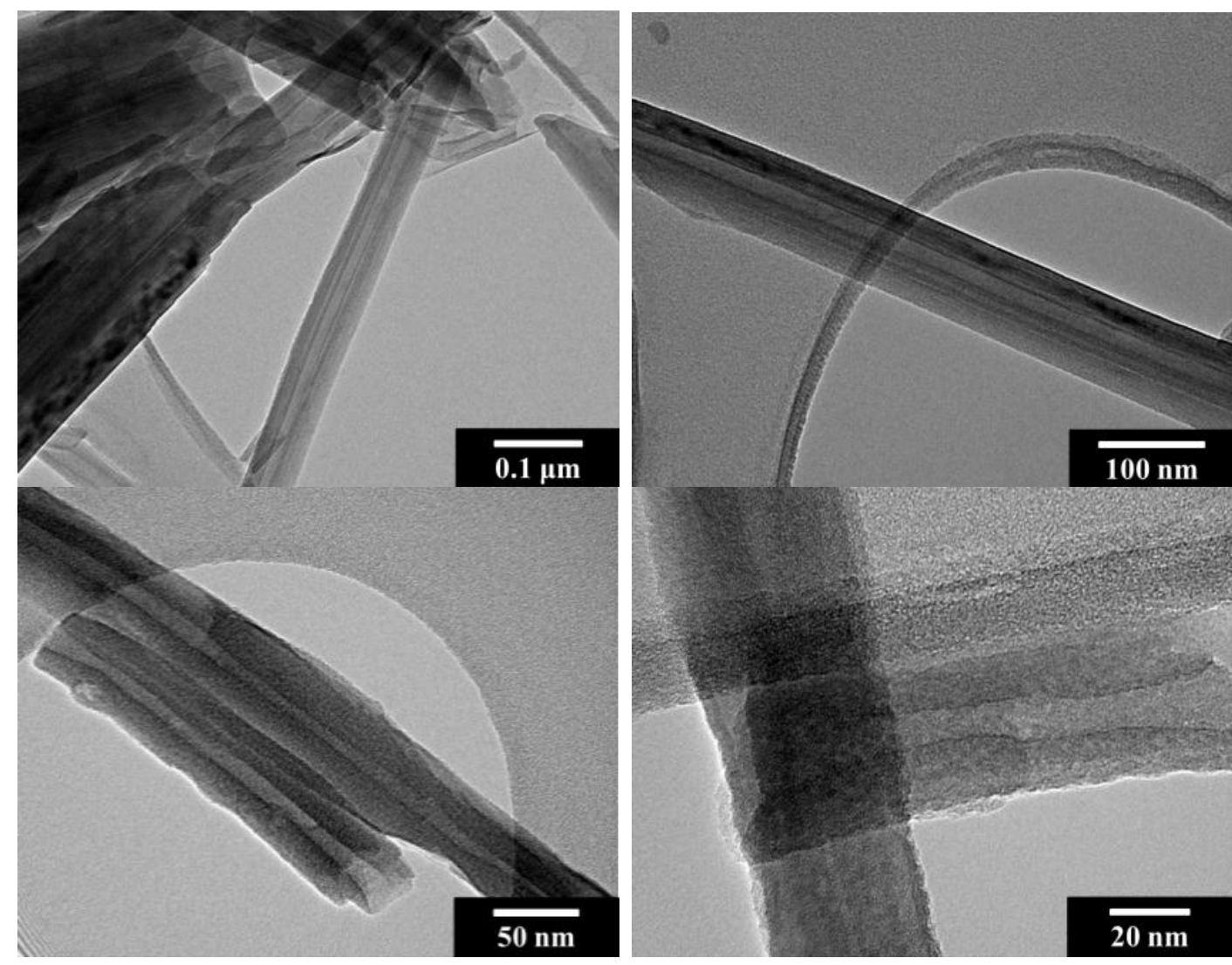

Figure 5.1: As-received HNT viewed under TEM 

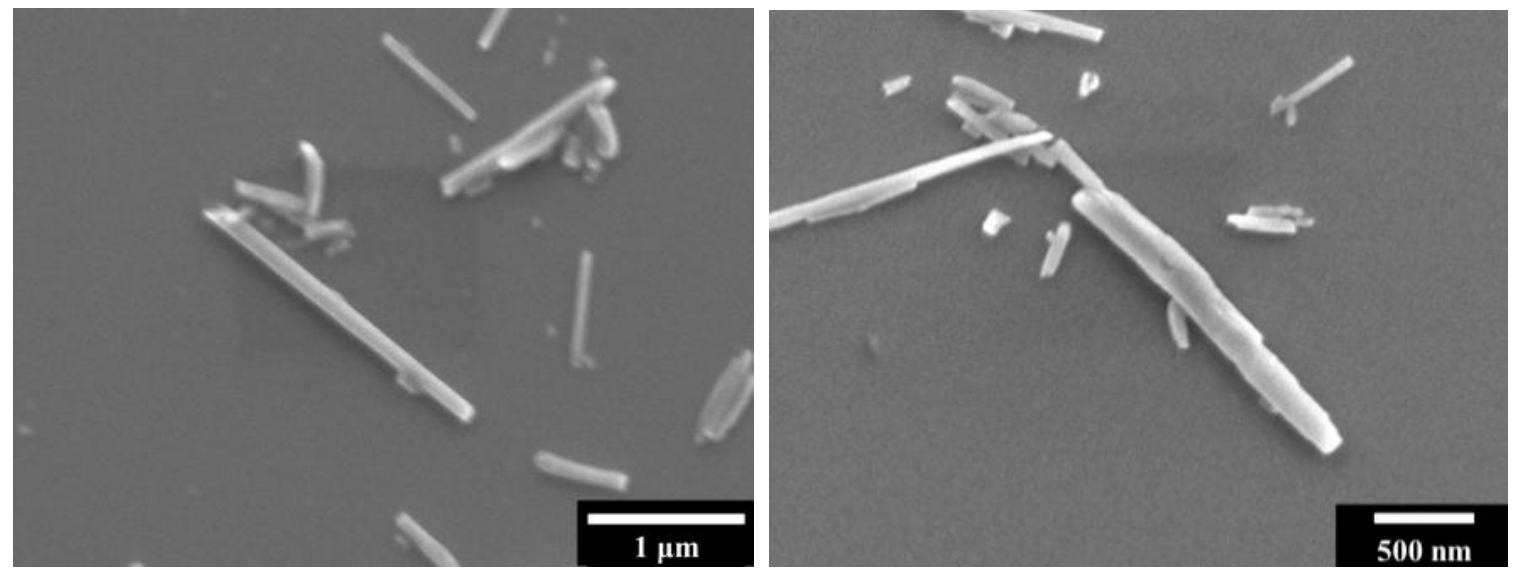

Figure 5.2: As-received HNT viewed under SEM

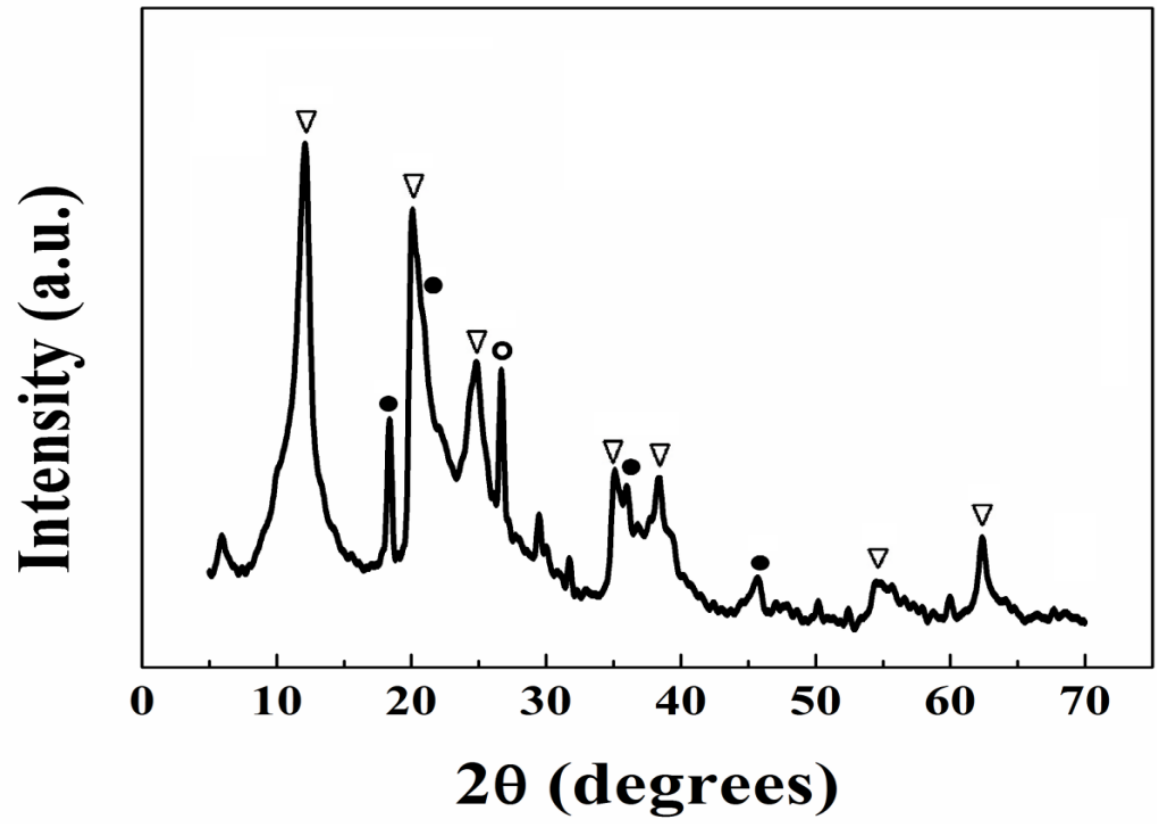

Figure 5.3: XRD pattern for as-received HNT ( $\nabla$ - JCPDS file 29-1487 of halloysite, • - JCPDS file 33-0018 of gibbsite, 0 - JCPDS file 46-1045 of quartz)

X-ray diffraction of HNT was used to determine the presence of hydrated or dehydrated HNT, as well as the phases present in the sample (see Figure 5.3). The presence of a large peak at $12.05^{\circ}$ of HNT (corresponding to JCPDS file 29-1487), along with the absence of a peak at $8.76^{\circ}$, indicates this particular of type of HNT has a basal 
plane spacing of $7 \AA$ and is dehydrated. The broad peaks also indicate that there is stress present in the material, which is in accordance with what we know about HNT and its lattice mismatch. It is shown that there are significant peaks of gibbsite (corresponding to JCPDS file 33-0018) and a peak of quartz (corresponding to JCPDS file 46-1045), which is unsurprising as these are known to form together with HNT [94].

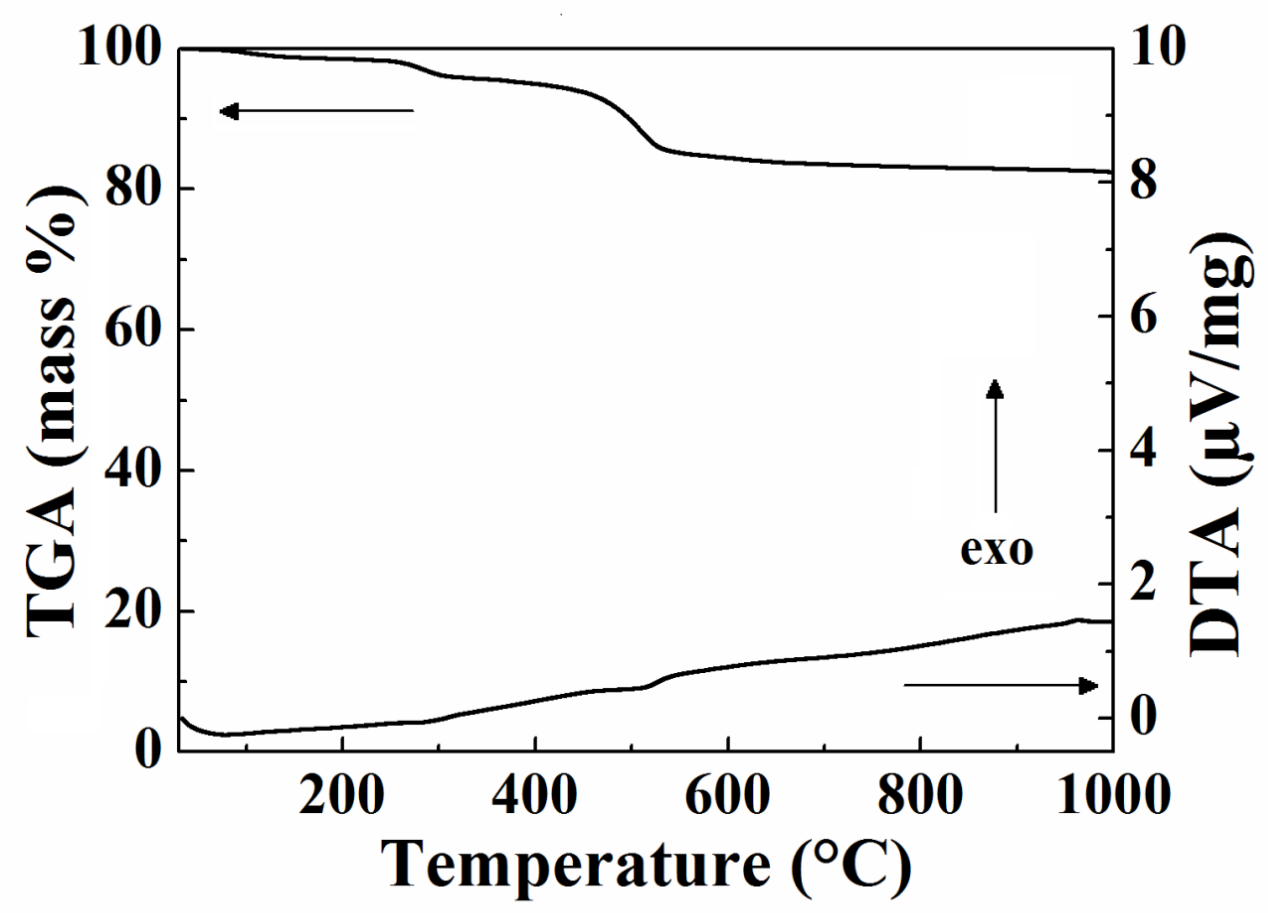

Figure 5.4: DTA/TGA results for as-received HNT

DTA and TGA were used to analyse the water content of as-received HNT. The TGA of HNT showed a mass loss of $17.6 \%$ in two steps between 100 to $330^{\circ} \mathrm{C}$ and 330 to $550^{\circ} \mathrm{C}$, which is attributed to the dehydration of the HNT. Above $550^{\circ} \mathrm{C}$ the mass of the sample remained mainly constant. The DTA data supports this, as there is a slight endotherm below $100^{\circ} \mathrm{C}$, attributed to dehydration. 


\subsection{Electrodeposition of biopolymers and composite films}

\subsubsection{Electrodeposition of Chitosan}

\subsubsection{Chitosan and Halloysite Films}

Suspensions consisting solely of HNT were unstable and resulted in fast sedimentation. Furthermore, attempt to deposit HNT by EPD were unsuccessful, which could be attributed to poor suspension stability and to the fact that HNT had low charge, which isn't enough to provide electrophoresis.

The addition of chitosan stabilized the HNT suspensions and allowed for cathodic EPD due to the protonation of the amino group (see Figure 5.5) at low $\mathrm{pH}$. The protonated chitosan is soluble in the water-ethanol solution, becoming a cationic polyelectrolyte [95]:

$$
\mathrm{CHIT}-\mathrm{NH}_{2}+\mathrm{H}_{3} \mathrm{O}^{+} \rightarrow \mathrm{CHIT}-\mathrm{NH}_{3}^{+}+\mathrm{H}_{2} \mathrm{O}
$$

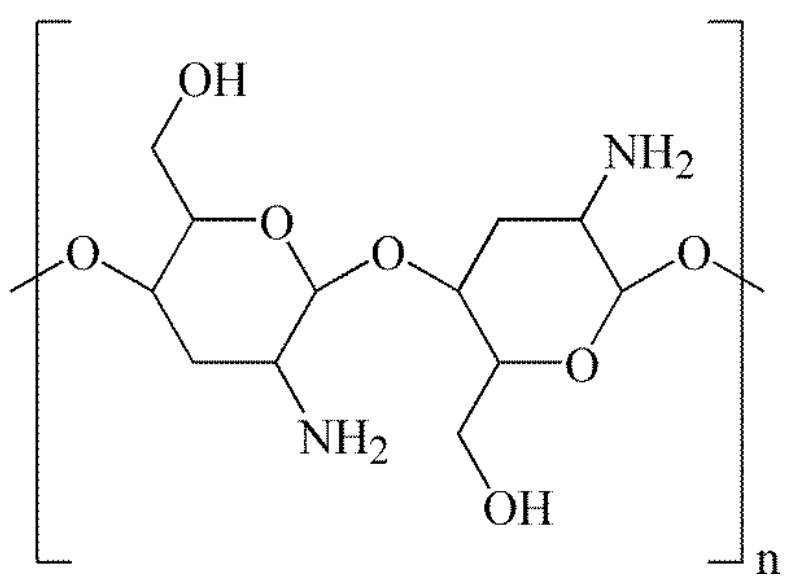

Figure 5.5: Chemical structure of chitosan 
An electric field provides electrophoretic motion of the charged macromolecules to the cathode, where $\mathrm{pH}$ increases due to electrochemical decomposition of water and an insoluble CHIT-HNT deposit forms [95]:

$$
\begin{gathered}
2 \mathrm{H}_{2} \mathrm{O}+2 \mathrm{e}^{-} \rightarrow \mathrm{H}_{2}+2 \mathrm{OH}^{-} \\
\mathrm{CHIT}-\mathrm{NH}_{3}{ }^{+}+\mathrm{OH}^{-} \rightarrow \mathrm{CHIT}-\mathrm{NH}_{2}+\mathrm{H}_{2} \mathrm{O}
\end{gathered}
$$

The deposition of chitosan-HNT films was analysed using QCM data (see Figure 5.6) and it was found that there was a continuous increase in the mass of the deposit as time progressed (see Figure 5.6a) and as the concentration of HNT in the solution increased (see Figure 5.6b,c). The slope of the curve decreased as time progressed indicating decreasing electric field in the suspension. The growing film acted as an insulator, causing a drop in the electric field in the suspension. The increase in mass deposited as HNT was added indicates the co-deposition of chitosan and HNT and the formation of chitosan-HNT films. The adsorbed chitosan provided the necessary charge and suspension stabilisation for the EPD of HNT. 


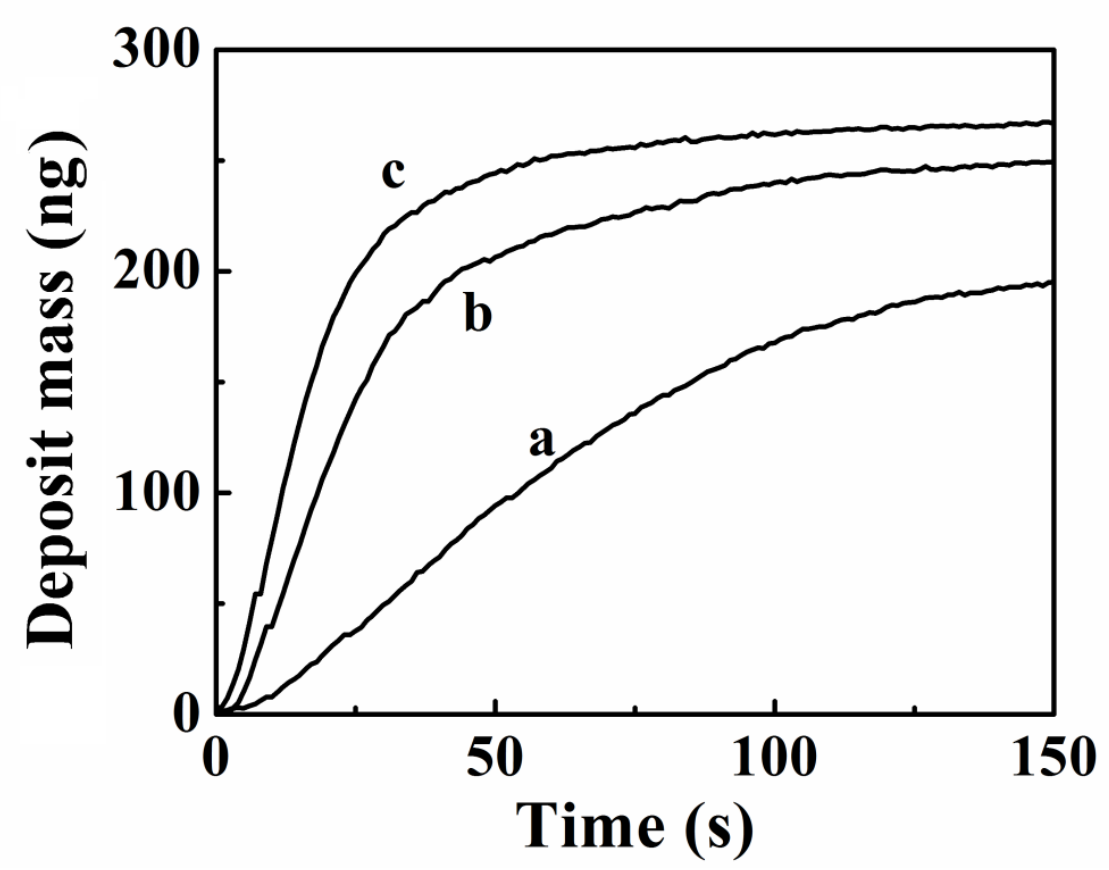

Figure 5.6: QCM results for the EPD of $0.1 \mathrm{gL}^{-1}$ chitosan and a) no $\mathrm{HNT}$, b) $0.01 \mathrm{gL}^{-1} \mathrm{HNT}$ and c) $0.05 \mathrm{gL}^{-1} \mathrm{HNT}$

The characterization of composite chitosan-HNT was performed using TGA/DTA, XRD and SEM. For TGA and DTA, a comparison between HNT and chitosan-HNT deposit (see Figure 5.7) showed a significant difference in mass loss. The TGA data for the deposit prepared from a $0.5 \mathrm{gL}^{-1}$ chitosan solution containing $0.3 \mathrm{gL}^{-1}$ HNT showed a an initial mass loss at $\sim 200^{\circ} \mathrm{C}$ is mainly attributed to dehydration, while the additional steps between 250 to 300 and 350 to $500^{\circ} \mathrm{C}$ were attributed to the thermal degradation and the burning off of the organic phase. The sample maintains a constant mass above $500^{\circ} \mathrm{C}$.

The results of the DTA are in agreement with the analysis of the TGA data, as it shows a slight exotherm observed below $100^{\circ} \mathrm{C}$, which is attributed to the dehydration of the deposit, and a broad exothermic peak in the range of 300 to $500^{\circ} \mathrm{C}$ that is not present 
for the analysis of as-received HNT and is attributed to the burning of chitosan. A similar exotherm was observed in previous DTA studies conducted on pure chitosan and chitosan films $[54,95]$.

The total mass loss at $1000^{\circ} \mathrm{C}$ was found to be $64.4 \%$, and is mainly attributed to the burning out of the organic phase. The mass loss for as-received HNT over the same temperature range was found to be $17.6 \%$ (see Figure 5.4), which indicates the mass of the composite film is composed of approximately $43 \% \mathrm{HNT}$ and $57 \%$ chitosan.

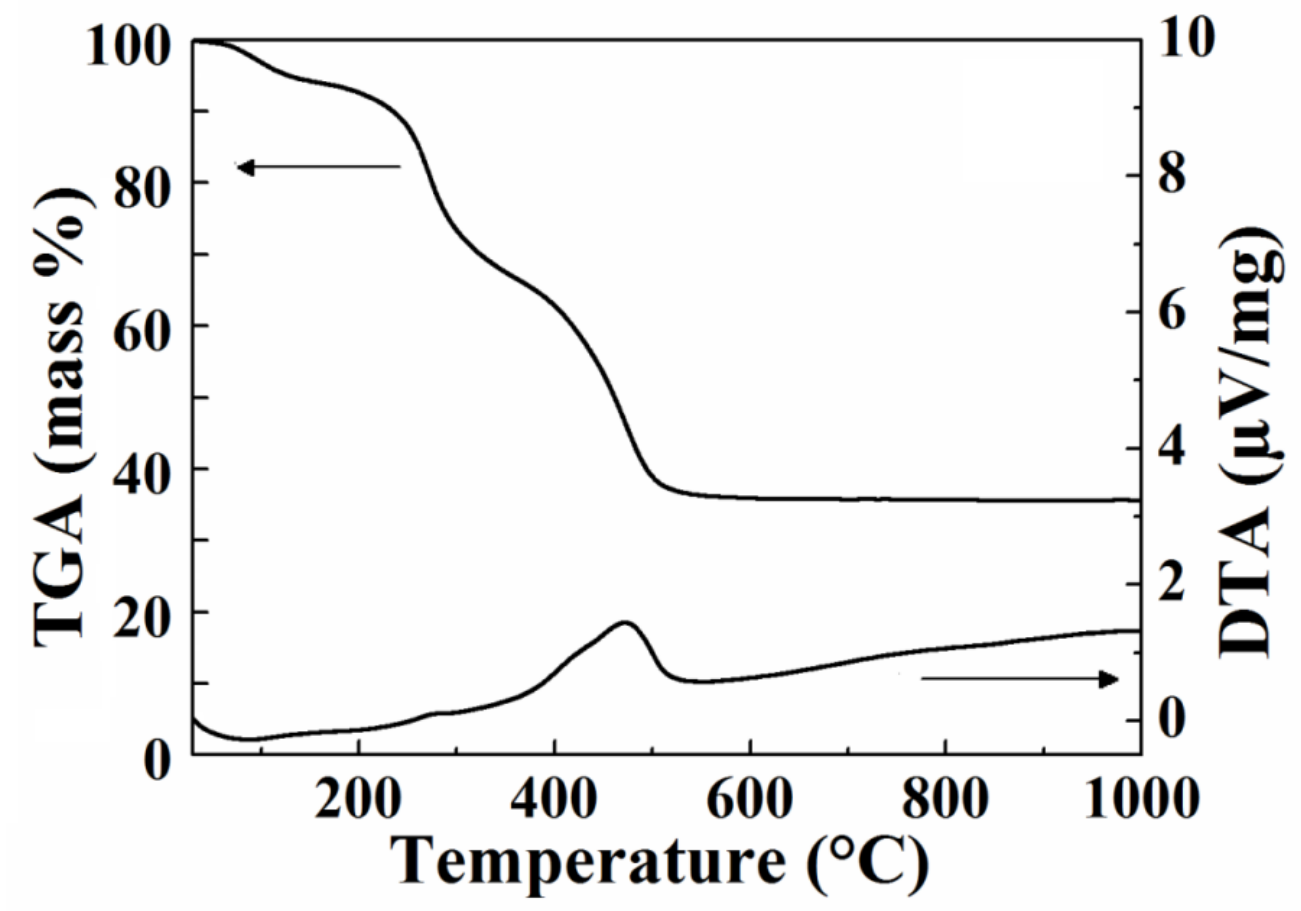

Figure 5.7: DTA/TGA results for chitosan-HNT film prepared from a $0.5 \mathrm{gL}^{-1}$ chitosan suspension with $0.3 \mathrm{gL}^{-1} \mathrm{HNT}$ X-ray diffraction was performed on a chitosan-HNT deposit and compared to the pattern obtained for as-received HNT (see Figure 5.8). The result showed that, in addition 
to the halloysite peaks (corresponding to JCPDS file 29-1487), there are also peaks of gibbsite and quartz (corresponding to JCPDS files 33-0018 and 46-1045 respectively). This is in agreement with XRD studies of natural halloysite, which also revealed minor amounts of gibbsite and quartz phases [96,97]. The XRD pattern of the deposit prepared from the chitosan solution containing HNT (see Figure 5.8b) showed peaks of HNT and confirmed the formation of chitosan-HNT films.

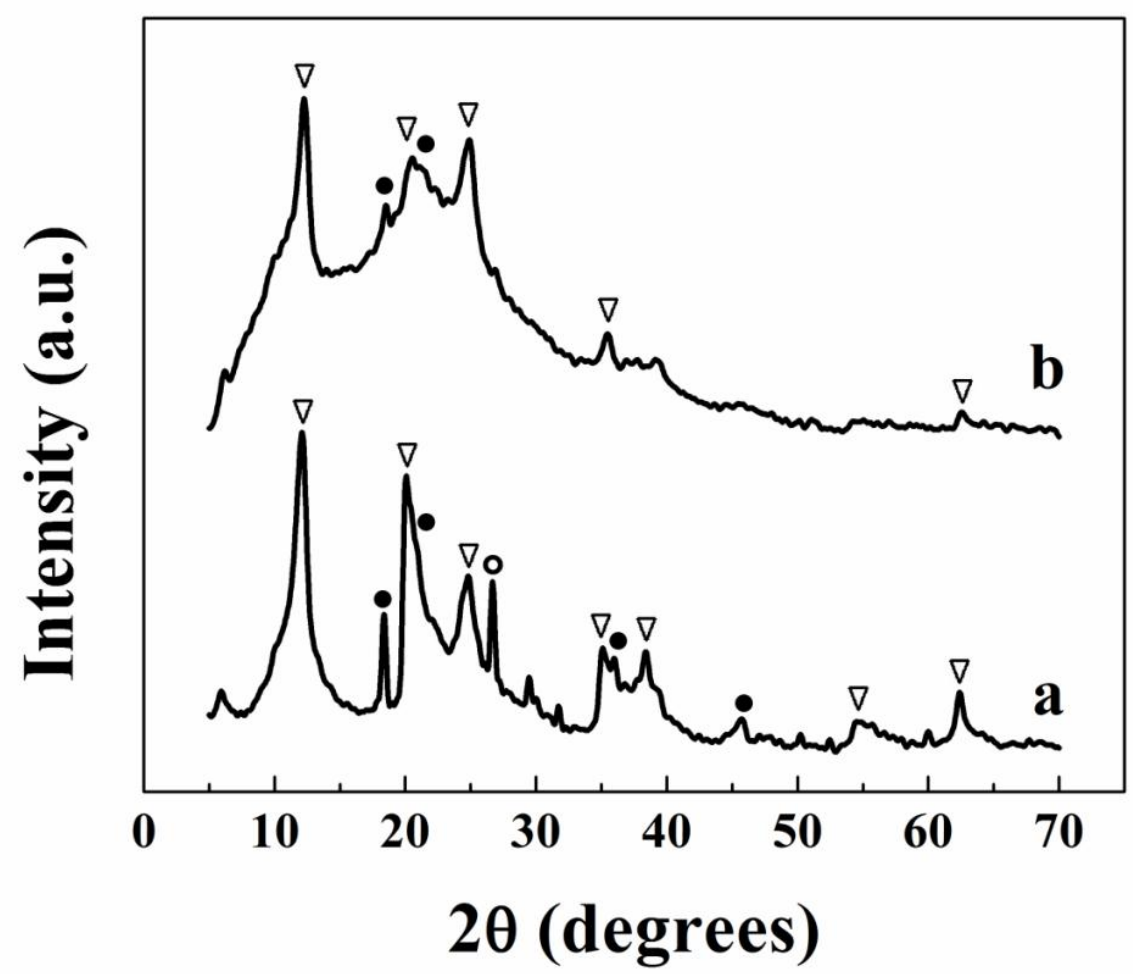

Figure 5.8 XRD patters for a) as-received HNT and b) chitosan-HNT film prepared from a $0.5 \mathrm{gL}^{-1} \mathrm{chitosan}$ suspension containing $0.3 \mathrm{gL}^{-1} \mathrm{HNT}$ ( $\nabla$ - JCPDS file 29-1487 of halloysite, $\bullet-J C P D S$ file 33-0018 of gibbsite, 0 - JCPDS file 46-1045 of quartz). The XRD pattern of HNT of Figure 5.3 is presented here for comparison.

The results of the SEM studies of the composite chitosan-HNT films show HNT incorporated in the chitosan matrix. The SEM images were taken from a deposit prepared from a $0.5 \mathrm{gL}^{-1}$ chitosan, $0.3 \mathrm{gL}^{-1} \mathrm{HNT}$ suspension (see Figure 5.9A,B) and $0.6 \mathrm{gL}^{-1} \mathrm{HNT}$ 
suspension (see Figure 5.9C,D) showed a large number of HNT in the chitosan matrix, though significantly more were observed in the deposit prepared from the $0.6 \mathrm{gL}^{-1}$ suspension. The SEM images taken at low magnification (see Figure 5.9A,C) show that the films are continuous, crack-free and free of major agglomeration, while the images taken at high magnification (see Figure 5.9B,D) indicate that the films are relatively dense and that the HNT are lined up parallel to the substrate.
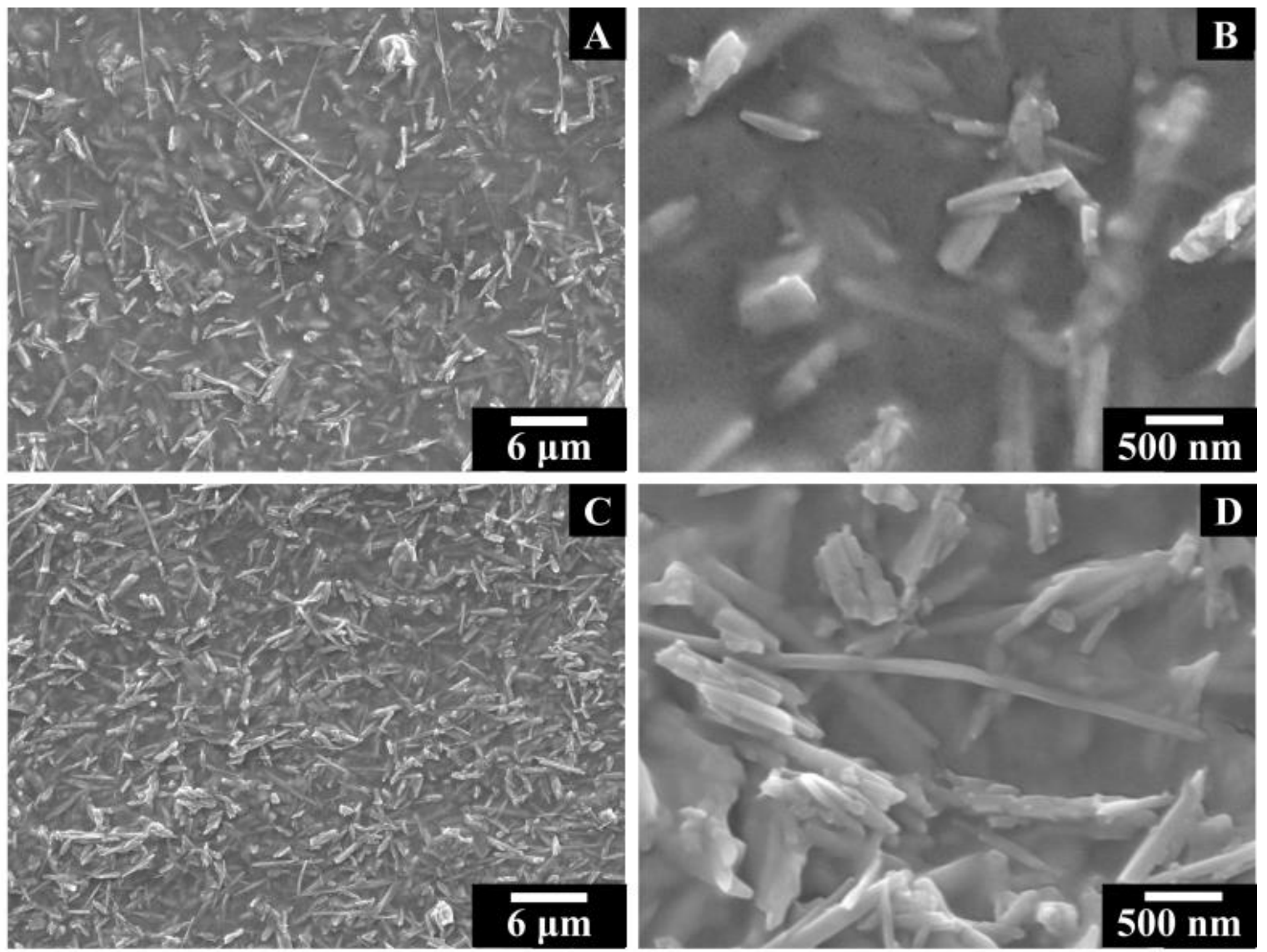

Figure 5.9: SEM of chitosan-HNT films containing $A, B$ ) 0.3 and $C, D) 0.6$ gL-1 HNT at low and high magnification

The cross-section showed that films were of uniform thickness and achieved a thickness of 0.1-5 $\mu \mathrm{m}$ by varying deposition condition (see Figure 5.10). It was observed that the chitosan-HNT is packed in a sedimentary manner, and the HNT embedded in the 
film lies parallel to the substrate. The deposition time was in the range of 1 to $10 \mathrm{~min}$ and the deposition voltage was in the range of 3 to $20 \mathrm{~V}$. The deposited coatings also showed good adhesion to the substrate.
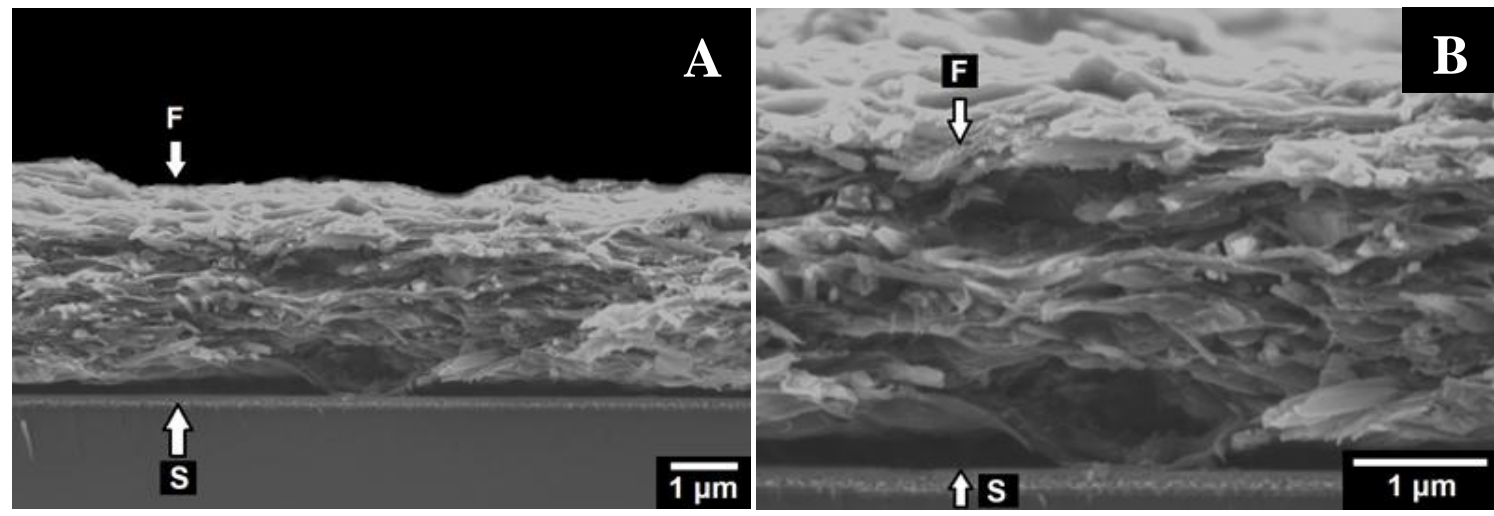

Figure 5.10: SEM of chitosan-HNT films containing 0.6 gL-1 HNT (arrows show film thickness, F-film, $\mathrm{S}$ - substrate)

\subsubsection{Multilayered Chitosan, Halloysite and Hydroxyapatite Films}

X-ray diffraction analysis was carried out on the deposit obtained from a $0.5 \mathrm{gL}^{-1}$

chitosan solution with $0.6 \mathrm{gL}^{-1} \mathrm{HNT}$ and $1.0 \mathrm{gL}^{-1} \mathrm{HA}$ and was compared to HNT, HA, chitosan films and chitosan-HNT films (see Figure 5.11). The pattern for HA, HNT, chitosan and chitosan-HNT deposits are presented for comparison (see Figure 5.11a-d). The pattern of the composite (see Figure 5.11e) showed peaks for HNT, gibbsite and quartz (corresponding to JCPDS files 29-1487, 33-0018 and 46-1045 respectively), as well as peaks for HA (corresponding to JCPDS file 9-0432) were observed. The pattern was different to that of a chitosan-HNT film in that the HNT peaks were much smaller due to the presence of HA, which is consistent with the fact that the chitosan-HNT-HA film was prepared from a suspension containing $0.3 \mathrm{gL}^{-1} \mathrm{HNT}$ and $1.0 \mathrm{gL}^{-1} \mathrm{HA}$, and confirmed the formation of chitosan-HNT-HA films. 


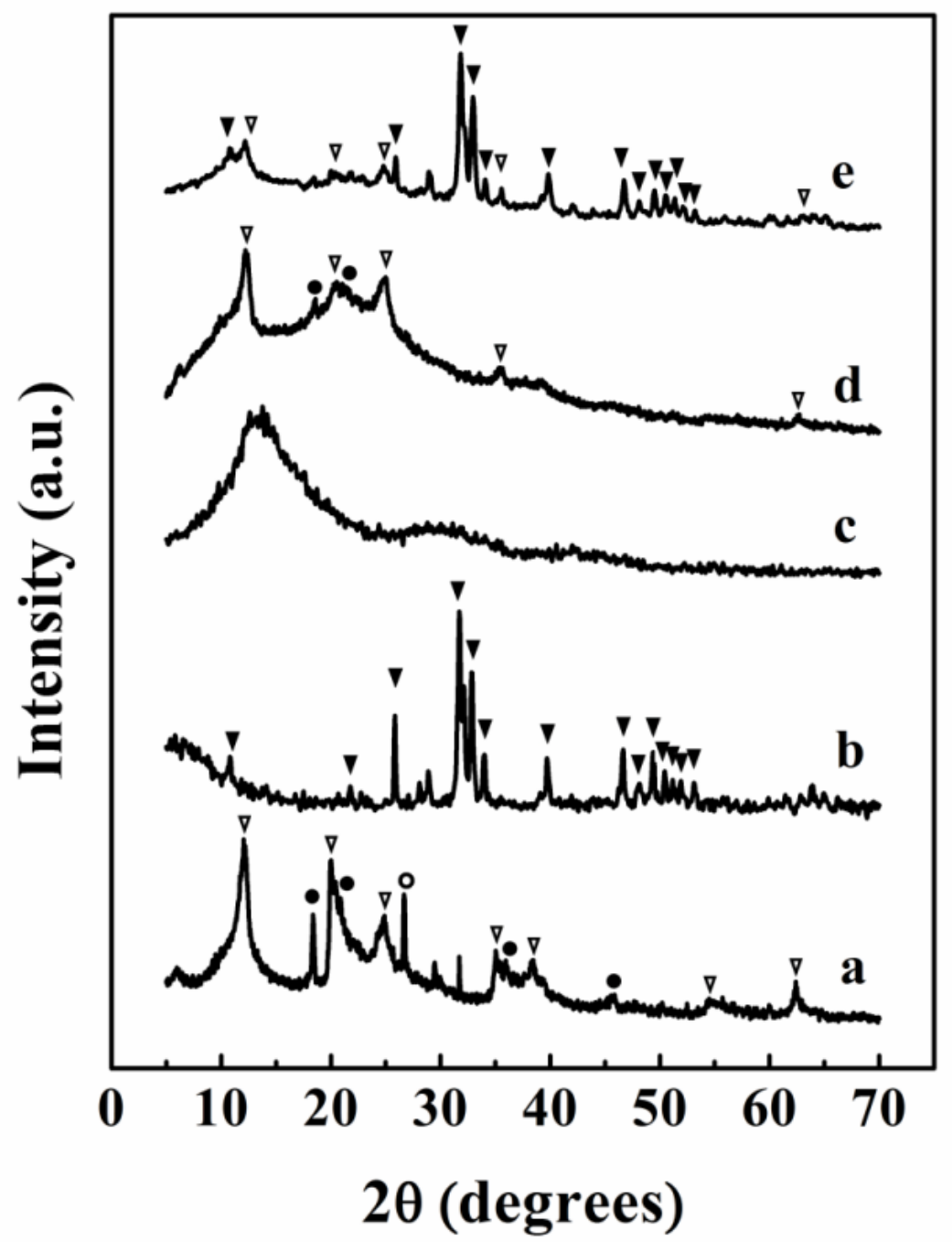

Figure 5.11: XRD patterns for a) as-received HNT, b) as-prepared HA, c) chitosan film without additives, d) chitosanHNT film and e) chitosan-HNT-HA film prepared from a $0.5 \mathrm{gL}^{-1}$ chitosan suspension containing $0.3 \mathrm{gL}^{-1} \mathrm{HNT}$ and 1.0 $\mathrm{gL}^{-1} \mathrm{HA}$ ( $\nabla$ - JCPDS file 29-1487 of halloysite, • - JCPDS file 33-0018 of gibbsite, $\bigcirc-$ JCPDS file 46-1045 of quartz, $\nabla-$ JCPDS file 9-0432 of HA). Previous XRD patterns of HNT and chitosan-HNT from Figure 5.8 are presented for comparison.

The results from the SEM studies of chitosan-HNT-HA films prepared from a 0.5 $\mathrm{gL}^{-1}$ solution of chitosan with 0.3 and $0.6 \mathrm{gL}^{-1} \mathrm{HNT}$ and $1.0 \mathrm{gL}^{-1} \mathrm{HA}$ showed both HNT and HA being incorporated into the chitosan matrix. Films prepared with and without HA were compared (see Figure 5.12), and resulted in different morphologies. The addition of HA to both the 0.3 and $0.6 \mathrm{gL}^{-1} \mathrm{HNT}$ suspensions showed significantly different 
compositions and microstructures. Images taken at low magnification (see Figure 5.13A,C) showed the films were continuous and crack-free, and those at higher magnification (see Figure 5.13B,D) showed the HA and HNT particles incorporated into the films, which is in agreement with the XRD analysis. The increase of HNT concentration from 0.3 to $0.6 \mathrm{gL}^{-1}$ in the suspension resulted in a significant increase of HNT incorporated into the film matrix (see Figure 5.13B,D) as well as a change in morphology. Chitosan-HNT-HA films were shown to be porous, with porosity increasing with the concentration of HA and HNT in the suspension. The images at high magnification (see Figure 5.13B,D) showed pore sizes on the order of 0.1-0.6 $\mu \mathrm{m}$., The porosity can be attributed to the increase of inorganic phases content and packing of the HA and HNT particles.
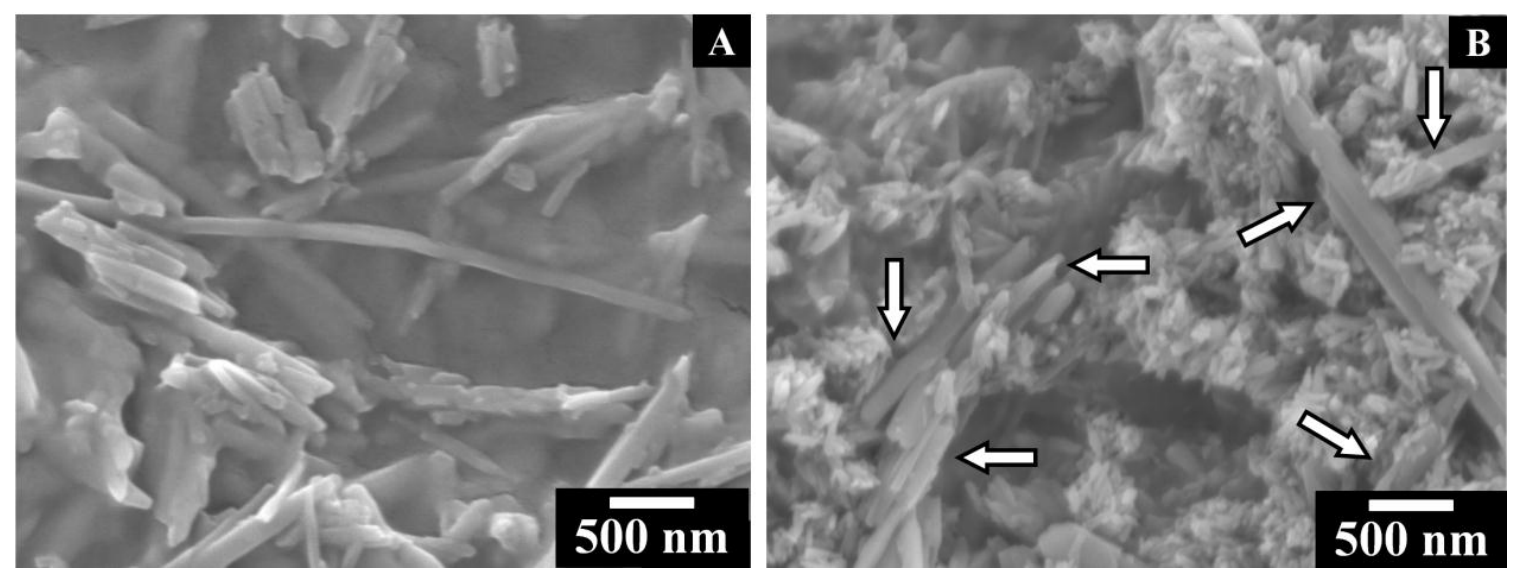

Figure 5.12: SEM of chitosan-HNT films prepared from a $0.5 \mathrm{gL}^{-1}$ chitosan suspension containing $0.6 \mathrm{gL}^{-1} \mathrm{HNT} \mathrm{A}^{\text {) }}$ without HA and B) with $1.0 \mathrm{gL}^{-1} \mathrm{HA}$ (arrows show HNT)

Like with previous chitosan-HNT films, HNT appears to be oriented parallel to the substrate, though the deposition of HA was more random, and tended to deposit in aggregates, creating an uneven surface. This can be attributed to the presence of HNT in 
the suspension - a comparison of films prepared from a $0.5 \mathrm{gL}^{-1}$ chitosan suspension with $1.0 \mathrm{gL}^{-1} \mathrm{HA}$ and varying amount of HNT showed different morphologies.
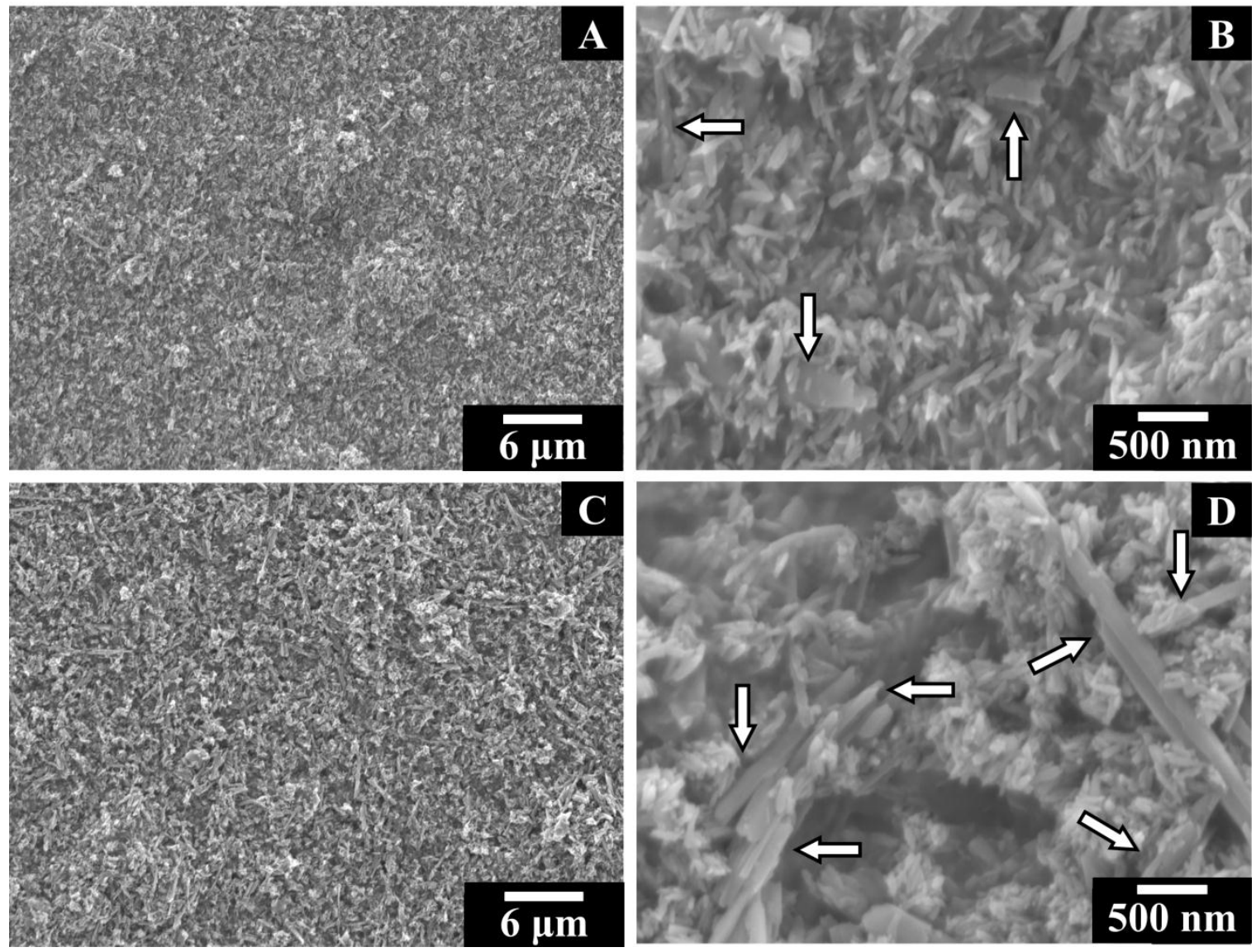

Figure 5.13: SEM of chitosan-HNT-HA films prepared from a $0.5 \mathrm{gL}^{-1}$ chitosan suspension containing $1.0 \mathrm{gL}^{-1} \mathrm{HA}$ and $(A, B) 0.3$ and $(C, D) 0.6 \mathrm{gL}^{-1} \mathrm{HNT}$ (arrows show HNT) at low and high magnification

While both films were continuous and crack-free (see Figure 5.13A,C) the films prepared from the suspension containing $0.3 \mathrm{gL}^{-1} \mathrm{HNT}$ showed a much more even morphology, with HA depositing more evenly (see Figure 5.13B) compared to that prepared from a suspension containing $0.6 \mathrm{gL}^{-1} \mathrm{HNT}$, in which the $\mathrm{HA}$ deposited in aggregates (see Figure 5.13D). 
Functionally graded (FG) and multilayer films containing chitosan, HNT and HA were prepared by EPD. A cross-section of a multilayer film containing a pure chitosan layer and composite chitosan-HNT and chitosan-HA layers (see Figure 5.14) showed good interfacial bonding between the deposited layers. The layered structure opens the possibility of fabrication of coatings that contain and combine the properties of different materials. For example, it has been shown that films containing HA offer a bioactive surface due to the similarity of HA to natural bone [54]. Additionally, the chitosan-HNT layer can be used for the controlled release of drugs or anti-microbial agents, whose release rate can be modified by the variation of thickness or composition of the top layer (previous investigations of chitosan-HA/chitosan-Ag laminates showed that the chitosanHA layer can modify the release rate of $\mathrm{Ag}^{+}$from the chitosan-Ag layer) [98].

The layers of chitosan, chitosan-HNT and chitosan-HA all showed uniform thickness, with the initial chitosan layer being the most uniform. Furthermore, the actual thickness of the chitosan and chitosan-HTN layers were extremely similar $(\sim 1.5 \mu \mathrm{m})$, while the chitosan-HA layer was smaller, even though the deposition condition (time and voltage) were the same for all three layers. This could be attributed to a shielding effect the previous two layers provided, which acted as insulators for the electric field. 


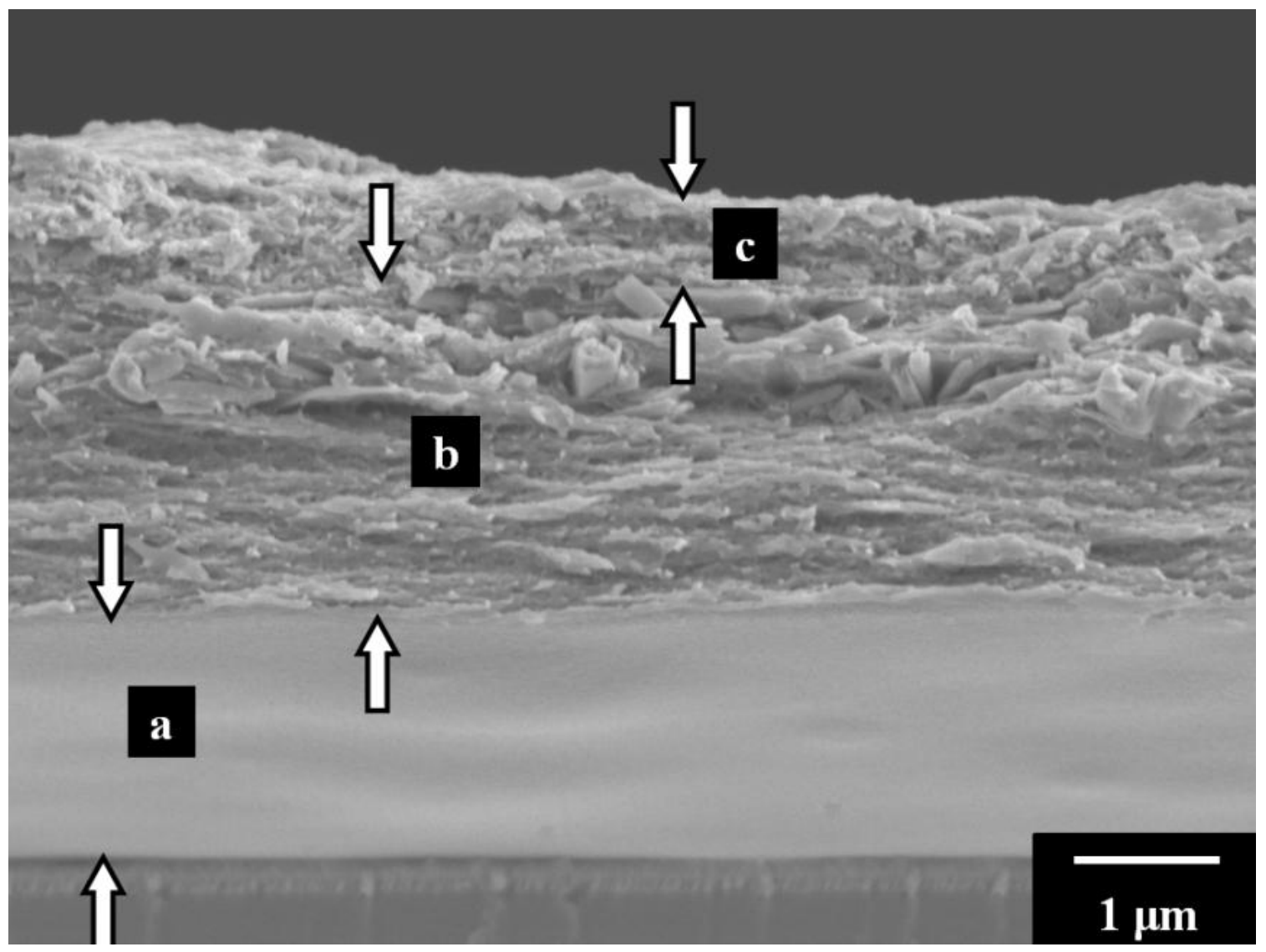

Figure 5.14: SEM of chitosan-HNT-HA multilayer films cross-section prepared from a $0.5 \mathrm{gL}^{-1} \mathrm{chitosan}$ suspension containing a) no additives, b) $0.6 \mathrm{gL}^{-1} \mathrm{HNT}$, and c) $1.0 \mathrm{gL}^{-1} \mathrm{HA}$ (arrows indicate layer thickness)

In addition to the previous multilayer film, a laminate consisting of alternation chitosan-HA/chitosan-HNT was formed through EPD (see Figure 5.15). Like the previous multilayer film, good interfacial bonding between the layers was observed. Furthermore, it was shown that the number of layers can be varied, with multiple layers possible. The multiple layers all seemed to be of similar thickness, and the composition of the layers didn't show any variation. Like with previous chitosan-HNT films, the HNT in the multilayer deposit appears to have deposited parallel to the substrate. Unlike previous films, the multilayer deposit was extremely hard to break, and showed an increase in toughness. Previous studies of multilayer films obtained through EPD showed that crack 
propagation through the film can be stopped at the interface of individual layers [99], and reinforcing films with HNT improve their tensile strength, flexural strength, flexural modulus, and impact strength [100], in some cases by several orders of magnitude [101], which would account for this.
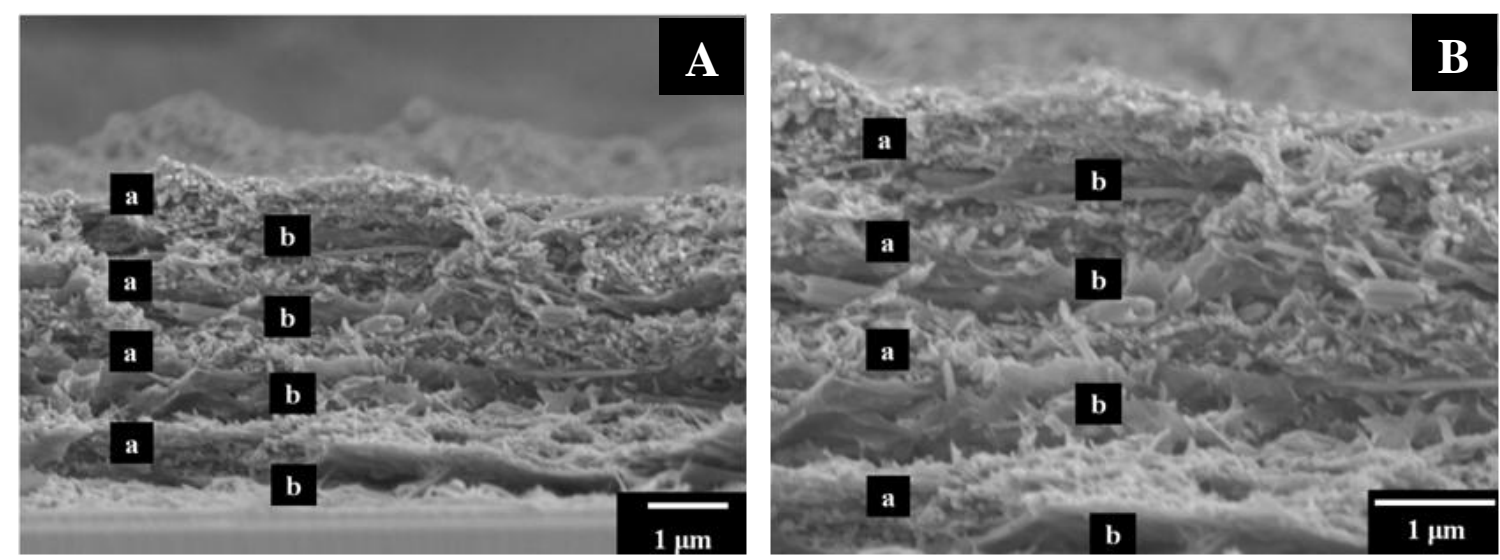

Figure 5.15: SEM of chitosan-HNT-HA films cross-sections prepared from a $0.5 \mathrm{gL}^{-1}$ chitosan suspension containing a) $1.0 \mathrm{gL}^{-1} \mathrm{HA}$, and b) $0.6 \mathrm{gL}^{-1} \mathrm{HNT}$

In order to analyse the biocompatibility, stability, and mechanical properties of EPD prepared films containing HNT, further studies are needed. As a step in this direction, the behaviour of films in simulated body fluids (SBF) was investigated (see Figure 5.16). It was found that the composite coatings provided protection for the stainless steel substrate in SBF solutions (see Figure 5.16a,b). The corrosion potential of stainless steel, $E_{\text {corr }}$, for the chitosan-HNT coated substrate was almost $100 \mathrm{mv}$ higher than that of bare stainless steel, and the anodic current, $i_{a}$, was smaller as well. The electrochemical results for the chitosan-HNT-HA coated substrate were significantly better $-E_{\text {corr }}$ for the stainless steel substrate was almost $200 \mathrm{mV}$ higher than that of stainless steel, and $i_{a}$ was less than a tenth of that observed for stainless steel (see Figure $5.16 \mathrm{c})$. 
Both the corrosion potential and the corrosion current, and thus the rate of corrosion, were significantly reduced by the film (see Figure 5.16). These results confirm that the composite coating would acts as a protective layer and provide corrosion protection under physiological conditions.

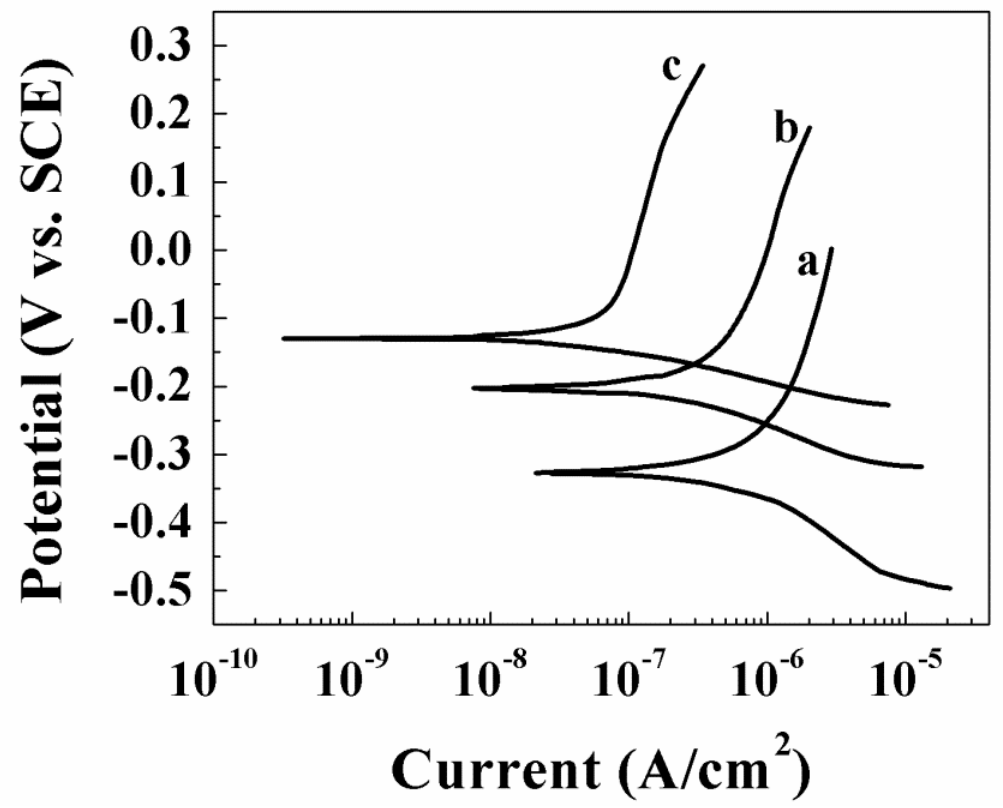

Figure 5.16: Tafel plots for a) uncoated stainless steel and stainless steel coated with a film prepared from a $0.5 \mathrm{gL}^{-1}$ chitosan suspension containing $0.3 \mathrm{gL}^{-1} \mathrm{HNT}$ and b) no $\mathrm{HA}$ and c) $1.0 \mathrm{gL}^{-1} \mathrm{HA}$

\subsubsection{Electrodeposition of Hyaluronic Acid}

Similar to chitosan-HNT suspensions, addition of hyaluronic acid resulted in improved stability of the HNT in suspension. Furthermore, anodic deposition of HYHHNT films were successful under various conditions.

Previous works have suggested that sodium hyaluronate (HYNa) dissociates as follows [102]:

$$
\mathrm{HYNa} \rightarrow \mathrm{HY}^{-}+\mathrm{Na}^{+}
$$


The HYNa dissociation resulted in the formation of an anionic species, $\mathrm{HY}^{-}$. These were adsorbed onto the HNT particles and provided steric stabilization, as well as a providing the charge necessary for EPD due to the deprotonation of the carboxyl groups (see Figure 5.17). The applied electric field allowed for electrophoresis of the anionic $\mathrm{HY}^{-}$ macromolecule towards the anode, where the low $\mathrm{pH}$ region was due to the generation of acids [102]:

$$
2 \mathrm{H}_{2} \mathrm{O} \rightarrow \mathrm{O}_{2}+4 \mathrm{H}^{+}+4 \mathrm{e}^{-}
$$

The reaction (Equation 5-5) allowed for the charge neutralization of $\mathrm{HY}^{-}$, which then formed a coherent deposit on the anode [102]:

$$
\mathrm{HY}^{-}+\mathrm{H}^{+} \rightarrow \mathrm{HYH}
$$

The HNT particles, which had been carried along by the adsorbed $\mathrm{HY}^{-}$, were incorporated into the HYH deposit, creating a composite HYH-HNT film.

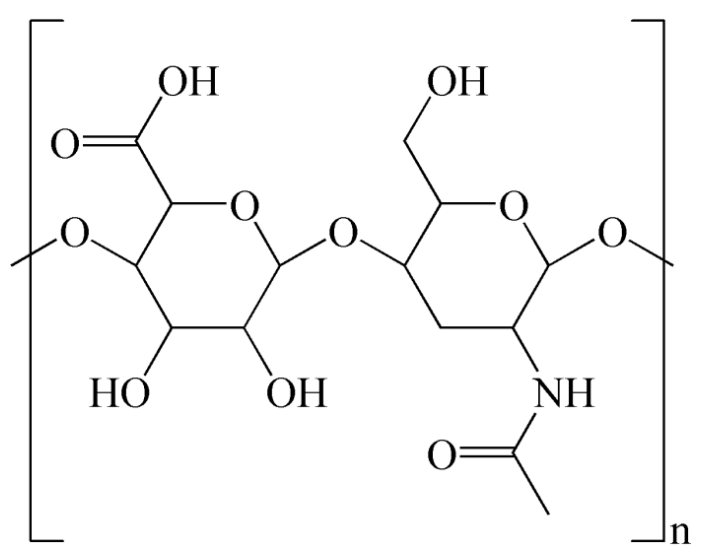

Figure 5.17: Chemical structure of hyaluronic acid

The deposition kinetics of HYH was studied using a QCM. The data obtained showed a continuous decrease in the rate of mass deposited as time progressed (see 
Figure 5.18). The slope of the curve is initially linear, and then shows a decrease, indicating the film is electrically insulating and a causes decrease in voltage in the bulk of the suspension. The initial part of the curve shows a steep linear increase, which can be attributed to the film not being thick enough to insulate the electric field or the concentration of HYH in the suspension being relatively stable for a short initial time period. The curve initially corresponds to Hamaker's equation (Equation 2-9), which assumes constant current and constant concentration (Equation 2-15).

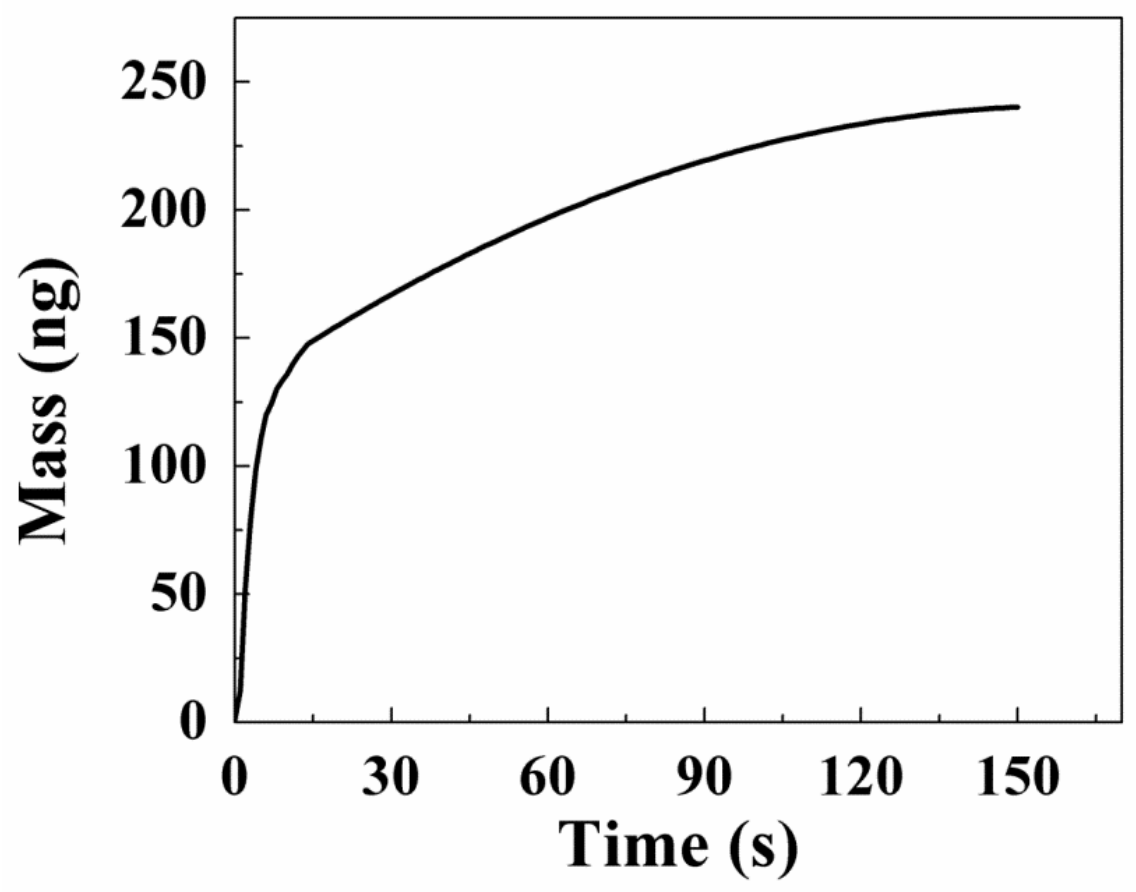

Figure 5.18: QCM results for the EPD of $0.1 \mathrm{gL}^{-1} \mathrm{HYH}$

The formation of composite HYH-HNT films was confirmed through the results obtained from TGA/DTA, XRD analysis and SEM. The DTA/TGA (see Figure 5.19) obtained from a deposit prepared from a $1 \mathrm{gL}^{-1} \mathrm{HYNa}$ solution, containing $0.3 \mathrm{gL}^{-1} \mathrm{HNT}$, 
showed significant mass loss between 200 to $500^{\circ} \mathrm{C}$. The initial mass loss below $200^{\circ} \mathrm{C}$ is attributed to the dehydration of the deposit, while the mass loss between 200 to $500^{\circ} \mathrm{C}$ is attributed to the burning out of the organic phase. Past $500^{\circ} \mathrm{C}$ the mass of the sample remained fairly constant.

The DTA data is in agreement with the TGA findings, as there is a slight endotherm below $100^{\circ} \mathrm{C}$ that is attributed to the dehydration of the sample, and a broad exothermic peak at between 200 to $500^{\circ} \mathrm{C}$ that is not present in the DTA of as-received HNT (see Figure 5.4), while a similar peak was observed in previous studies of pure HYH [102], and is thus attributed to the burning out of the organic phase.

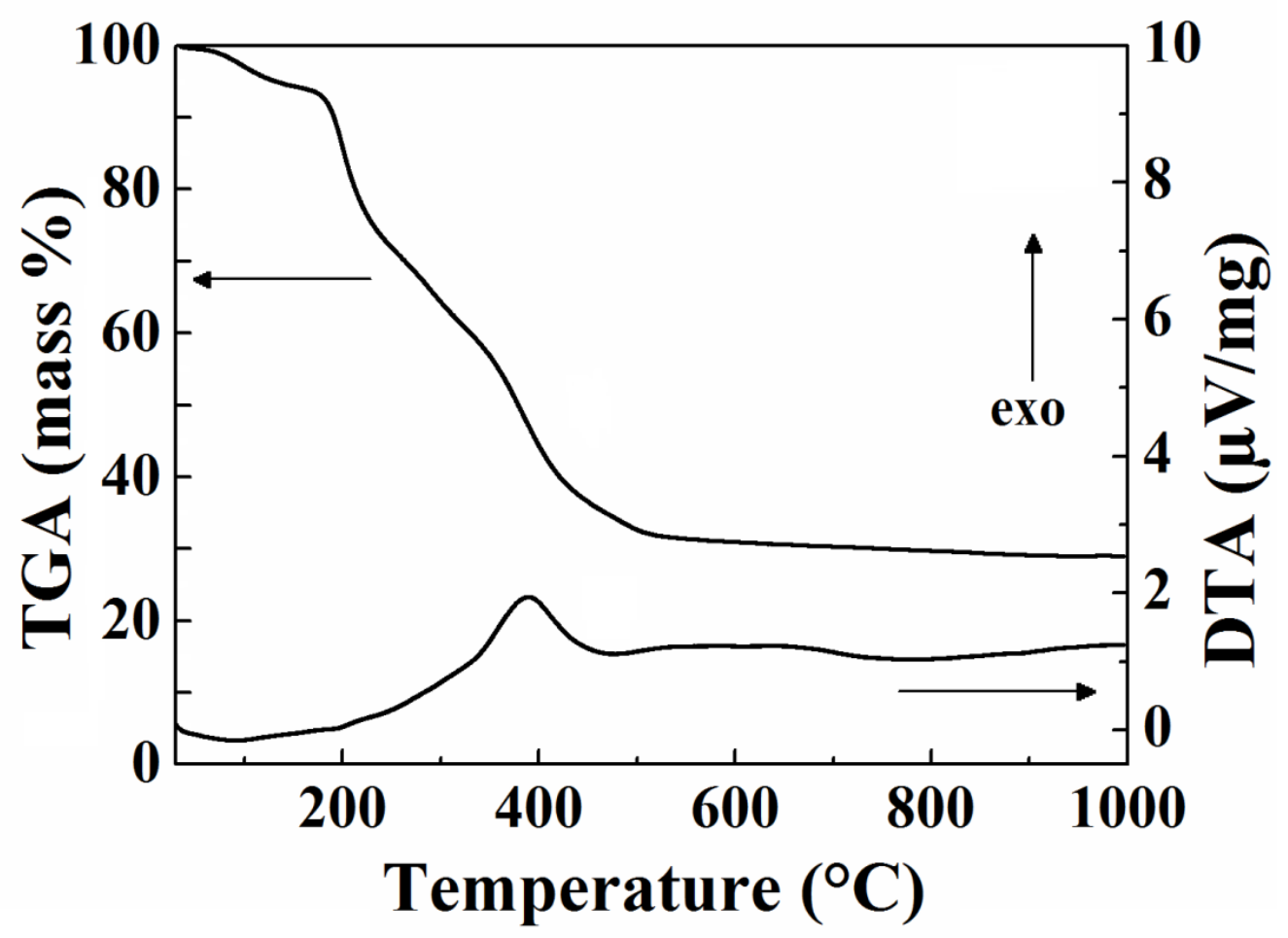

Figure 5.19: DTA/TGA results for HYH-HNT film prepared from a $1.0 \mathrm{gL}^{-1} \mathrm{HYNa}$ suspension containing $0.3 \mathrm{gL}^{-1} \mathrm{HNT}^{-}$ 
The total mass loss of the deposit over a range of 30 to $1000^{\circ} \mathrm{C}$ was found to be $71.1 \%$, which was mainly attributed to the burning out of HYH. Taking into account mass loss for pure HNT, the results showed that approximately $65.4 \%$ of the mass of the composite is composed of $\mathrm{HYH}$ and $34.6 \%$ is $\mathrm{HNT}$.
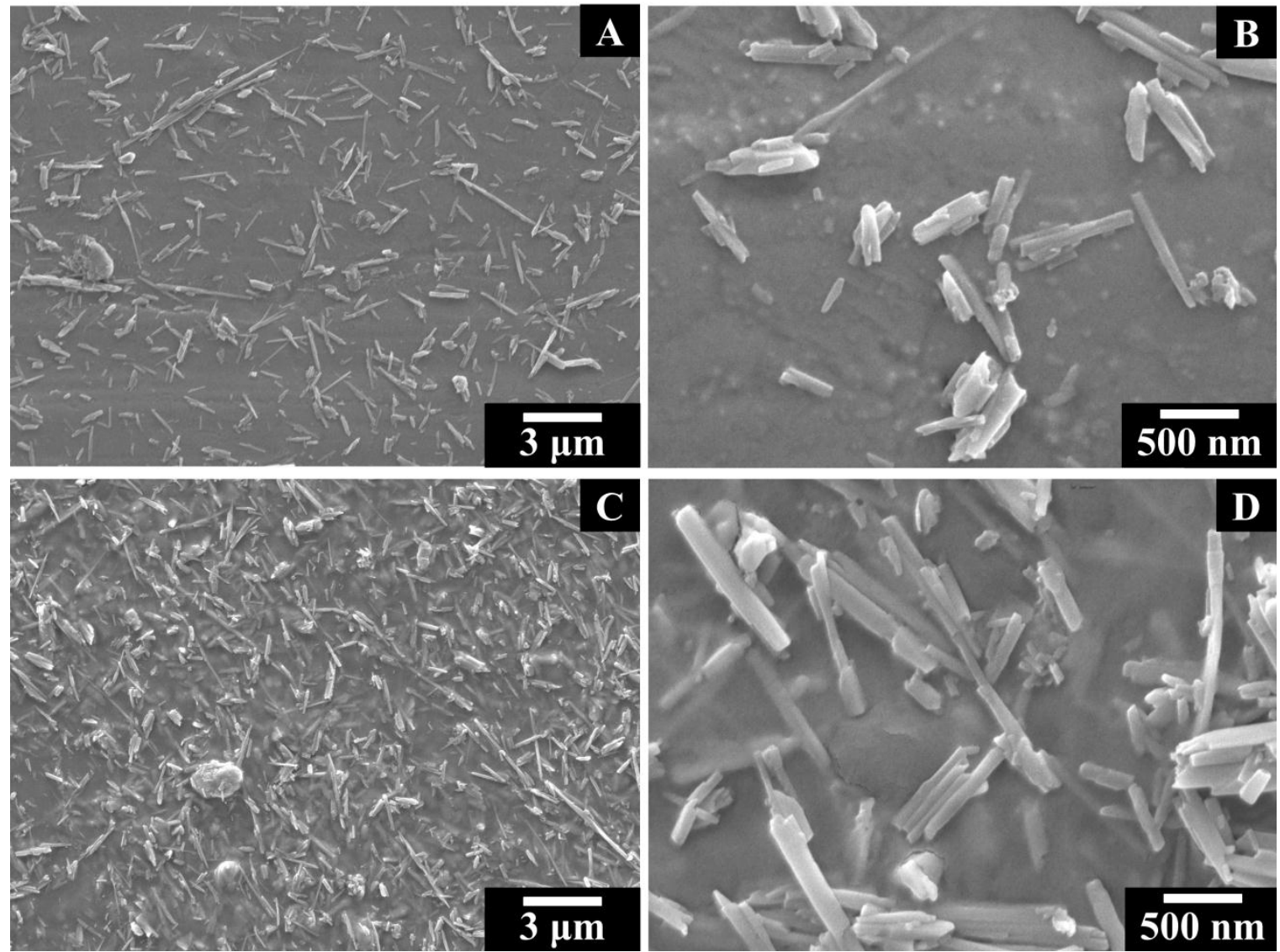

Figure 5.20: SEM images of HYH-HNT films prepared from solution of $1.0 \mathrm{gL}^{-1} \mathrm{HYH}$ containing A,B) $0.3 \mathrm{gL}^{-1} \mathrm{HNT}_{\text {and }}$ C,D) $0.6 \mathrm{gL}^{-1} \mathrm{HNT}$

The SEM results of the HYH-HNT films (see Figure 5.20) show that HNT are embedded in the HYH matrix. Deposits prepared from a $0.6 \mathrm{gL}^{-1} \mathrm{HNT}$ suspension (see Figure 5.20C,D) show significantly more HNT in the HYH matrix than those prepared from a $0.3 \mathrm{gL}^{-1}$ HNT suspension (see Figure 5.20A,B). The SEM images at low magnification (see Figure 5.20A,C) show the films are continuous, crack-free, and 
without agglomeration, while the images at high magnification (see Figure 5.20B,D) show that the HNT align parallel to the substrate.

In addition to HYH-HNT films, coatings of HYH-HNT-HA were prepared from solutions of $1.0 \mathrm{gL}^{-1} \mathrm{HYH}$, containing 1.0 and $2.0 \mathrm{gL}^{-1} \mathrm{HA}$, and 0.3 and $0.6 \mathrm{gL}^{-1} \mathrm{HNT}$. Images taken of films containing $1.0 \mathrm{gL}^{-1} \mathrm{HA}$ show that they are continuous and crackfree, and varying the amount of HNT in these films led to a change in morphology (see Figure 5.21). There was a significant difference in morphology between films containing $0.3 \mathrm{gL}^{-1} \mathrm{HNT}$ (see Figure 5.21) and $0.6 \mathrm{gL}^{-1} \mathrm{HNT}$ (see Figure 5.21B) - the films contacting extra HNT showed more agglomeration of HA, and had a less uniform distribution.
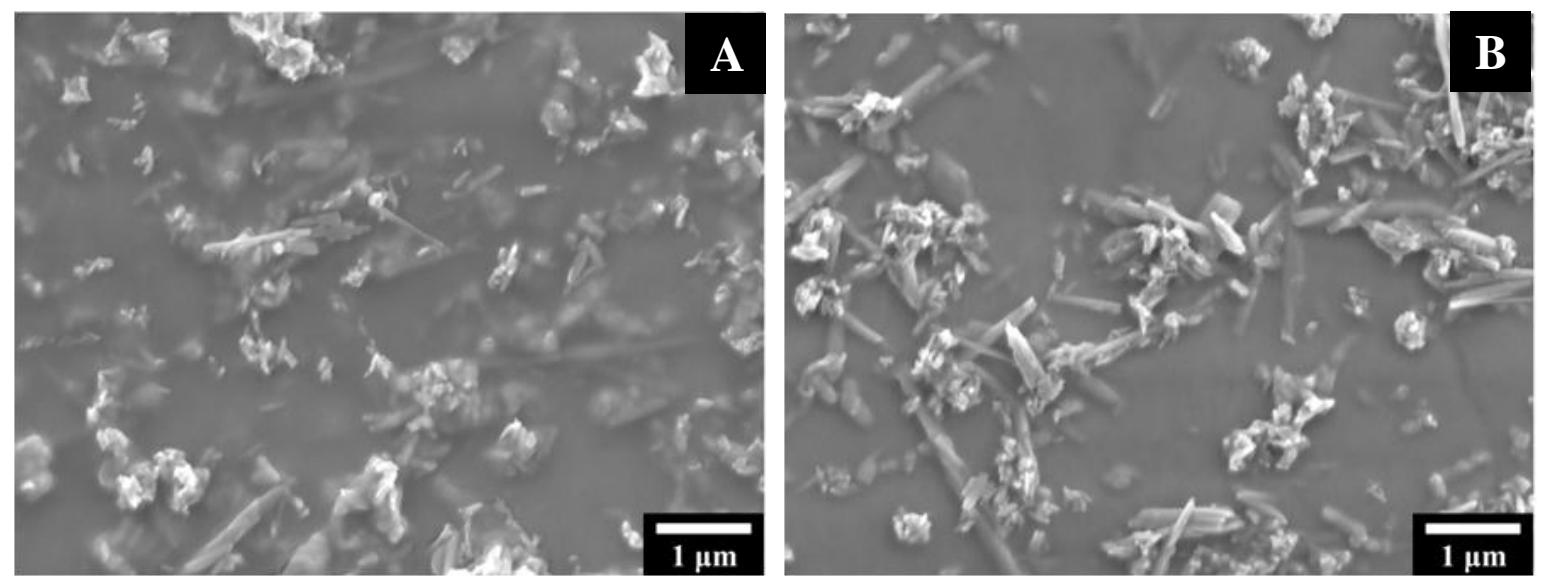

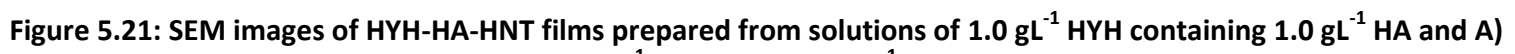
$0.3 \mathrm{gL}^{-1} \mathrm{HNT}$ and B) $0.6 \mathrm{gL}^{-1} \mathrm{HNT}$

Films containing $2.0 \mathrm{gL}^{-1} \mathrm{HA}$ were shown to be continuous and crack-free as well (see Figure 5.22A,C), but unlike the previous films showed a significant change in morphology when the amount of HNT was varied (see Figure 5.22B,D). While a similar 
effect was shown (increased HNT led to a more agglomerated deposition of HA), the degree to which it occurs is completely different.
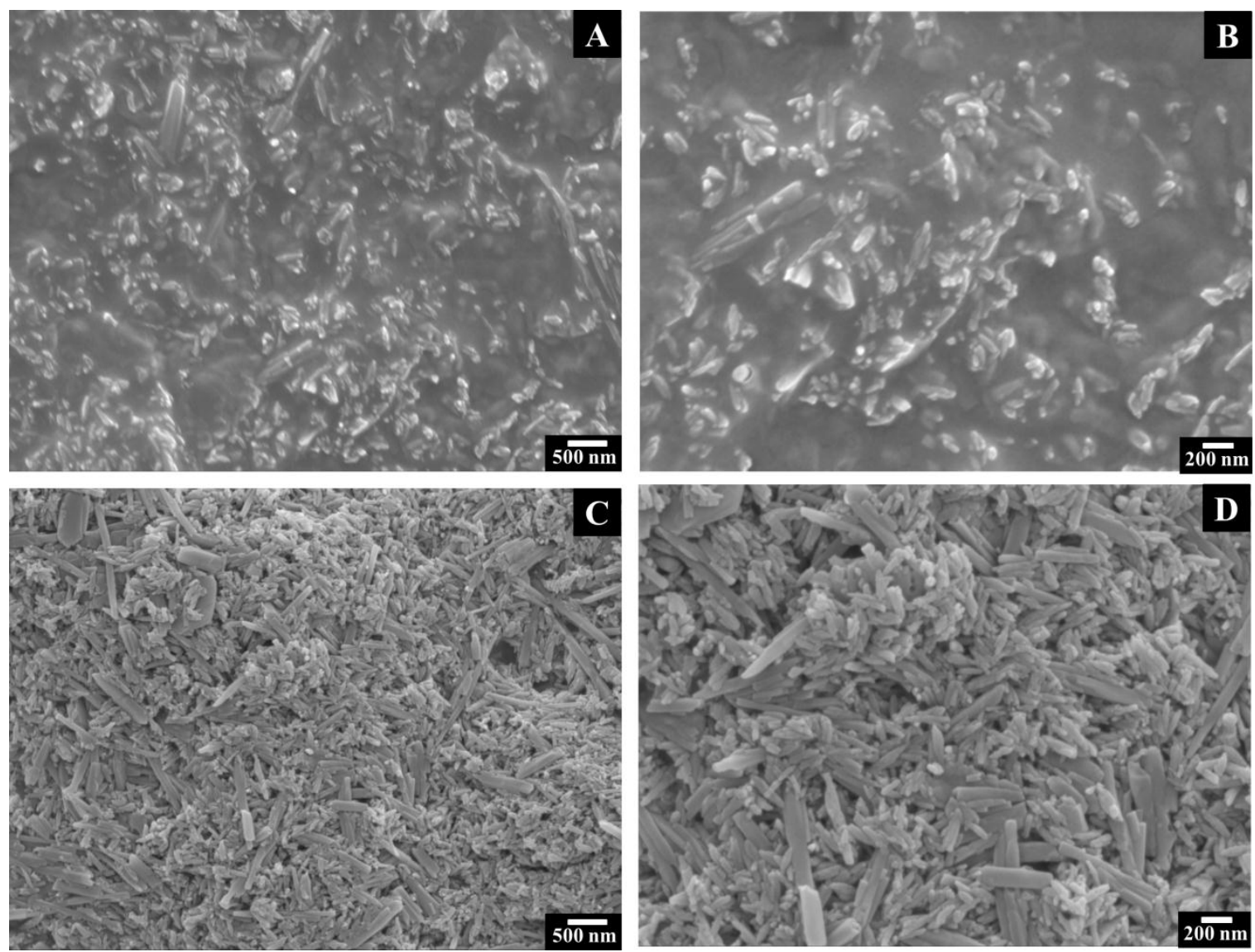

Figure 5.22: SEM images of HYH-HA-HNT films prepared from solutions of $1.0 \mathrm{gL}^{-1} \mathrm{HYH}$ containing $2.0 \mathrm{gL}^{-1} \mathrm{HA}$ and A,B) $0.3 \mathrm{gL}^{-1} \mathrm{HNT}$ and C,D) $0.6 \mathrm{gL}^{-1} \mathrm{HNT}$

The SEM images of film cross-sections (see Figure 5.23) showed that the film thickness varied in the range of 0.1 to $5 \mu \mathrm{m}$ by varying the deposition time in the range of 1 to $10 \mathrm{~min}$ and voltage in the range of 5 to $20 \mathrm{~V}$. Furthermore, the images show the films are of non-uniform thickness, and the distribution of HNT is uniform throughout the film. 


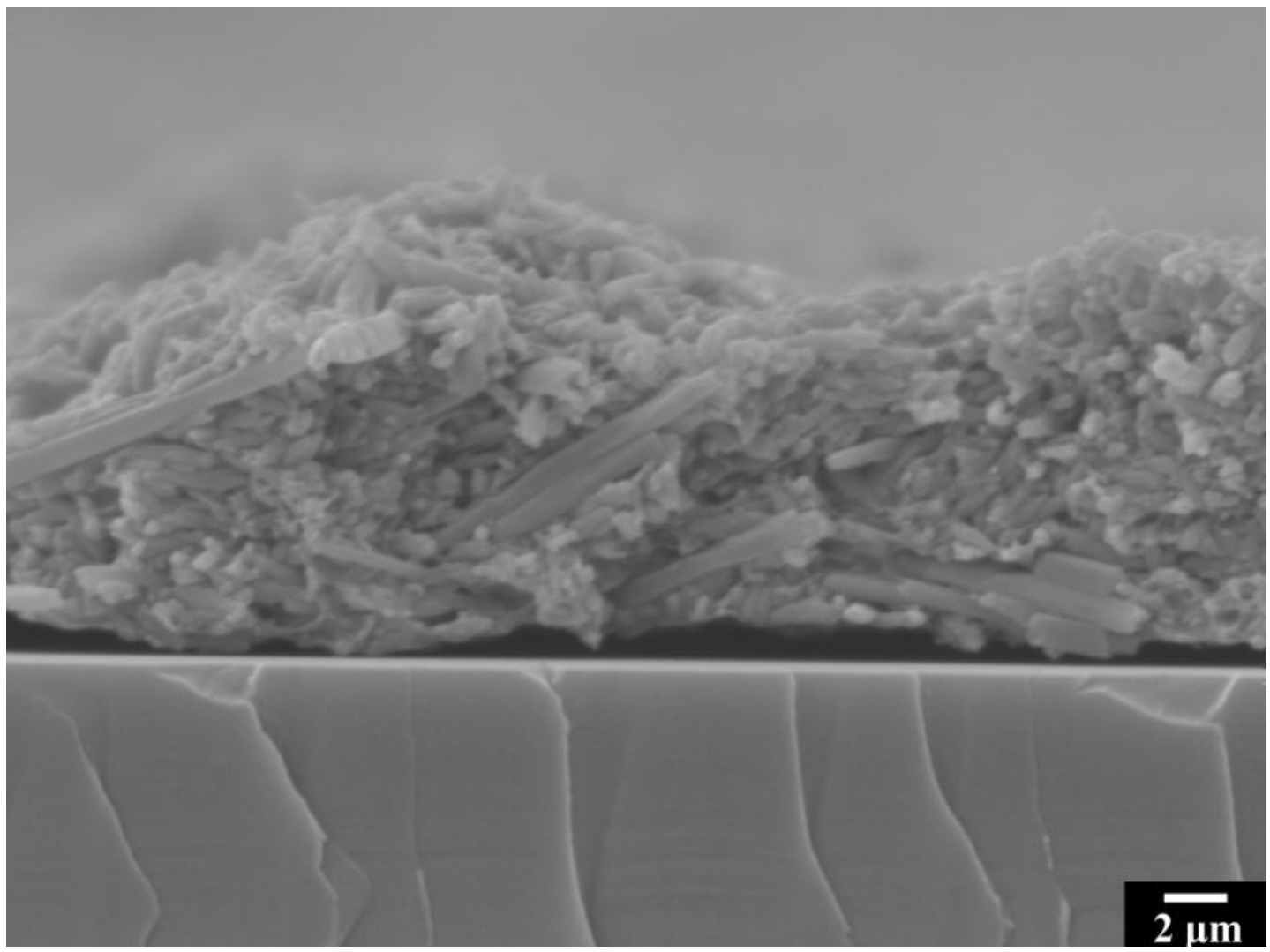

Figure 5.23: SEM images of HYH-HNT-HA film cross-section prepared from a $1.0 \mathrm{gL}^{-1} \mathrm{HYNa}$ suspension containing 0.3 $\mathrm{gL}^{-1} \mathrm{HNT}$ and $2.0 \mathrm{gL}^{-1} \mathrm{HA}$

In addition to SEM, the XRD patterns obtained from HNT, HA, HYH and deposits support the SEM evidence of formation of composite films. Peaks present in the XRD of HNT (corresponding to JCPDS file 29-1487) (see Figure 5.24a) are also present in the HYH-HNT films (prepared from a $1.0 \mathrm{gL}^{-1} \mathrm{HYNa}$ suspension containing $0.3 \mathrm{gL}^{-1}$ HNT and $2.0 \mathrm{gL}^{-1} \mathrm{HA}$ ), which showed peaks at $2 \theta \sim 12^{\circ}$ and $25^{\circ}$ (see Figure 5.24d). After the addition of $\mathrm{HA}$ to the suspension, peaks at $2 \theta \sim 26^{\circ}, 32^{\circ}, 40^{\circ}$ and $46^{\circ}-53^{\circ}$ appeared, corresponding to peaks present in the XRD of HA (corresponding to JCPDS file 9-0432 ) (see Figure 5.24b) in addition to the peaks of HNT present at $2 \theta \sim 12^{\circ}$ and $25^{\circ}$. Furthermore, both deposits showed a broadening of peaks at $2 \theta \sim 12^{\circ}$ and $20^{\circ}$, which is 
also seen in the XRD pattern of HYH (see Figure 5.24c). This evidence supports that of the formation of composite HYH-HNT and HYH-HNT-HA films.

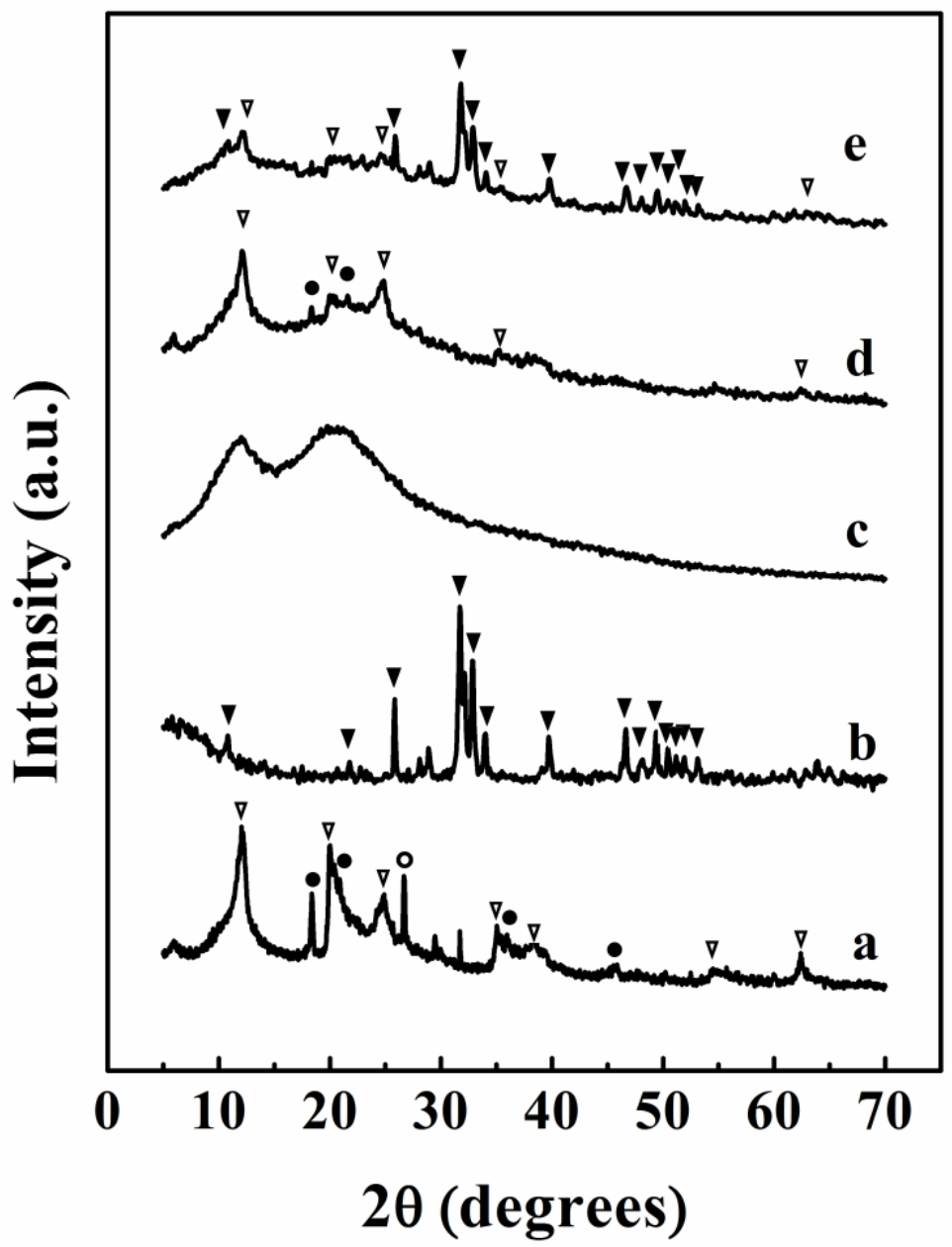

Figure 5.24: XRD patters for a) as-received HNT, b) as-prepared HA, c) HYH film without additives, d) HYH-HNT film and e) HYH-HNT-HA film ( $\nabla$-JCPDS file 29-1487 of halloysite, •-JCPDS file 33-0018 of gibbsite, O-JCPDS file 46-1045 of quartz, $\nabla$ - JCPDS file 9-0432 of HA)

\subsubsection{Electrodeposition of Poly-L-Lysine and Poly-L-Ornithine}

Similar to other polymers, the addition of PLO and PLL to HNT suspensions improved the suspension stability and allowed for the deposition of composite films under various conditions. Previous work has shown that Poly-L-lysine hydrobromide (PLL- 
$\mathrm{HBr}$ ) and Poly-L-ornithine hydrobromide (PLO-HBr) were both used to form cathodic deposits, which can be attributed to the fact that both PLL and PLO contain amino groups (see Figure 5.25), which allow them to be protonated in acidic solutions [31]:

$$
\begin{aligned}
& \mathrm{PLL}-\mathrm{HBr} \rightarrow \mathrm{PLL}^{+} \mathrm{H}^{+}+\mathrm{Br}^{-} \\
& \mathrm{PLO}-\mathrm{HBr} \rightarrow \mathrm{PLO}^{-} \mathrm{H}^{+}+\mathrm{Br}^{-}
\end{aligned}
$$

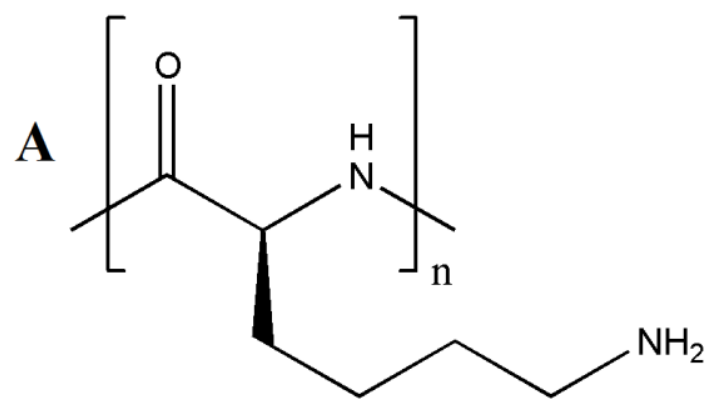

Poly-L-lysine

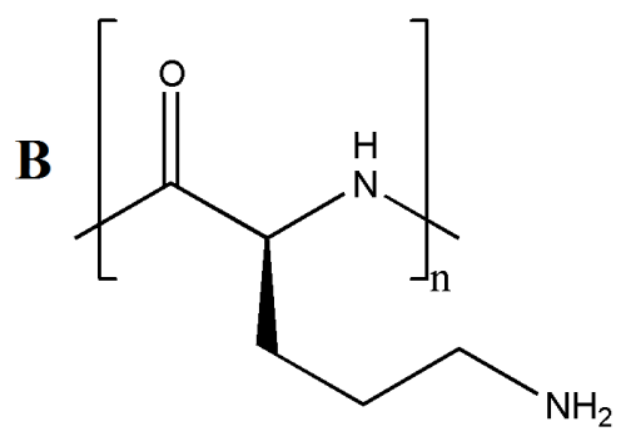

\section{Poly-L-Ornithine}

Figure 5.25: Chemical structure of A) PLL and B) PLO

The resulting cationic species were adsorbed onto the HNT particles, and provided steric stabilization, while the electric field provided electrophoretic mobility towards the 
cathode surface, where an increase of $\mathrm{pH}$ occurred (Equation 5-2), which led to the charge neutralization of the PLL- $\mathrm{H}^{+} / \mathrm{PLO}-\mathrm{H}^{+}$then occurred, forming a coherent deposit at the cathode:

$$
\begin{gathered}
\mathrm{PLL}_{-}{ }^{+}+\mathrm{OH}^{-} \rightarrow \mathrm{PLL}+\mathrm{H}_{2} \mathrm{O} \\
\mathrm{PLO}-\mathrm{H}^{+}+\mathrm{OH}^{-} \rightarrow \mathrm{PLO}+\mathrm{H}_{2} \mathrm{O}
\end{gathered}
$$

The HNT particles, which had been carried along by the adsorbed polymer, were released due to the charge neutralization at the cathode, and were incorporated into the PLL/PLO deposit, creating composite PLL-HNT and PLO-HNT films.

Films prepared from $2.0 \mathrm{gL}^{-1}$ PLL and PLO suspensions, containing either 0.5 or $2.0 \mathrm{gL}^{-1} \mathrm{HA}$ or 0.3 or $0.6 \mathrm{gL}^{-1} \mathrm{HNT}$ were prepared using EPD and analysed under SEM (see Figure 5.27, Figure 5.26 and Figure 5.28). The films were crack-free and continuous, though they showed significantly different morphologies depending on their additive and additive concentration.

The PLL-HNT and PLO-HNT films showed similar SEM images (see Figure 5.27B and Figure 5.26C), EPD produced uniform films with pores of approximately 50$160 \mathrm{~nm}$ which can be attributed to the hydrogen evolution at the cathode during deposition.

There was significant difference between films containing $\mathrm{HA}$ and HNT, especially in morphology. The HA films were more porous $(\sim 40 \mathrm{~nm})$ and had a branched structure (see Figure 5.26A,B and Figure 5.27A), which can be attributed to the increased 
content of the inorganic phase and the packing of the HA nanoparticles, as well as the difference in zeta potential of both particles - HNT has a potential of approximately -27 $\mathrm{mV}$ [24] while $\mathrm{HA}$ is $\sim 20 \mathrm{mV}$ [103]. The difference in morphology between HA and HNT films is attributed to the cationic nature of PLL and PLO, as well as the difference in size and zeta potential of the particles and the fact that HA tends to deposit in agglomerates at high concentrations.Halloysite was completely submersed in the polymers while HA formed a more porous structure.
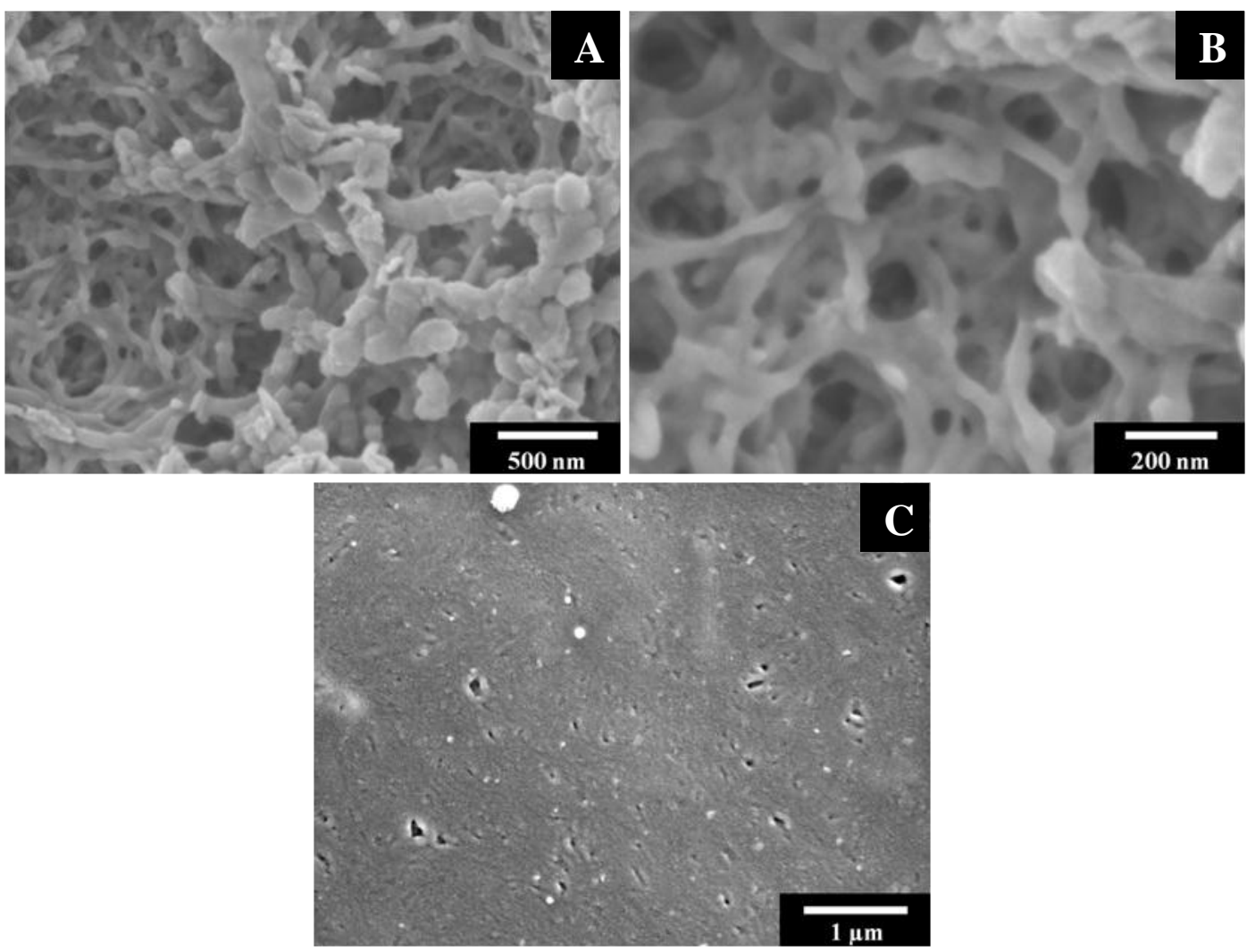

Figure 5.26: Film prepared from a $2.0 \mathrm{gL}^{-1} \mathrm{PLO}$ suspension containing $\mathrm{A}, \mathrm{B}$ ) $2.0 \mathrm{gL}^{-1} \mathrm{HA}$ (low and high magnification), C) $0.3 \mathrm{gL}^{-1} \mathrm{HNT}$ 


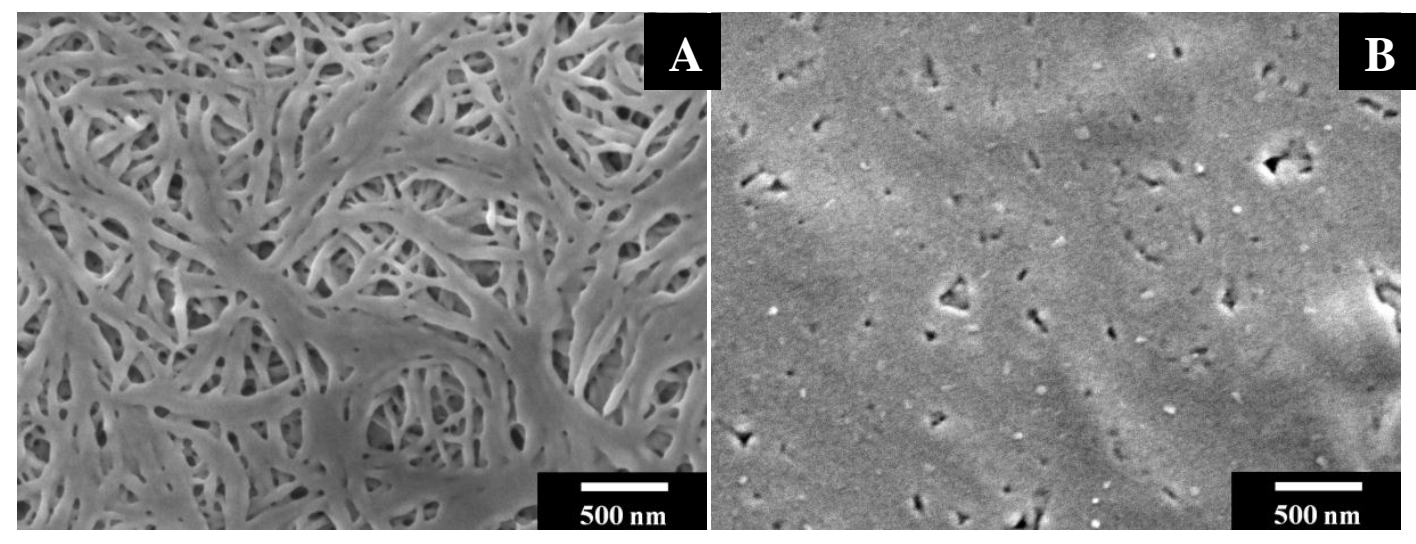

Figure 5.27: Film prepared from a $2.0 \mathrm{gL}^{-1} \mathrm{PLL}$ suspension containing $\left.\mathrm{A}\right) 2.0 \mathrm{gL}^{-1} \mathrm{HA}$ and $\left.\mathrm{B}\right) 0.3 \mathrm{gL}^{-1} \mathrm{HNT}$

In addition to varying the type of additive, it was found that varying the concentration of the additive has an impact on the film's morphology. Films prepared from a $2.0 \mathrm{gL}^{-1}$ PLO suspension containing either 0.5 or $2.0 \mathrm{gL}^{-1} \mathrm{HA}$ were deposited at 10 $\mathrm{V}$ and $20 \mathrm{~V}$ (see Figure 5.28). The films deposited at the lower voltage lacked significant porosity (see Figure 5.28A,C), while the films deposited at $20 \mathrm{~V}$ (see Figure 5.28B,D) showed significantly higher porosity. The concentration of the additive has an effect on the film morphology as well, as the films with a lower concentration of HA (see Figure 5.28A,B) have a more agglomerated, porous morphology, while the higher concentration of HA (see Figure 5.28C,D) resulted in a more even distribution of HA, as well as smaller pore size. 

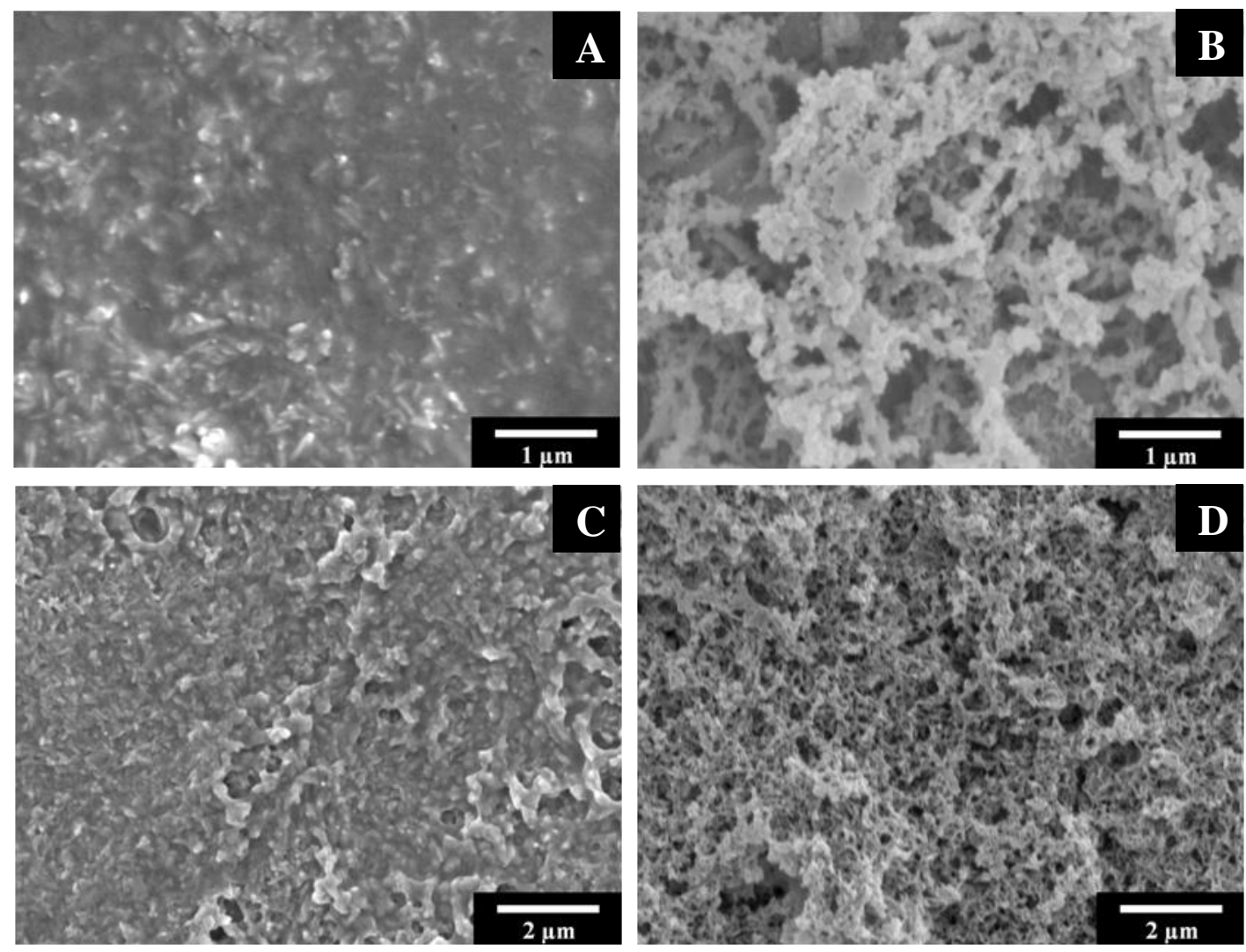

Figure 5.28: Film prepared from a $2.0 \mathrm{gL}^{-1}$ PLO suspension containing $0.5 \mathrm{gL}^{-1} \mathrm{HA}$ deposited at A) $10 \mathrm{~V}$ and B) $20 \mathrm{~V}$, and containing $2.0 \mathrm{gL}^{-1} \mathrm{HA}$ deposited at C) $10 \mathrm{~V}$ and D) $20 \mathrm{~V}$

\subsubsection{Electrodeposition of Polyacrylic acid}

Electrophoretic deposition was conducted using PAA and additives, similar to previous examples. The deposits obtained were analysed and characterized using DTA/TGA and SEM.

Polyacrylic acid is known to obtain a negative charge at $\mathrm{pH}>4$ thanks to the deprotonation of its carboxyl group (see Figure 5.29). At $\mathrm{pH}<4$, PAA becomes protonated [104]. 


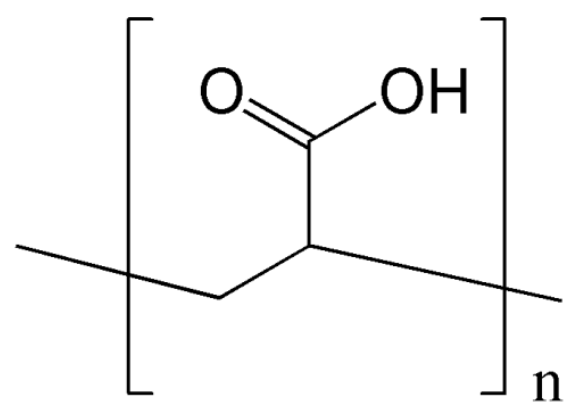

Figure 5.29: Structure of PAA

The deprotonation of PAA resulted in the formation of an anionic species, PAA$\mathrm{COO}^{-}$. These were adsorbed onto the HNT particles and provided steric stabilization. Due to the charge obtained from deprotonation, the PAA molecules undergo electrophoresis towards the anode, where the low $\mathrm{pH}$ region due to the generation of electrochemical acids (Equation 5-5) allowed for the following [104]:

$$
\mathrm{PAA}-\mathrm{COO}^{-}+\mathrm{H}^{+} \rightarrow \text { PAA-COOH }
$$

A coherent deposit was formed at the anode, composed of PAA forming an insoluble matrix with HNT embedded in the deposit.

The formation of composite PAA-HNT films was confirmed through the results obtained from TGA/DTA. The TGA data (see Figure 5.30) obtained from a deposit prepared from a $1.0 \mathrm{gL}^{-1}$ PAA suspension containing $0.6 \mathrm{gL}^{-1} \mathrm{HNT}$, showed significant mass loss between 200 to $500^{\circ} \mathrm{C}$ (see Figure 5.4) compared to that of as-received HNT (see Figure 5.30). There was a slight mass loss of approximately $10 \%$ below $210^{\circ} \mathrm{C}$, and a significant mass loss of $51.1 \%$ in the range of 210 to $470^{\circ} \mathrm{C}$, which was attributed to the burning out of the organic phase. The mass of the sample remained stable above $500^{\circ} \mathrm{C}$. 
The DTA data is in agreement with the TGA findings, as there is a slight endotherm below $100^{\circ} \mathrm{C}$ which can be attributed to the dehydration of the deposit, and a broad exothermic peak at $\sim 420^{\circ} \mathrm{C}$ that is not present in the DTA of as-received HNT (see Figure 5.4), while a similar peak was observed in previous studies of pure PAA [104] and can be attributed to the burning out of the organic phase.

The TGA and DTA data showed the formation of composite PAA-HNTs, and the total mass loss of $61.1 \%$ at $1000^{\circ} \mathrm{C}$ indicates that approximately $53.2 \%$ of the composite mass was composed of PAA and 46.8\% was HNT (taking into account mass loss related to dehydration of pure HNT).

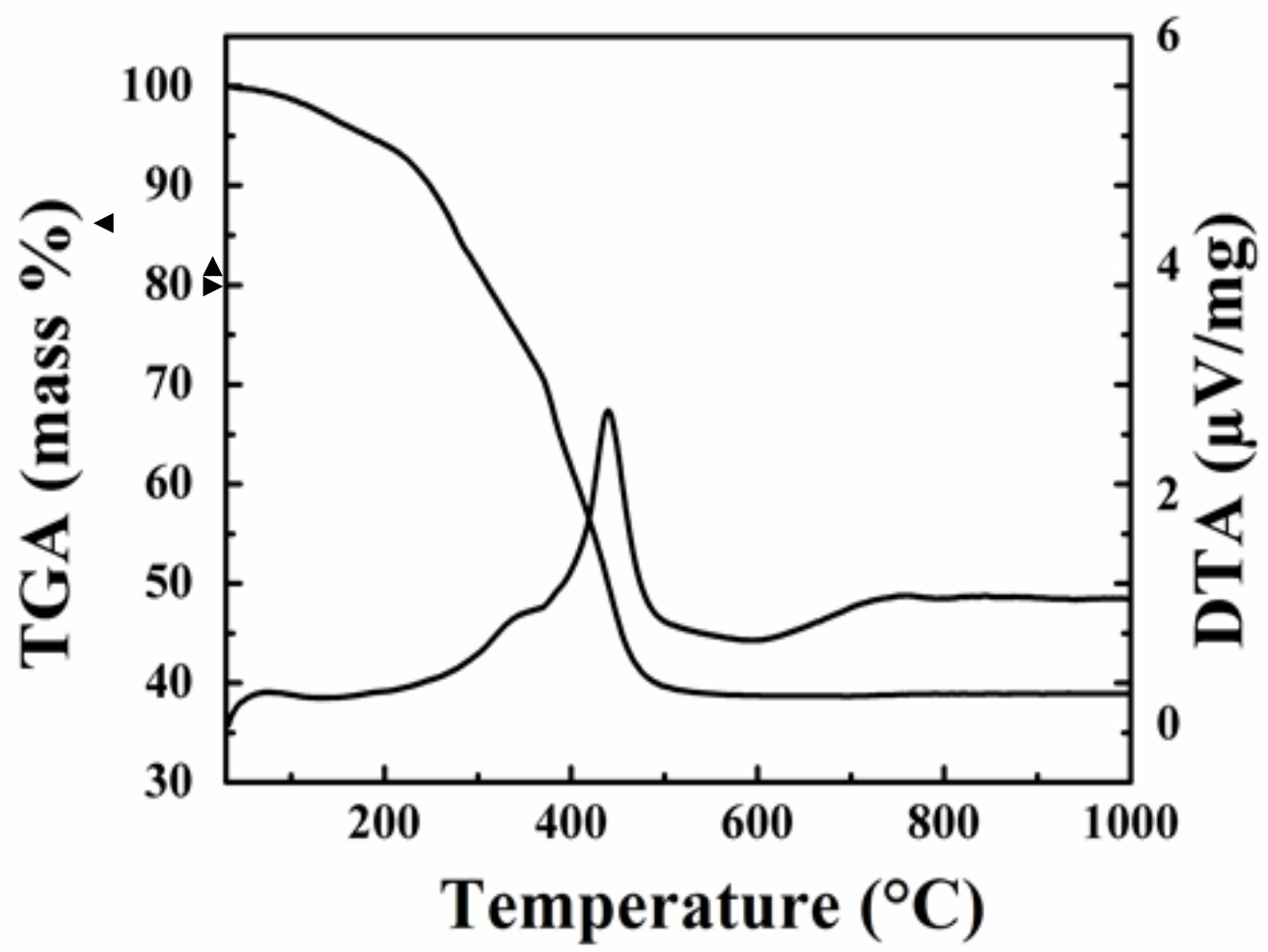

Figure 5.30: DTA/TGA of a deposit prepared from $1.0 \mathrm{gL}^{-1}$ PAA suspension containing $0.6 \mathrm{gL}^{-1} \mathrm{HNT}$ 
Deposits obtained from the EPD of $1.0 \mathrm{gL}^{-1}$ PAA suspensions containing $0.1,0.3$ and $0.6 \mathrm{gL}^{-1} \mathrm{HNT}$ were examined under SEM (see Figure 5.31). These were found to be continuous, crack-free and generally free of agglomerates (see Figure 5.31A,C,E). The SEM images confirm the DTA/TGA data that composite PAA-HNT films were formed through EPD. The SEM images also showed that there is a change in morphology of the films as HNT concentration increases. The surface roughness increased, and the HNT present was more tightly packed (see Figure 5.31B,D,F).

Deposits obtained from the EPD of $1.0 \mathrm{gL}^{-1}$ PAA suspensions containing $0.1,0.3$ and $0.6 \mathrm{gL}^{-1} \mathrm{HNT}$ were examined under SEM (see Figure 5.31). These were found to be continuous, crack-free and generally free of agglomerates (see Figure 5.31A,C,E). The SEM images confirm the DTA/TGA data that composite PAA-HNT films were formed through EPD. The SEM images also showed that there is a change in morphology of the films as HNT concentration increases. The surface roughness increased, and the HNT present was more tightly packed (see Figure 5.31B,D,F).

Deposits obtained from the EPD of $1.0 \mathrm{gL}^{-1}$ PAA suspensions containing $0.1,0.3$ and $0.6 \mathrm{gL}^{-1} \mathrm{HNT}$ were examined under SEM (see Figure 5.31). These were found to be continuous, crack-free and generally free of agglomerates (see Figure 5.31A,C,E). The SEM images confirm the DTA/TGA data that composite PAA-HNT films were formed through EPD. The SEM images also showed that there is a change in morphology of the films as HNT concentration increases. The surface roughness increased, and the HNT present was more tightly packed (see Figure 5.31B,D,F). 
Deposits obtained from the EPD of $1.0 \mathrm{gL}^{-1}$ PAA suspensions containing $0.1,0.3$ and $0.6 \mathrm{gL}^{-1} \mathrm{HNT}$ were examined under SEM (see Figure 5.31). These were found to be continuous, crack-free and generally free of agglomerates (see Figure 5.31A,C,E). The SEM images confirm the DTA/TGA data that composite PAA-HNT films were formed through EPD. The SEM images also showed that there is a change in morphology of the films as HNT concentration increases. The surface roughness increased, and the HNT present was more tightly packed (see Figure 5.31B,D,F). 
Master Thesis

McMaster University
Imran A. Deen

Materials Science and Engineering
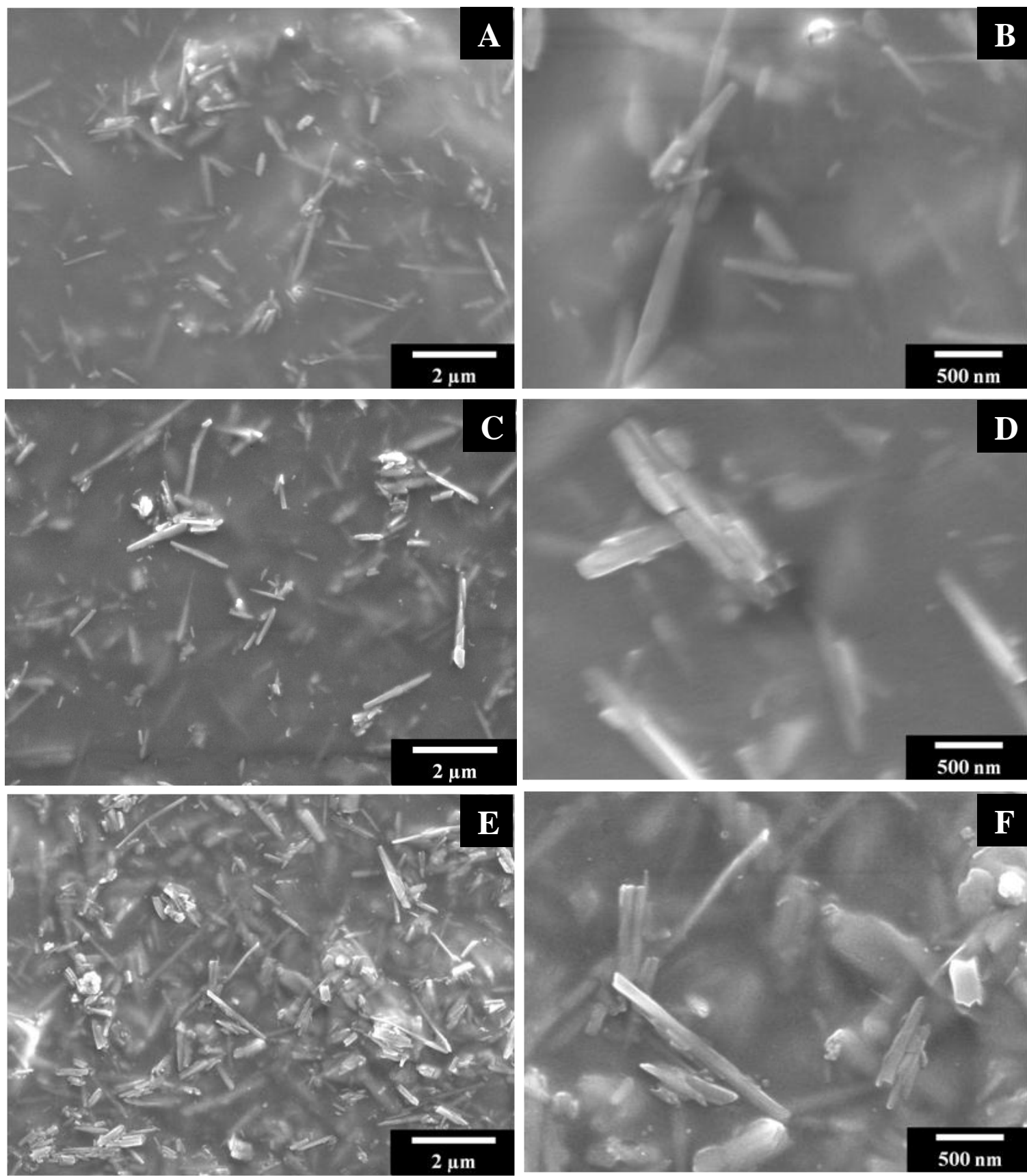

Figure 5.31: PAA films prepared from 1.0 gL-1 PAA containing A,B) 0.1 gL-1 HNT, C,D) 0.3 gL-1 HNT, E,F) 0.6 gL-1 HNT ( $A, C, E$ at low magnification and $B, D, F$ high magnification) 

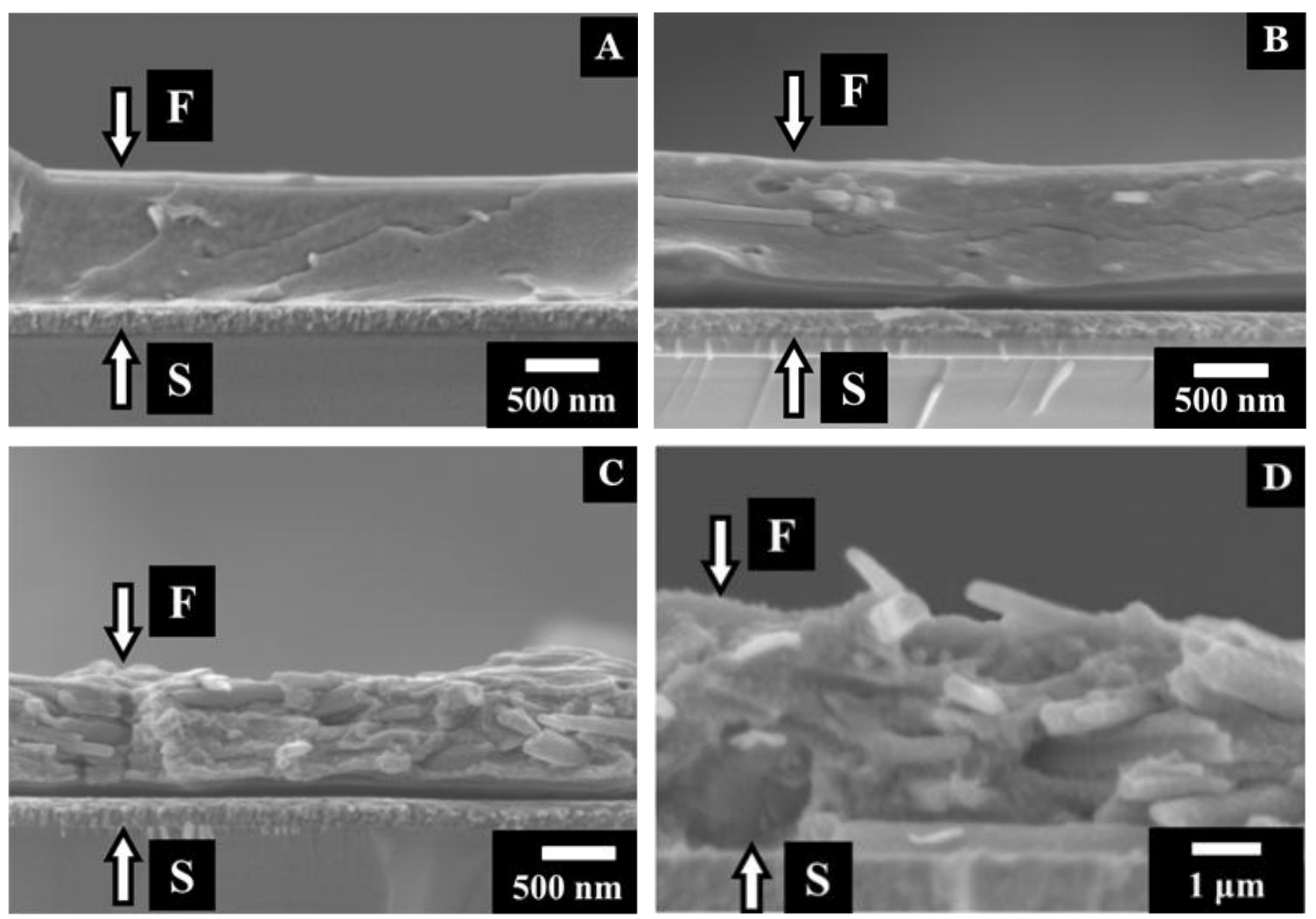

Figure 5.32: Cross-sections of PAA films prepared from $1 \mathrm{gL}^{-1}$ PAA containing A) $0.1 \mathrm{gL}^{-1} \mathrm{HNT}$, B) $\left.0.3 \mathrm{gL}^{-1} \mathrm{HNT}, \mathrm{C}\right) 0.6$ $\mathrm{gL}^{-1} \mathrm{HNT}$ (low magnification) and D) $0.6 \mathrm{gL}^{-1} \mathrm{HNT}$ (high magnification) (F-Film, S-Substrate)

Cross-section of PAA-HNT films were examined under SEM (see Figure 5.32).

The films were uniform and shoed good adhesion to the substrate, with the film thickness varying between 0 to $4 \mu \mathrm{m}$ by varying the deposition time at a deposition voltage of $5 \mathrm{~V}$. Deposition of HNT in the PAA matrix tended to be oriented parallel to the substrate, with HNT being difficult to observe at low concentration (see Figure 5.32A,B) and present through the film at higher concentrations (see Figure 5.32C,D). With an increase in concentration, packing of HNT became more random (see Figure 5.32D), and tended to result in non-uniform films. 


\section{Conclusions}

\subsection{Summary of Project}

Over the course of this project, it was shown that electrophoretic deposition could be used to successfully deposit composite films using biopolymer suspensions containing HNT additives for biomedical implants. Halloysite was successfully deposited under anodic and cathodic conditions using many different biopolymers. The use of chitosan, HYH, PLL, PLO and PAA provided a method of dispersion, stabilisation and charging of HNT. This allowed for the successful EPD of HNT, and composite coatings of polymerHNT were prepared using this method.

The cathodic EPD of chitosan, PLL, and PLO was performed in an aqueous ethanol-water mixture. The method was based on the electrophoresis of protonated polymer macromolecules in acidic solutions, base generation at the cathode surface, charge neutralization and deposition of insoluble polymer films. The polymers were adsorbed onto the HNT particles and underwent electrophoresis towards a high $\mathrm{pH}$ surface where they were deprotonated and formed a coherent deposit with HNT embedded in the polymer matrix on the cathode surface.

The EPD of HYH and PAA was performed by anodic method, which was based on the electrophoresis of the anionic $\mathrm{HYH}$ and PAA, $\mathrm{pH}$ decrease at the anode surface, protonation of the polymer macromolecules at the electrode surface, charge neutralization and formation of polymer films.. The polymers were deprotonated and adsorbed onto the HNT particle and underwent electrophoresis towards a low $\mathrm{pH}$ surface where they were 
protonated and neutralized, and formed a coherent deposit with HNT embedded in the polymer matrix on the anode surface.

Following the successful EPD of HNT, the film thickness, composition, morphology and deposition yield were measured. It was shown that these could be controlled by varying deposition parameters such the deposition time and deposition voltage. Film thicknesses of $0-5 \mu \mathrm{m}$ were observed by varying deposition time between 2 to 10 minutes and using a deposition voltage between 5 to $30 \mathrm{~V}$. Additionally, different morphologies were observed by varying the HNT concentration in the suspension between 0.3 and $0.6 \mathrm{gL}^{-1}$. Analysis of the films also showed good adhesion to the substrate following EPD, and continuous, crack-free films. Porosity was observed in certain films, and this could be regulated by controlling deposition parameters and changing the concentration of additives in the suspension or deposition voltage.

Tests in SBF showed the films were well-suited to work in physiological conditions as well, showing increased corrosion protection.

Following the successful EPD of HNT, it was shown HA could be successfully co-deposited with HNT using the same method, and the creation of multilayer laminates and FGM coatings containing HNT were shown to be achievable. This combination showed good film-forming properties as well, with laminates and FGM showing good adhesion between interfaces. The characteristics of the film, such as the film thickness, composition and morphology, were shown to be adjustable by varying the concentration of additives, the applied voltage and the deposition time. Furthermore, films were tested 
in SBF and were shown to provide better corrosion protection than films containing solely HNT.

The method of depositing HNT using EPD as shown here offers the advantage of room temperature processing using cheap and readily available materials to deposit organic-inorganic coatings for biomedical applications. The coatings are also promising with regards to being able to provide advanced functionality cost-effectively, as HNT can be used for drug delivery, loaded with antimicrobial agents and other functional materials, in addition to being available at low-cost and in large amounts. The results obtained also indicate that polymer-HNT films deposited using HNT are likely to be suitable for physiological applications, especially with regards to creating next-generation of biomedical implants.

\subsection{Future work}

Future work based of the results obtained over the course of this project can be divided into three main lines of inquiry:

1) Creating and analysing different composition of films, multilayer laminates and FGM coatings. The results obtained here are promising, and show that the composition, thickness, and morphology of films can be controlled. As such, creating a film that mimics the natural structure of bone more closely should be investigated to ensure better biocompatibility and biofunctionality.

2) Investigating the use of HNT for advanced functionalities such as drug delivery, similar to chitosan-Ag coatings. The use of HNT as a nanocontainer 
has already been shown to be feasible, but polymer-HNT films have yet to be investigated.

3) Investigating HNT coatings under physiological condition, including both in vitro and in vivo tests. Tests conducted in SBF resulted in promising results, but much more is needed to ensure HNT coatings will work well within the body under physiological conditions.

\subsection{Contributions}

This thesis aims to prove the viability of creating organic-inorganic coatings for biomedical applications using HNT. The experiments conducted for and presented in this thesis have resulted in many important observations about the nature of HNT deposition which, to our knowledge, has not been reported previously. Many of the results pertaining to the deposition of polymer-HNT coatings have been published in the following:

- Y. Wang, I. Deen, I. Zhitomirsky, "Electrophoretic deposition of polyacrylic acid and composite films containing nanotubes and oxide particles", Journal of Colloid \& Interface Science, Vol. 362(2), pp. 367-374 (October, 2011)

- X. Pang, I. Deen, I. Zhitomirsky, "Electrophoretic deposition of composite chitosan-halloysite nanotube-hydroxyapatite films", Colloids and Surfaces A, Vol. 410, pp. 38-44 (September 2012)

- I.Deen, I.Zhitomirsky, "Electrophoretic deposition of composite halloysite nanotube-hydroxyapatite-hyaluronic acid films", Journal of Alloys and Compounds (submitted) 


\section{References}

[1] U. Kamachimudali, T.M. Sridhar, and B. Raj, "Corrosion of bio implants," Sadhana, vol. 28, Jun. 2003, pp. 601-637.

[2] I. Gotman, "Characteristics of Metals Used in Implants," Journal of Endourology, vol. 11, Dec. 1997, pp. 383-389.

[3] P.X. Ma and J.H. Elisseeff, Scaffolding In Tissue Engineering, Boca Raton, FL: Taylor \& Francis, 2006.

[4] Canadian Institute for Health Information, Hip and Knee Replacements in Canada - 2007 Annual Report, Ottawa: Canadian Institute for Health Information, 2007.

[5] M.D. Sikirić, C. Gergely, R. Elkaim, E. Wachtel, F.J.G. Cuisinier, and H. Füredi-Milhofer, "Biomimetic organic-inorganic nanocomposite coatings for titanium implants," Journal of Biomedical Materials Research Part A, vol. 89A, Jun. 2009, pp. 759-771.

[6] A.L. Wagner, S. Cooper, and M. Riedlinger, "Natural nanotubes enhance biodegradable and biocompatible nanocomposites," Industrial Biotechnology, vol. 1, 2005, pp. 190-193.

[7] L.L. Hench and J.R. Jones, Biomaterials, artificial organs and tissue engineering, Cambridge: Woodhead Publishing, 2005.

[8] L.L. Hench and E.C. Ethridge, Biomaterials: an interfacial approach, New York: Academic Press, 1982. 
[9] A.C. Guyton and J.E. Hall, Textbook of medical physiology, Philadelphia: Elsevier Saunders, 2006.

[10] M.J. Olszta, X. Cheng, S.S. Jee, R. Kumar, Y.-Y. Kim, M.J. Kaufman, E.P. Douglas, and L.B. Gower, "Bone structure and formation: A new perspective," Materials Science and Engineering: R: Reports, vol. 58, Nov. 2007, pp. 77-116.

[11] J.-Y. Rho, L. Kuhn-Spearing, and P. Zioupos, "Mechanical properties and the hierarchical structure of bone," Medical Engineering \& Physics, vol. 20, Mar. 1998, pp. 92-102.

[12] E.R. Wise, S. Maltsev, M.E. Davies, M.J. Duer, C. Jaeger, N. Loveridge, R.C. Murray, and D.G. Reid, "The Organic-Mineral Interface in Bone Is Predominantly Polysaccharide," Chem. Mater., vol. 19, 2007, pp. 5055-5057.

[13] D.G. Reid, M.J. Duer, R.C. Murray, and E.R. Wise, "The Organic-Mineral Interface in Teeth Is Like That in Bone and Dominated by Polysaccharides: Universal Mediators of Normal Calcium Phosphate Biomineralization in Vertebrates?," Chem. Mater., vol. 20, 2008, pp. 3549-3550.

[14] Julia M. Polak, ed., Advances in Tissue Engineering, London: Imperial College Press, 2008.

[15] C. Chung and J.A. Burdick, "Engineering cartilage tissue," Advanced Drug Delivery Reviews, vol. 60, Jan. 2008, pp. 243-262.

[16] H. Park, J. Temenoff, and A. Mikos, "Biodegradable Orthopedic Implants," Engineering of Functional Skeletal Tissues, F. Bronner, M.C. Farach-Carson, 
A.G. Mikos, F. Bronner, and M.C. Farach-Carson, eds., London: Springer, 2007, pp. 55-68.

[17] R. Rhoades and G.A. Tanner, Medical physiology, Philadelphia: Lippincott Williams \& Wilkins, 2003.

[18] J.R. Davis and A. S. M. International, Handbook of materials for medical devices, ASM International, 2003.

[19] T.S. Hin, Engineering Materials For Biomedical Applications, Singapore: World Scientific, 2004.

[20] A. Kurella and N.B. Dahotre, "Review Paper: Surface Modification for Bioimplants: The Role of Laser Surface Engineering," Journal of Biomaterials Applications, vol. 20, Jul. 2005, pp. 5-50.

[21] T.M. Sridhar, N. Eliaz, U. Kamachi Mudali, and B. Raj, "Electrophoretic deposition of hydroxyapatite coatings and corrosion aspects of metallic implants," Corrosion reviews, vol. 20, 2002, pp. 255-294.

[22] C. Aguzzi, P. Cerezo, C. Viseras, and C. Caramella, "Use of clays as drug delivery systems: Possibilities and limitations," Applied Clay Science, vol. 36, Apr. 2007, pp. 22-36.

[23] H. Cornejo-Garrido, A. Nieto-Camacho, V. Gómez-Vidales, M.T. RamírezApan, P. del Angel, J.A. Montoya, M. Domínguez-López, D. Kibanova, and J. Cervini-Silva, "The anti-inflammatory properties of halloysite," Applied Clay Science, vol. 57, Mar. 2012, pp. 10-16. 
[24] S.R. Levis and P.B. Deasy, "Characterisation of halloysite for use as a microtubular drug delivery system," International Journal of Pharmaceutics, vol. 243, Aug. 2002, pp. 125-134.

[25] M.N.. Ravi Kumar, "A review of chitin and chitosan applications," Reactive and Functional Polymers, vol. 46, Nov. 2000, pp. 1-27.

[26] H.K. No, N. Young Park, S. Ho Lee, and S.P. Meyers, "Antibacterial activity of chitosans and chitosan oligomers with different molecular weights," International Journal of Food Microbiology, vol. 74, Mar. 2002, pp. 65-72.

[27] X. Fei Liu, Y. Lin Guan, D. Zhi Yang, Z. Li, and K. De Yao, “Antibacterial action of chitosan and carboxymethylated chitosan," Journal of Applied Polymer Science, vol. 79, Feb. 2001, pp. 1324-1335.

[28] A. Di Martino, M. Sittinger, and M.V. Risbud, "Chitosan: A versatile biopolymer for orthopaedic tissue-engineering," Biomaterials, vol. 26, Oct. 2005, pp. 5983-5990.

[29] J.R. Fraser, T.C. Laurent, and U.B. Laurent, "Hyaluronan: its nature, distribution, functions and turnover," Journal of internal medicine, vol. 242, Jul. 1997, pp. 27-33.

[30] M.D. Darrabie, W.F. Kendall Jr., and E.C. Opara, "Characteristics of Poly-lOrnithine-coated alginate microcapsules," Biomaterials, vol. 26, Dec. 2005, pp. $6846-6852$. 
[31] Y. Wang, X. Pang, and I. Zhitomirsky, "Electrophoretic deposition of chiral polymers and composites," Colloids and Surfaces B: Biointerfaces, vol. 87, Oct. 2011, pp. 505-509.

[32] S. Rosiński, D. Lewińska, M. Wójcik, G. Orive, J.L. Pedraz, and A. Weryński, "Mass transfer characteristics of poly-lysine, poly-ornithine and poly-methyleneco-guanidine membrane coated alginate microcapsules," Journal of Membrane Science, vol. 254, Jun. 2005, pp. 249-257.

[33] G. Orive, S.K. Tam, J.L. Pedraz, and J.-P. Hallé, "Biocompatibility of alginatepoly-1-lysine microcapsules for cell therapy," Biomaterials, vol. 27, Jul. 2006, pp. 3691-3700.

[34] M. Rinaudo, "Chitin and chitosan: Properties and applications," Progress in Polymer Science, vol. 31, Jul. 2006, pp. 603-632.

[35] V. Mittal, Nanocomposites with Biodegradable Polymers: Synthesis, Properties, and Future Perspectives, Oxford University Press, 2011.

[36] F. Sun, X. Pang, and I. Zhitomirsky, "Electrophoretic deposition of composite hydroxyapatite-chitosan-heparin coatings," Journal of Materials Processing Technology, vol. 209, Feb. 2009, pp. 1597-1606.

[37] L.A. Solchaga, J.E. Dennis, V.M. Goldberg, and A.I. Caplan, "Hyaluronic acidbased polymers as cell carriers for tissue-engineered repair of bone and cartilage," Journal of Orthopaedic Research: Official Publication of the Orthopaedic Research Society, vol. 17, Mar. 1999, pp. 205-213. 
[38] R.K. Reed, K. Lilja, and T.C. Laurent, "Hyaluronan in the rat with special reference to the skin," Acta Physiologica Scandinavica, vol. 134, Nov. 1988, pp. $405-411$.

[39] H. Nojehdehian, F. Moztarzadeh, H. Baharvand, H. Nazarian, and M. Tahriri, "Preparation and surface characterization of poly-1-lysine-coated PLGA microsphere scaffolds containing retinoic acid for nerve tissue engineering: In vitro study," Colloids and Surfaces B: Biointerfaces, vol. 73, Oct. 2009, pp. 2329.

[40] F. Lim and A.M. Sun, "Microencapsulated islets as bioartificial endocrine pancreas," Science, vol. 210, Nov. 1980, pp. 908-910.

[41] Z. Zheng, Y. Wei, G. Wang, Y. Gong, and X. Zhang, "Surface characterization and cytocompatibility of three chitosan/polycation composite membranes for guided bone regeneration," Journal of biomaterials applications, vol. 24, Sep. 2009, pp. 209-229.

[42] S.K. Tam, S. Bilodeau, J. Dusseault, G. Langlois, J.-P. Hallé, and L.H. Yahia, "Biocompatibility and physicochemical characteristics of alginate-polycation microcapsules," Acta Biomaterialia, vol. 7, Apr. 2011, pp. 1683-1692. K. HASEGAWA, H. NISHIMORI, M. TATSUMISAGO, and T. MINAMI, "Effect of poly(acrylic acid) on the preparation of thick silica films by electrophoretic sol-gel deposition of re-dispersed silica particles," Journal of Materials Science, vol. 33, 1998, pp. 1095-1098. 
[44] M. Fujiwara, R.H. Grubbs, and J.D. Baldeschwieler, "Characterization of pHDependent Poly(acrylic Acid) Complexation with Phospholipid Vesicles," Journal of Colloid and Interface Science, vol. 185, Jan. 1997, pp. 210-216.

[45] H. Nishimori, K. Hasegawa, M. Tatsumisago, and T. Minami, "Preparation of thick silica films in the presence of poly(acrylic acid) by using electrophoretic sol-gel deposition," Journal of Sol-Gel Science and Technology, vol. 7, 1996, pp. 211-216.

[46] K. Sato, Y. Tachibana, S. Hattori, T. Chiba, and S. Kuwabata, "Polyacrylic acid coating of highly luminescent $\mathrm{CdS}$ nanocrystals for biological labeling applications," Journal of Colloid and Interface Science, vol. 324, Aug. 2008, pp. $257-260$.

[47] V. Vergaro, E. Abdullayev, Y.M. Lvov, A. Zeitoun, R. Cingolani, R. Rinaldi, and S. Leporatti, "Cytocompatibility and Uptake of Halloysite Clay Nanotubes," Biomacromolecules, vol. 11, Mar. 2010, pp. 820-826.

[48] E. Joussein, S. Petit, J. Churchman, B. Theng, D. Righi, and B. Delvaux, “Halloysite clay minerals - a review," Clay Minerals, vol. 40, Dec. 2005, pp. $383-426$.

[49] P. Yuan, P.D. Southon, Z. Liu, M.E.R. Green, J.M. Hook, S.J. Antill, and C.J. Kepert, "Functionalization of Halloysite Clay Nanotubes by Grafting with $\gamma$ Aminopropyltriethoxysilane," The Journal of Physical Chemistry C, vol. 112, Oct. 2008, pp. 15742-15751. 
[50] D. Shchukin, G. Sukhorukov, R. Price, and Y. Lvov, "Halloysite Nanotubes as Biomimetic Nanoreactors," Small, vol. 1, May. 2005, pp. 510-513.

[51] D. Shi, Introduction to Biomaterials, Beijing: Tsinghua University Press, 2006.

[52] N. Ikawa, T. Kimura, Y. Oumi, and T. Sano, "Amino acid containing amorphous calcium phosphates and the rapid transformation into apatite," Journal of Materials Chemistry, vol. 19, Jul. 2009, pp. 4906-4913.

[53] H.S. Ryu and S.-H. Hong, "Hybrid coatings of poly(L-lysine) and apatite on micro-arc oxidized titania," Materials Letters, vol. 63, Oct. 2009, pp. 21072110.

[54] X. Pang and I. Zhitomirsky, "Electrophoretic deposition of composite hydroxyapatite-chitosan coatings," Materials Characterization, vol. 58, Apr. 2007, pp. 339-348.

[55] M.A. Attawia, K.M. Herbert, and C.T. Laurencin, "Osteoblast-like Cell Adherance and Migration Through Three-Dimensional Porous Polymer Matrices," Biochemical and Biophysical Research Communications, vol. 213, Aug. 1995, pp. 639-644.

[56] G. Sui, X. Yang, F. Mei, X. Hu, G. Chen, X. Deng, and S. Ryu, "Poly-L-lactic acid/hydroxyapatite hybrid membrane for bone tissue regeneration," Journal of Biomedical Materials Research. Part A, vol. 82, Aug. 2007, pp. 445-454.

[57] Z.R. Ulberg and Y.F. Deinega, Electrophoretic composite coatings /, London, NY: Ellis Horwood, 1992. 
[58] G. Cao, Nanostructures and Nanomaterials: Synthesis, Properties, and Applications, London: Imperial College Press, 2004.

[59] O.O.V. der Biest and L.J. Vandeperre, "ELECTROPHORETIC DEPOSITION OF MATERIALS,” Annual Review of Materials Science, vol. 29, 1999, pp. 327352.

[60] L. Besra and M. Liu, "A review on fundamentals and applications of electrophoretic deposition (EPD)," Progress in Materials Science, vol. 52, Jan. 2007, pp. 1-61.

[61] B. Bhushan, ed., Springer Handbook of Nanotechnology, Berlin: Springer, 2010.

[62] I. Zhitomirsky, "Cathodic electrodeposition of ceramic and organoceramic materials. Fundamental aspects," Advances in Colloid and Interface Science, vol. 97, Mar. 2002, pp. 279-317.

[63] H.C. Hamaker and E.J.W. Verwey, "Part II.-(C) Colloid stability. The role of the forces between the particles in electrodeposition and other phenomena," Transactions of the Faraday Society, vol. 35, Jan. 1940, pp. 180-185.

[64] H. Koelmans and J.T.G. Overbeek, "Stability and electrophoretic deposition of suspensions in non-aqueous media," Discussions of the Faraday Society, vol. 18, Jan. 1954, pp. 52-63.

[65] F. Grillon, D. Fayeulle, and M. Jeandin, "Quantitative image analysis of electrophoretic coatings," Journal of Materials Science Letters, vol. 11, 1992, pp. $272-275$. 
[66] P. Sarkar and P.S. Nicholson, "Electrophoretic Deposition (EPD): Mechanisms, Kinetics, and Application to Ceramics," Journal of the American Ceramic Society, vol. 79, Aug. 1996, pp. 1987-2002.

[67] J. Ma, C. Wang, and C.H. Liang, "Colloidal and electrophoretic behavior of polymer particulates in suspension," Materials Science and Engineering: C, vol. 27, May. 2007, pp. 886-889.

[68] H.C. Hamaker, "Formation of a deposit by electrophoresis," Transactions of the Faraday Society, vol. 35, 1940, p. 279.

[69] Z. Zhang, Y. Huang, and Z. Jiang, "Electrophoretic Deposition Forming of SiCTZP Composites in a Nonaqueous Sol Media," Journal of the American Ceramic Society, vol. 77, Jul. 1994, pp. 1946-1949.

[70] J.A. Dean, Lange's Handbook of Chemistry, New York, NY: McGraw-Hill, 1998.

[71] K.O. Liden and O.A. Schjeide, "Ultrastructural variations following use of several weakly protic alcohols as dehydration agents," Cytobios, vol. 28, 1980, pp. $103-127$.

[72] R.W. Powers, "The Electrophoretic Forming of Beta-Alumina Ceramic," Journal of The Electrochemical Society, vol. 122, 1975, pp. 490-500.

[73] J. Cordelair and P. Greil, "Discrete element modeling of solid formation during electrophoretic deposition," Journal of Materials Science, vol. 39, 2004, pp. $1017-1021$. 
[74] I. Zhitomirsky and A. Petric, "Electrophoretic deposition of electrolyte materials for solid oxide fuel cells," Journal of Materials Science, vol. 39, 2004, pp. 825831.

[75] Y.-C. Wang, I.-C. Leu, and M.-H. Hon, "Kinetics of Electrophoretic Deposition for Nanocrystalline Zinc Oxide Coatings," Journal of the American Ceramic Society, vol. 87, 2004, pp. 84-88.

[76] W.R. Lacefield, "Hydroxyapatite Coatings," Annals of the New York Academy of Sciences, vol. 523, 1988, pp. 72-80.

[77] P. Ducheyne, W. Van Raemdonck, J.C. Heughebaert, and M. Heughebaert, "Structural analysis of hydroxyapatite coatings on titanium," Biomaterials, vol. 7, Mar. 1986, pp. 97-103.

[78] J. Ma, C. Wang, and K.W. Peng, "Electrophoretic deposition of porous hydroxyapatite scaffold," Biomaterials, vol. 24, Sep. 2003, pp. 3505-3510.

[79] L. Ágata de Sena, M. Calixto de Andrade, A. Malta Rossi, and G. de Almeida Soares, "Hydroxyapatite deposition by electrophoresis on titanium sheets with different surface finishing," Journal of Biomedical Materials Research, vol. 60, 2002, pp. 1-7.

[80] X. Zhu, K.-H. Kim, and Y. Jeong, “Anodic oxide films containing Ca and P of titanium biomaterial,” Biomaterials, vol. 22, Aug. 2001, pp. 2199-2206.

[81] K.A. Gross and C.C. Berndt, "Thermal processing of hydroxyapatite for coating production,” Journal of Biomedical Materials Research, vol. 39, 1998, pp. 580587. 
[82] K.A. Gross, C.C. Berndt, and H. Herman, "Amorphous phase formation in plasma-sprayed hydroxyapatite coatings," Journal of Biomedical Materials Research, vol. 39, 1998, pp. 407-414.

[83] Y. Yang and J.L. Ong, "Bond strength, compositional, and structural properties of hydroxyapatite coating on $\mathrm{Ti}, \mathrm{ZrO} 2$-coated $\mathrm{Ti}$, and TPS-coated Ti substrate," Journal of Biomedical Materials Research Part A, vol. 64A, 2003, pp. 509-516.

[84] T. Shunyan, J. Heng, and D. Chuanxian, "Effect of vapor-flame treatment on plasma sprayed hydroxyapatite coatings," Journal of Biomedical Materials Research, vol. 52, 2000, pp. 572-575.

[85] M. Manso, M. Langlet, C. Jiménez, and J.. Martínez-Duart, "Microstructural study of aerosol-gel derived hydroxyapatite coatings," Biomolecular Engineering, vol. 19, Aug. 2002, pp. 63-66.

[86] D.-M. Liu, Q. Yang, and T. Troczynski, "Sol-gel hydroxyapatite coatings on stainless steel substrates," Biomaterials, vol. 23, Feb. 2002, pp. 691-698.

[87] C.S. Chai, K.A. Gross, and B. Ben-Nissan, "Critical ageing of hydroxyapatite sol-gel solutions," Biomaterials, vol. 19, Dec. 1998, pp. 2291-2296.

[88] X. Pang, T. Casagrande, and I. Zhitomirsky, "Electrophoretic deposition of hydroxyapatite-CaSiO3-chitosan composite coatings," Journal of Colloid and Interface Science, vol. 330, Feb. 2009, pp. 323-329.

[89] A.R. Boccaccini, S. Keim, R. Ma, Y. Li, and I. Zhitomirsky, "Electrophoretic deposition of biomaterials," Journal of the Royal Society, Interface / the Royal Society, vol. 7 Suppl 5, Oct. 2010, pp. S581-613. 
[90] I. Zhitomirsky and L. Gal-Or, "Electrophoretic deposition of hydroxyapatite," Journal of Materials Science: Materials in Medicine, vol. 8, 1997, pp. 213-219.

[91] S. Kannan, A. Balamurugan, and S. Rajeswari, "Hydroxyapatite coatings on sulfuric acid treated type 316L SS and its electrochemical behaviour in Ringer's solution," Materials letters, vol. 57, 2003, pp. 2382-2389.

[92] R.M. Souto, M.M. Laz, and R.L. Reis, "Degradation characteristics of hydroxyapatite coatings on orthopaedic TiAlV in simulated physiological media investigated by electrochemical impedance spectroscopy," Biomaterials, vol. 24, Oct. 2003, pp. 4213-4221.

[93] T.M. Sridhar, U. Kamachi Mudali, and M. Subbaiyan, "Sintering atmosphere and temperature effects on hydroxyapatite coated type 316L stainless steel," Corrosion Science, vol. 45, Oct. 2003, pp. 2337-2359.

[94] M. Kleber, L. Schwendenmann, E. Veldkamp, J. Rößner, and R. Jahn, "Halloysite versus gibbsite: Silicon cycling as a pedogenetic process in two lowland neotropical rain forest soils of La Selva, Costa Rica," Geoderma, vol. 138, Feb. 2007, pp. 1-11.

[95] X. Pang and I. Zhitomirsky, "Electrodeposition of composite hydroxyapatitechitosan films," Materials Chemistry and Physics, vol. 94, Dec. 2005, pp. 245251.

[96] S. Deng, J. Zhang, L. Ye, and J. Wu, "Toughening epoxies with halloysite nanotubes," Polymer, vol. 49, Oct. 2008, pp. 5119-5127. 
[97] E. Joussein, S. Petit, and B. Delvaux, "Behavior of halloysite clay under formamide treatment," Applied Clay Science, vol. 35, Jan. 2007, pp. 17-24.

[98] X. Pang and I. Zhitomirsky, "Electrodeposition of hydroxyapatite-silverchitosan nanocomposite coatings," Surface and Coatings Technology, vol. 202, May. 2008, pp. 3815-3821.

[99] I. Zhitomirsky and L. Gal-Or, "Formation of hollow fibers by electrophoretic deposition," Materials Letters, vol. 38, Jan. 1999, pp. 10-17.

[100] M. Du, B. Guo, and D. Jia, "Newly emerging applications of halloysite nanotubes: a review," Polymer International, vol. 59, 2010, pp. 574-582.

[101] Z. Jia, Y. Luo, B. Guo, B. Yang, M. Du, and D. Jia, "Reinforcing and FlameRetardant Effects of Halloysite Nanotubes on LLDPE," Polymer-Plastics Technology and Engineering, vol. 48, 2009, pp. 607-613.

[102] F. Sun and I. Zhitomirsky, "Electrodeposition of hyaluronic acid and composite films," Surface Engineering, vol. 25, Nov. 2009, pp. 621-627.

[103] C.R. Kothapalli, M. Wei, and M.T. Shaw, "Solvent-specific gel-like transition via complexation of polyelectrolyte and hydroxyapatite nanoparticles suspended in water-glycerin mixtures: a rheological study," Soft Matter, vol. 4, 2008, p. 600.

[104] Y. Wang, I. Deen, and I. Zhitomirsky, "Electrophoretic deposition of polyacrylic acid and composite films containing nanotubes and oxide particles," Journal of Colloid and Interface Science, vol. 362, Oct. 2011, pp. 367-374. 